Modelagem e Análise de Conhecimento para Planejamento Automático: Uma abordagem baseada em GORE e Redes de Petri 



\title{
Modelagem e Análise de Conhecimento para Planejamento Automático: Uma abordagem baseada em GORE e Redes de Petri
}

\author{
Javier Martinez Silva
}

Orientador: Prof. Dr. José Reinaldo Silva

\begin{abstract}
Tese apresentada à Escola Politécnica da Universidade de São Paulo, para obtenção do título de Doutor em Ciências. Área de Concentração: Engenharia de Controle e Automação Mecânica.
\end{abstract}

USP - Escola Politécnica

Fevereiro de 2017 
Este exemplar foi revisado e corrigido em relação à versão original, sob responsabilidade única do autor e com a anuência de seu orientador.

São Paulo, de de

Assinatura do autor:

Assinatura do orientador:

Catalogação-na-publicação

Martinez, Javier

Modelagem e Análise de Conhecimento para Planejamento

Automático: Uma abordagem baseada em GORE e Redes de Petri / J.

Martinez -- versão corr. -- São Paulo, 2017.

$128 \mathrm{p}$.

Tese (Doutorado) - Escola Politécnica da Universidade de São Paulo. Departamento de Engenharia Mecânica.

1.Engenharia de Requisitos 2.Planejamento Automático Inteligente 3.Redes de Petri 4.GHENeSys 5.ReKPlan I.Universidade de São Paulo. Escola Politécnica. Departamento de Engenharia Mecânica II.t. 
Este trabalho é dedicado à memoria de minha avô Yolanda Luisa Shombert Burgos, que quando mais eu precisava, sempre incentivou-me a lutar e não desistir jamais por meus sonhos. 

Principal agradecimento a meu orientador o Prof. Dr. José Reinaldo Silva por sua confiança, oportuna orientação, e constante apoio durante o desenvolvimento deste trabalho.

Especial agradecimento ao Laboratório de Pesquisa Design-Lab ${ }^{1}$ e ao Departamento de Engenharia Mecânica da Escola Politécnica da Universidade de São Paulo ${ }^{2}$ pelos recursos fornecidos durante minha formação.

Aos professores do corpo docente do programa de pós-graduação da Universidade de São Paulo.

A minha mãe Yolanda por ser meu farol e guia. A ela devo tudo o que sou.

A meu pai Humberto pelo apoio incondicional.

A minha querida esposa Katia pelo amor, dedicação, paixão e paciência nesta jornada. Sem sua constante motivação e companhia, este sonho jamais se tornaria possível.

A meu irmão Humberto, por sempre ter me mostrado o caminho certo e por se fazer presente, mesmo estando longe.

A minha cunhada Idalmis, por me demonstrar com sua coragem que sempre temos motivos, a pesar das dificuldade, para um sincero sorriso.

As minhas sobrinhas Claudia e Aitana pela alegria transmitida.

A Dna Mitico pelos conselhos sempre oportunos.

À todos.

Muito obrigado! 

"Você deve encontrar o lugar dentro de si, onde nada é impossível." (Deepak Chopra) 



\section{RESUMO}

MARTINEZ SILVA, J.. Modelagem e Análise de Conhecimento para Planejamento Automático: Uma abordagem baseada em GORE e Redes de Petri. 2017. 128 f. Tese (Doutorado em em Ciências. Área de Concentração: Engenharia de Controle e Automação Mecânica) Escola Politécnica (POLI/USP), São Paulo.

Trabalhos recentes na área de Planejamento e Escalonamento têm gerado uma grande expectativa em relação à aplicação dos resultados em sistemas reais. Neste cenário, métodos, ferramentas e conceitos provenientes das Engenharia do Conhecimento e da Engenharia de Requisitos se tornam fundamentais para caracterizar melhor, entender e especificar os domínios de planejamento.

Nesse caso uma especial importância deve ser dada às etapas iniciais do processo, onde o conhecimento sobre o domínio é incompleto e onde existem poucas ferramentas, seja para o suporte ou automação parcial do processo, e as ferramentas já existentes carecem de métodos formais para a modelagem e análise dos requisitos.

Neste trabalho propõe-se o ReKPlan (Ambiente para a Engenharia de Requisitos usando KAOS em problemas de planejamento), que usa KAOS, um método orientado a objetivos, para a modelagem de requisitos. Entretanto, o uso do KAOS (ou de qualquer outro método goaloriented) não atende à necessidade de verificar formalmente o comportamento dinâmico quando o alvo são sistemas de planejamento. A proposta deste trabalho é combinar o uso do método orientado a objetivos com o formalismo das Redes de Petri (Rdp) -especificamente a abordagem seguida pelo GHENeSys- para representar e analisar requisitos no projeto de sistemas de planejamento.

Finalmente é proposto um método sobre o processo de projeto que, guiado por modelos, gera instruções PDDL servindo de entrada para os planejadores. A método foi aplicado a vários estudos de caso que o avaliam como um mecanismo promissor e eficiente na Engenharia de Requisitos resultando em uma melhor definição dos requisitos em problemas de planejamento.

Palavras-chave: Engenharia de Requisitos, Planejamento Automático Inteligente, Redes de Petri, GHENeSys, ReKPlan. 



\section{ABSTRACT}

MARTINEZ SILVA, J.. Modelagem e Análise de Conhecimento para Planejamento Automático: Uma abordagem baseada em GORE e Redes de Petri. 2017. 128 f. Tese (Doutorado em em Ciências. Área de Concentração: Engenharia de Controle e Automação Mecânica) - Escola Politécnica (POLI/USP), São Paulo.

Recent works in Planning and Scheduling, lead to a great expectations about how to apply achieved results in real systems. In this scenario, methods, tools and concepts from Knowledge and Requirements Engineering seem to be a key issue for characterizing, understanding and specifying the domain of planning problems.

In this case a special attention should be given to the initial stages of the process, where knowledge about the domain is incomplete and there are a few tools to support or partially automate the process, and there is a lack of formal methods for modeling and analysis of requirements in the existing tools.

This work proposes the ReKPlan (Requirement Engineering Using KAOS for Planning Problems) which uses KAOS, a goal-oriented method, for modeling requirements. However, the use of KAOS (or another goal-oriented method) don't seem the most appropriate for formal verification of the dynamic behavior of planning systems. The purpose of this work is to combine the use of KAOS with Petri Nets formalism (Rdp) - GHENeSys approach specifically - for modeling and analyzing requirements in the design of planning system.

Finally is proposed a model driven engineering mechanism over a design for guiding, until the generation of PDDL instructions as input for planners to solve problems.

Key-words: Requirement Engineering, Automated Intelligent Planning, Petri Net, GHENeSys, ReKPlan. 



\section{RESUMEN}

MARTINEZ SILVA, J.. Modelagem e Análise de Conhecimento para Planejamento Automático: Uma abordagem baseada em GORE e Redes de Petri. 2017. 128 f. Tese (Doutorado em em Ciências. Área de Concentração: Engenharia de Controle e Automação Mecânica) Escola Politécnica (POLI/USP), São Paulo.

Investigaciones recientes del área de planning y scheduling han generado una gran expectativa relacionada a la aplicación de los resultados en sistemas reales. En este contexto, métodos, herramientas y conceptos provenientes de la Ingenieria del Conocimiento e de la Ingenieria de Requisitos han sido fundamentales para caracterizar mejor, entender e especificar los domínios associados a los problemas de planning.

En esta caso una especial importancia debe ser dada a las etapas iniciales del proceso, en que el conocimiento sobre el dominio es incompleto y en donde existen pocas herramientas sean de soporte o automatización parcial del proceso, y las que existen no cuentan con métodos formales para el modelado y analisis de los requisitos.

En este trabajo se propone el ReKPlan (Ambiente para a la Ingenieria de Requisitos usando KAOS en problemas de planning), que usa KAOS como método orientado a objetivos para el modelado de los requisitos. Sin embargo, el uso de KAOS (o cualquier otro método orientado a objetivos) no atiende a la necesidad de verificar formalmente el comportamiento dinamico quando el objetivo son los sistemas de planning. La propuesta del presente trabajo es combinar el uso del método orientado a objetivos con el uso de las redes de Petri - en este caso redes de Petri de Alto Nivel - para representar y analisar los requisitos en el design de sistemas de planning. Finalmente es propuesto un mecanismo que sobre el design, que quiado por modelos genera instrucciones PDDL que sirven de entrada a softwares generadores de planos que resuelven los problemas de planning.

Palabras clave: Ingenieria de Requisitos, Planning Automático e Inteligente, redes de Petri, GHENeSys, ReKPlan. 



\section{LISTA DE ILUSTRAÇÕES}

Figura 1 - Desempenho de projetos na área de TI no período 2000-2014 (STANDISH GROUP, 2015). . . . . . . . . . . . . . . . . . 28

Figura 2 - Custos comprometido e incorrido em projetos grandes (BUEDE; MILLER, 2016).

Figura 3 - Relação conceitual entre um sistema de planejamento (planning system, $P S$ ), o ambiente externo que interage com o sistema de planejamento (work environment, $W e$ ), e as restrições de $W e$ sobre a dinâmica de $P s$. . . . . . .

Figura 4 - Diagrama clássico de um Sistema de Planejamento Automático (GHALLAB; NAU; TRAVERSO, 2004). . . . . . . . . . . . . . . . . . 36

Figura 5 - Esquema geral para ambiente de planejamento segundo (VAQUERO et al., 2006). . . . . . . . . . . . . . . . . . 36

Figura 6 - Perspectiva de sistema segundo (LAPLANTE, 2013) . . . . . . . . . . . . 40

Figura 7 - Classificação dos objetivos segundo (LAMSWEERDE, 2009). . . . . . . . 41

Figura 8 - Etapas do processo de projeto para sistemas de planejamento e escalonamento segundo $($ VAQUERO, 2011). . . . . . . . . . . . . . . . . 42

Figura 9 - Relações de Dependência e os elementos de intencionalidade entre atores em $\mathrm{I}^{*}(\mathrm{YU}, 2011) \ldots \ldots \ldots \ldots$. . . . . . . . . . . . . . . . 43

Figura 10 - Diagrama de Dependência simplificado: Sistema de Gerenciamento de Eventos Científicos. . . . . . . . . . . . . . . . . . . . . . 44

Figure 11 - Semântica dos Operadores Temporais. . . . . . . . . . . . . . . . . . 46

Figura 12 - Refinamento E/OU no modelo de Objetivo em KAOS. . . . . . . . . . . . . 48

Figura 13 - Diagrama de Objetivos que descreve a submissão de artigos científicos a tempo quando o prazo é aberto. . . . . . . . . . . . . . . . . . . 49

Figura 14 - Exemplo de uma rede de Petri. . . . . . . . . . . . . . . . . . . 52

Figura 15 - (a) Transição $t$ não é habilitada, (b) $t$ habilitada, (c) rede resultante depois de disparar-se t. . . . . . . . . . . . . . . . . . . 53

Figura 16 - Modelo de um protocolo de comunicações básico utilizando CPN (JENSEN; KRISTENSEN; WELLS, 2007). . . . . . . . . . . . . . 55

Figura 17 - O modelo do protocolo simples divido em módulos (JENSEN; KRISTENSEN; WELLS, 2007). . . . . . . . . . . . . . . . 56

Figura 18 - O rede hierarquica top-level do modelo do protocolo simples (JENSEN; KRISTENSEN; WELLS, 2007). . . . . . . . . . . . . 56

Figura 19 - Exemplo da hierarquia na rede GHENeSys (MIRALLES, 2012). . . . . . . 57 
Figura 20 - MDE proposto em ReKPlan. . . . . . . . . . . . . . . . . . . . . 61

Figura 21 - Ambiente de Análise e Modelagem do ReKPlan. . . . . . . . . . . . . . . 63

Figura 22 - Linguagens integradas no ReKPlan. . . . . . . . . . . . . . . . 63

Figura 23 - Framework ReKplan para a Engenharia de Requisitos complementado com o uso das Redes de Petri para a análise. . . . . . . . . . . . . . . . 64

Figura 24 - Proposta inserida no ciclo de processo de projeto proposto por (VAQUERO, 2011). . . . . . . . . . . . . . . . . 67

Figura 25 - Tradução do padrão de Refinamento por Etapas para uma estrutura de rede GHENeSys ........................... 71

Figura 26 - Diagrama de Objetivos do problema do Mundos dos Blocos em ReKPlan. . 76

Figura 27 - Geração dos objetos envolvidos no objetivo "O bloco é pego". . . . . . . . . 76

Figura 28 - Geração dos objetos envolvidos no objetivo "O bloco é empilhado". . . . . . 77

Figura 29 - Asistente incorporado ao ReKPlan para análise de instruções LTL Mundo dos Blocos. . . . . . . . . . . . . . . . . . . . . 77

Figura 30 - Diagrama de Classes do problema Mundo dos Blocos. . . . . . . . . . . . . 78

Figura 31 - (a) Estado Inicial e (b) Estado Objetivo de um problema simples do Mundo dos Blocos. . . . . . . . . . . . . . . . . . . 80

Figura 32 - Rede GHENeSys do problema do Mundo dos Blocos. . . . . . . . . . . . 81

Figura 33 - Rede GHENeSys do problema do Mundo dos Blocos com três blocos. . . . 81

Figura 34 - Áreas do domínio Montagem Seqüencial de Carros. . . . . . . . . . . . . 82

Figura 35 - itSIMPLE : Dos requisitos de um problema de planejamento até instruções

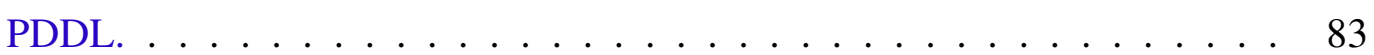

Figura 36 - Diagrama de Classe do domínio de manufatura ROADEF 2005 segundo (BASBAUM, 2015). . . . . . . . . . . . . . . . 84

Figura 37 - Diagrama de Estados Comportamental para o domínio de manufatura ROADEF 2005 (BASBAUM, 2015). . . . . . . . . . . . . . . . . . 84

Figura 38 - Diagrama de Objetivo para o estudo de caso de manufatura: Montagem Seqüencial de Carros. . . . . . . . . . . . . . . . . . . . . 85

Figura 39 - Geração dos objetos do objetivo "Carros montados na área de montagem uma vez foram pintados". . . . . . . . . . . . . . . .

Figura 40 - Geração dos objetos do objetivo "Carros pintados na área de pintura quando a fábrica recebe uma solicitude".

Figura 41 - Diagrama de Classe do domínio de manufatura ROADEF 2005 usando ReKPlan. . . . . . . . . . . . . . . . . 88

Figura 42 - Estado Inicial de um problema de planejamento no Montagem Seqüencial de Carros. . . . . . . . . . . . . . . . . . . . . 92

Figura 43 - Estado Objetivo de um problema de planejamento no Montagem Seqüencial de Carros. . . . . . . . . . . . . . . . . . . . . 92

Figura 44 - Rede GHENeSys do problema de manufatura Montagem Seqüencial de Carros. 94 
Figura 45 - Resultado de análise das propriedades da rede do domínio Montagem Seqüencial de Carros. . . . . . . . . . . . . . . . . . . . . . . . . . . . . . 94 



\section{LISTA DE ALGORITMOS}

Algoritmo 1 - Algoritmo para traduzir do diagrama em KAOS para GNML . . . . . . . 69

Algoritmo 2 - Algoritmo para traduzir desde LTL do diagrama em KAOS para PDDL . 72 

Código-fonte 1 - KML. Estrutura XML para problemas em KAOS . . . . . . . . . . 111

Código-fonte 2 - Domínio Mundo dos Blocos . . . . . . . . . . . . . . 115

Código-fonte 3 - Problema Mundo dos Blocos . . . . . . . . . . . . . 116

Código-fonte 4 - Domínio Montagem Seqüencial de Carros . . . . . . . . . . . . 116

Código-fonte 5 - Problema Montagem Seqüencial de Carros . . . . . . . . . . . . 121

Código-fonte 6 - Problema Montagem Seqüencial de Carros (3 carros azuis, pintura

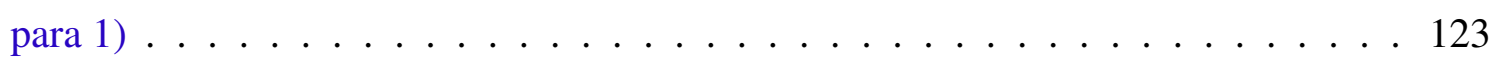

Código-fonte 7 - Gramática LTL criada para reconhecer formulas LTL . . . . . . . . 127 

Tabela 1 - Principais ferramentas e como modelam o domínio de um problema de

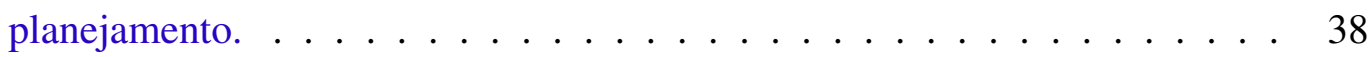

Tabela 2 - Classificação dos atores em I*. . . . . . . . . . . . . . . . 43

Tabela 3 - Principais Elementos do Diagrama Objetivo de KAOS. . . . . . . . . . . 48

Tabela 4 - Elementos GNML definidos em (MIRALLES, 2012) . . . . . . . . . . 68

Tabela 5 - Mapeamento do Modelo KML de KAOS para elementos GNML de GHENeSys 69

Tabela 6 - Tradução dos elementos do diagrama de Objetivos para uma rede GHENeSys. 70

Tabela 7 - Tradução dos refinamentos E/Ou para estruturas da rede GHENeSys. . . . . 70

Tabela 8 - Sentenças LTL associadas a cada objetivo do Diagrama de Objetivos do problemas do Mundo dos Blocos. . . . . . . . . . . . . . . . . . . 78

Tabela 9 - Sentenças LTL associadas a cada objetivo do Diagrama de Objetivos do problema Montagem Seqüencial de Carros. . . . . . . . . . . . . . . . . . 89

Tabela 10 - Sentenças LTL associadas à propriedade do domínio Cumprir N/P: N carros em cada P carros na seqüencia devem cumprir a característica especial. . .

Tabela 11 - Predicados PDDL gerados a partir das sentenças LTL para o domínio Montagem Seqüencial de Carros. . . . . . . . . . . . . . . . . . . . . . . . . . . 90 

INTRODUÇÃO . . . . . . . . . . . . . . . . . 27

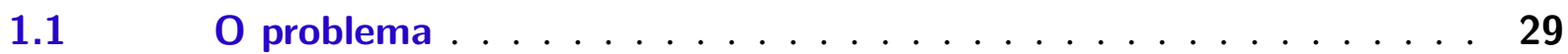

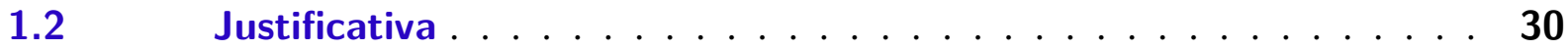

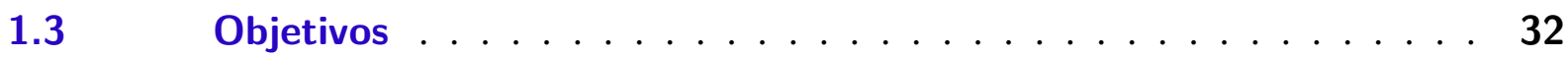

$1.4 \quad$ Contribuições . . . . . . . . . . . . . . . 33

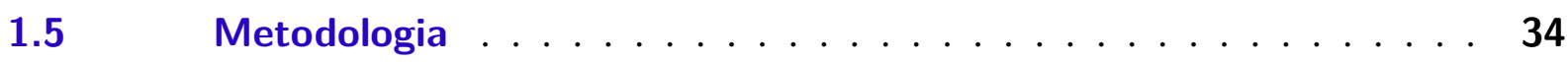

$1.6 \quad$ Organização do Trabalho . . . . . . . . . . . . . . . . 34

2 REVISÃO dA liteRATURA . . . . . . . . . . . . . . . . . 35

$2.1 \quad 0$ problema de planejamento . . . . . . . . . . 35

$2.2 \quad$ Engenharia do conhecimento em Planejamento Automático . . . . . 37

$2.3 \quad$ Metodologias GORE . . . . . . . . . . . . . . . . 39

2.3.1 Método $I^{*} \ldots \ldots \ldots \ldots \ldots \ldots$

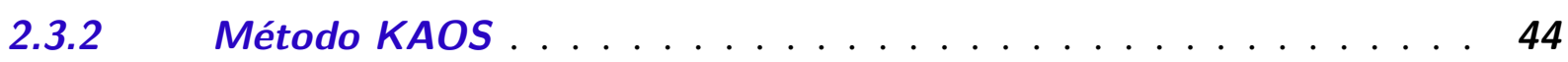

2.3.2.1 Lógica Linear Temporal . . . . . . . . . . . . . . . . . . . 45

2.3.3 Comparação entre $I^{*}$ e KAOS . . . . . . . . . . . . . . . . . 49

2.4 Redes de Petri na Engenharia de Requisitos em problemas de planejamento .................... 50

$2.5 \quad$ Redes de Petri . . . . . . . . . . . . . . . . 51

2.5.0.1 Definição formal das PNs . . . . . . . . . . . . . . . . 52

2.5.0.2 Principais propriedades das redes de Petri . . . . . . . . . . . . . . 52

$2.6 \quad$ Redes de Petri de Alto Nível (HLPN) . . . . . . . . . . . . . 54

2.6.1 Redes de Petri Coloridas . . . . . . . . . . . . . . . . . 55

$2.6 .2 \quad$ A rede GHENeSys . . . . . . . . . . . . . . . . 56

3 REKPLAN: ENGENHARIA DE REQUISITOS USANDO KAOS PARA PROBLEMAS DE PLANEJAMENTO . . . . . . . . . . . . . 59

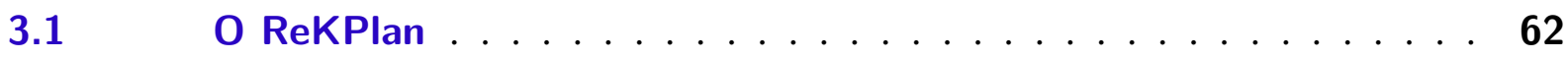

$3.2 \quad$ Arquitetura do ReKPlan ................. 63

3.2.1 Modelagem de um problema usando KAOS . . . . . . . . . . . 65

3.3 Análise de Requisitos usando redes de Petri . . . . . . . . . . . . 66

3.3.1 Traduzindo o diagrama de Objetivo em KAOS para GNML . . . . 68

3.3.2 Traduzindo desde o diagrama de Objetivo em KAOS para PDDL . 71 
3.3.3 Disciplina de Projeto para a Engenharia de Requisitos usando KAOS 72

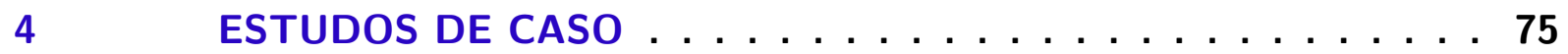

$4.1 \quad$ Problema Mundo dos Blocos . . . . . . . . . . . . . . . 75

4.1.1 Teste com planejador de um problema simples . . . . . . . . . . . . 80

4.1.2 Análise do Modelo do Domínio . . . . . . . . . . . . . . . . . . . . . . 80

4.2 ROADEF 2005 - Montagem Seqüiencial de Carros . . . . . . . . . 82

4.2.1 Modelagem do domínio usando o itSIMPLE . . . . . . . . . . 83

4.2.2 Modelagem do Domínio usando ReKPlan . . . . . . . . . . . . . . . . 85

4.2.3 Modelagem do Problema de Planejamento . . . . . . . . . . . . . . 91

4.2.4 Teste com planejador de um problema simples . . . . . . . . . . . . 92

4.2.5 $\quad$ Análise do Modelo do Domínio . . . . . . . . . . . . . . . . . . . . . . 93

4.2.6 Observações . . . . . . . . . . . . . . . . . . 95

5 CONCLUSÕES E TRABALHO FUTURO . . . . . . . . . . 97

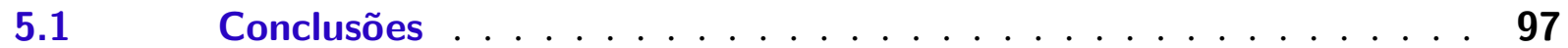

$5.2 \quad$ Considerações Finais . . . . . . . . . . . . . . . . 97

$5.3 \quad$ Contribuições . . . . . . . . . . . . . . . 98

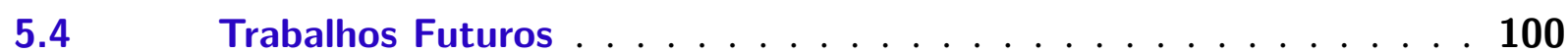

REFERÊNCIAS . . . . . . . . . . . . . . . . . . 103

APPENDIX A KML: EXTENSIBLE MARKUP LANGUAGE FOR KAOS111

APPENDIX B MODELOS DE DOMÍNIOS EM PDDL . . . . . . 115

APPENDIX C GRAMÁTICA LTL PROPOSTA PARA O PROCES-

SAMENTO DE EXPRESSÕES LTL . . . . . . . . 127 


\section{1}

\section{INTRODUÇÃO}

Pesquisadores da área de planejamento e escalonamento vêm centrando sua atenção na fase de aquisição de conhecimento e modelagem do domínio de planejamento, como uma forma de melhorar o desempenho dos planejadores, que na sua maioria usam métodos baseados no modelo estado-transição. Existe ainda uma etapa posterior, em que o domínio modelado deve ser transferido para os planejadores automatizados por meio de alguma linguagem. Várias ferramentas modelam o problema de planejamento usando diferentes técnicas e a linguagem como entrada para os planejadores automáticos (VAQUERO; SILVA; BECK, 2013).

Assim, a discussão principal concentra-se nas técnicas de análise e modelagem de requisitos, e na necessidade real de ter uma fase específica de Engenharia de Requisitos ou, ao invés disso, colapsar a modelagem de domínio e a representação formal dos requisitos, com o uso direto da uma linguagem de especificação como a PDDL (Planning Domain Definition Language).

Outros pesquisadores conferem maior importância ao tipo de problema a ser tratado e às técnicas de planejamento baseadas em Inteligência Artificial a serem usadas. $\mathrm{O}$ uso dessas técnicas torna-se mais complexo ao serem aplicadas em problemas reais do que em problemas modelos. Portanto, por um lado uma fase específica de modelagem de domínio é necessária (SETTE et al., 2008), e por outro lado, uma fase de modelagem e análise de requisitos é essencial para qualquer aplicação de planejamento e escalonamento (i.e. roteamento de carga, bagagens, operações de manufatura, inteligência de máquina, etc) (VAQUERO; SILVA; BECK, 2011). Essa modelagem pode ser dispensada quando o objetivo é analisar os métodos e algoritmos usados pelos planejadores.

O domínio de um problema deste tipo envolve todo o conhecimento necessário para que os algoritmos de planejamento automático interpretem restrições, e gerem os planos com as ações a serem executadas para atingir determinado objetivo. Neste contexto, exige-se um processo de projeto que visa a aplicação prática para obter novos sistemas, e que defina o ciclo 
de vida completo com as fases necessárias para resolver o problema (BASBAUM; VAQUERO; SILVA, 2013).

Estudos recentes mostraram a importância das etapas iniciais do processo de design (HASTIE; WOJEWODA, 2015) . Trata-se de uma fase importante, cuja influência no sucesso das fases restantes é suficiente para determinar o bom andamento do projeto, isto é, uma boa especificação de requisitos é condição necessária (mas não suficiente) para obter um bom design.

Segundo uma pesquisa feita pelo Standish Group (STANDISH GROUP, 2015) na área de Tecnologia da Informação, um fator importante para alcançar o sucesso de um projeto é contar, nas etapas iniciais, com mecanismos eficientes para a elicitação, modelagem e análise dos requisitos.

Na Figura 1 (STANDISH GROUP, 2015) ilustra-se como - desde 2000 até o 2014 - a taxa anual de projetos cancelados e problemáticos supera o volume dos projetos bem sucedidos. Precisamente, uma das principais razões para este quadro são os problemas detectados nos métodos usados (ou na falta destes) nas fases iniciais.

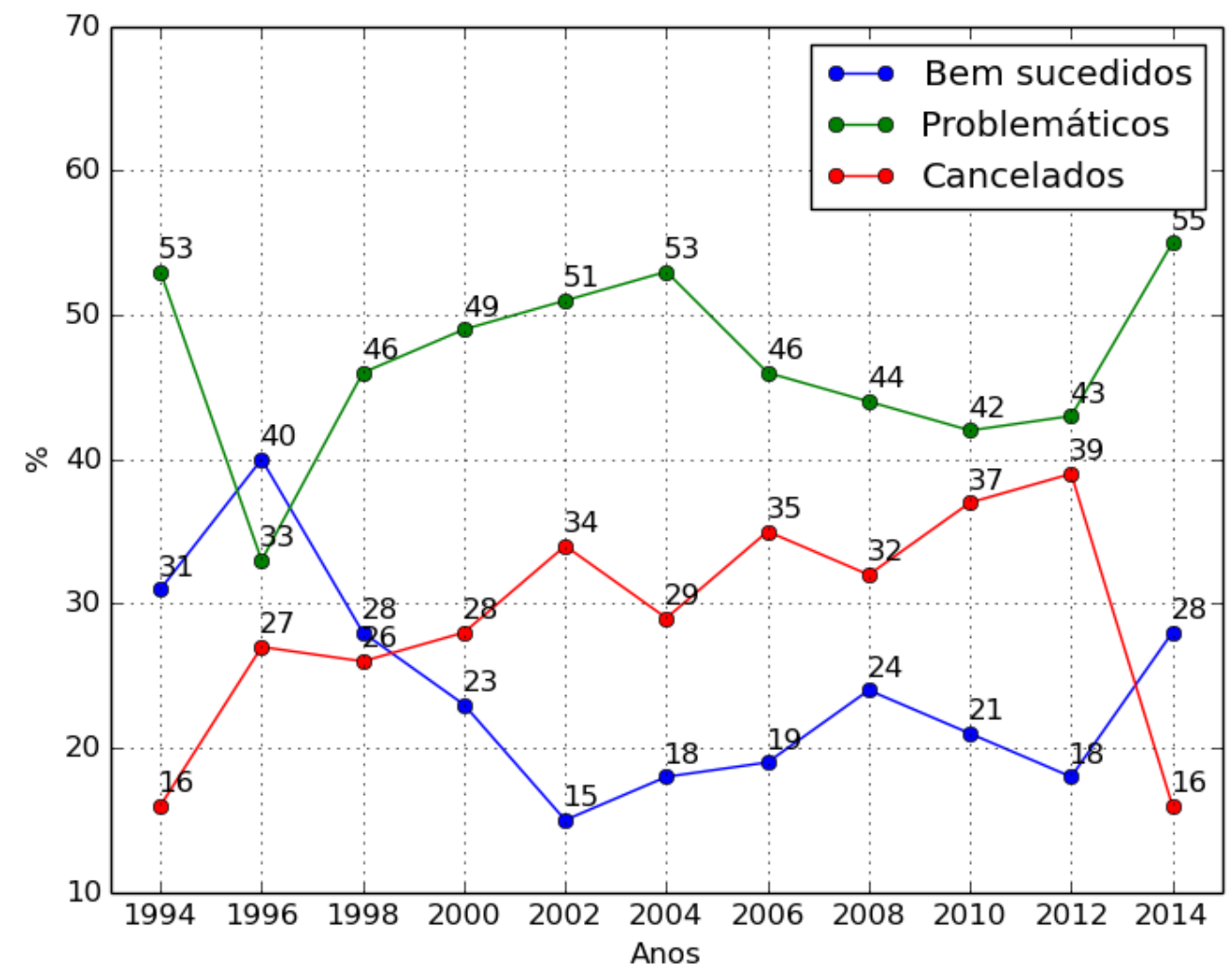

Figura 1 - Desempenho de projetos na área de TI no período 2000-2014 (STANDISH GROUP, 2015).

Em (BUEDE; MILLER, 2016) é feito um estudo comparativo em termos dos custos em projetos de grande porte. Na Figura 2 mostra-se o comportamento das curvas que representam 
o custo comprometido durante o processo de design, e o custo real com base nas despesas correntes.

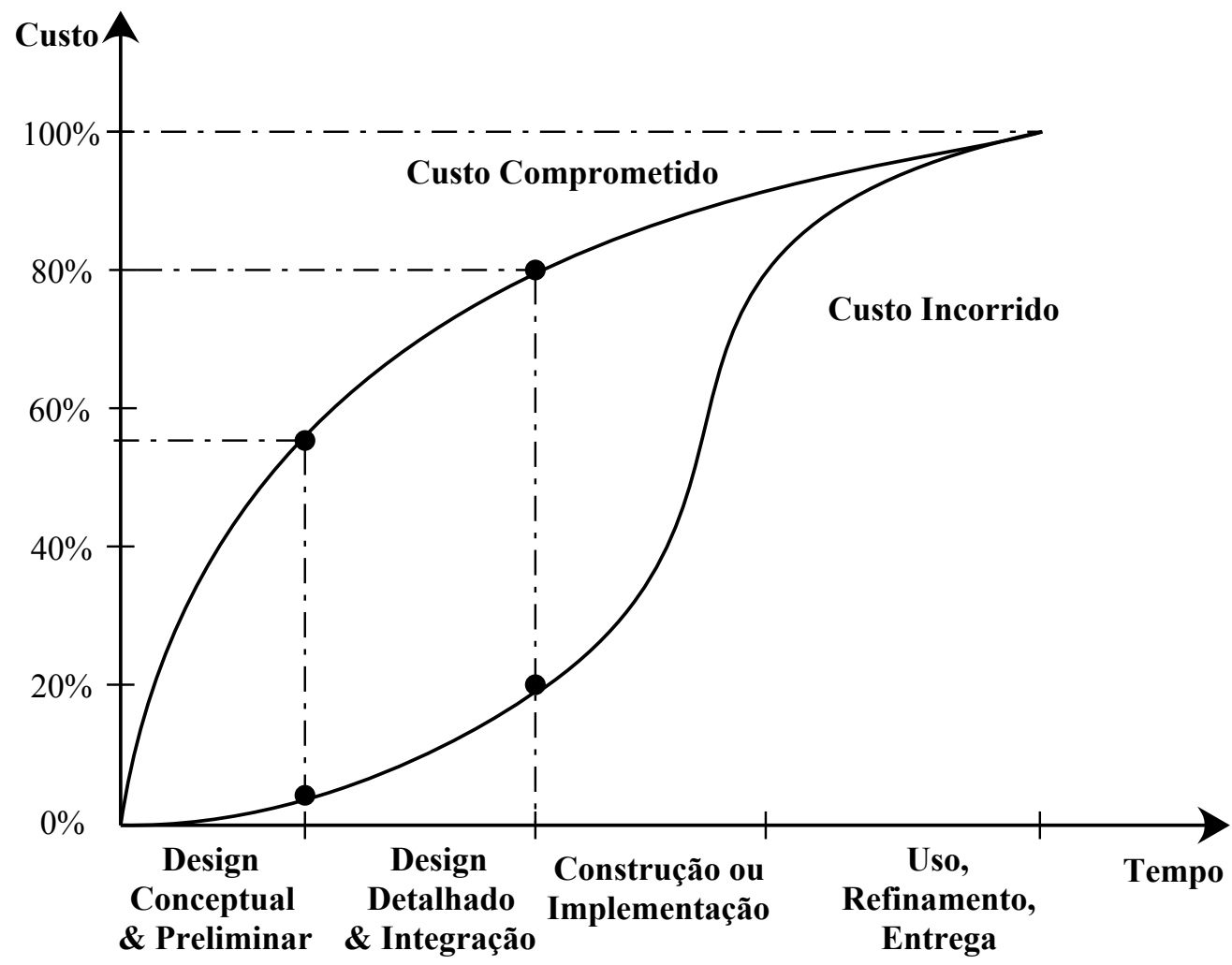

Figura 2 - Custos comprometido e incorrido em projetos grandes (BUEDE; MILLER, 2016).

Como pode ser visto, cerca de um $80 \%$ do custo total do sistema ocorre nas ultimas etapas, enquanto apenas cerca de $20 \%$ do custo real foi gasto nas fases preliminares. Obviamente, os erros encontrados nessas últimas etapas do ciclo terão impactos substancialmente negativos sobre o custo global do sistema, além de inviabilizar respostas às necessidades dos usuários.

O processo de projeto seguido para modelar sistemas de planejamento não escapa dessa problemática, e a etapa inicial que envolve a Engenharia de Requisitos também precisa ser melhorada, agora considerando uma estrutura especial para a formatação do domínio de planejamento.

\subsection{0 problema}

Um ponto importante para os pesquisadores é o uso de métodos formais para representar requisitos, que atualmente tem como ponto de partida as necessidades expressas informalmente pelos stakeholders - e/ou todas as pessoas que de alguma forma podem influir no projeto.

Portanto, o principal desafio é tentar expressar as características de um problema de planejamento na forma de requisitos, usando métodos formais - mesmo para problemas reais 
de médio e grande porte - usando uma linguagem esquemática, e fazer a análise, verificação e validação dos modelos iniciais para obter um modelo consistente que seria transferido para os planejadores automáticos em uma etapa posterior.

Levando em consideração os elementos antes mencionados, formula-se o seguinte problema: Como melhorar o processo de projeto usado em problemas de planejamento - especificamente nas etapas de eliciação e análise de requisitos, inserindo métodos GORE (LAMSWEERDE, 2009) para a modelagem de requisitos, formalizando a dinâmica do modelo em redes de Petri para a análise e verificação de propriedades no sistema GHENeSys eventualmente fazendo uso do verificador deste sistema que é capaz de verificar propriedades específicas usando model checking (FOYO, 2009). Este é o problema proposto, lembrando que na época que foi inciado este trabalho não havia nenhum outro trabalho usando GORE (e até agora não encontramos nenhum exceto o feito pelo grupo do D-Lab) na preparação de problemas de planejamento e escalonamento. Vale lembrar ainda que também não existe nenhum método de transferência de representações GORE, como o sistema KAOS, para redes de Petri (da mesma forma como existe o mesmo processo para requisitos em UML). O uso de redes hierárquicas já havia sido cogitado por outros autores como Dana Nau (NAU et al., 2013)(GHALLAB; NAU; TRAVERSO, 2004), que propôs as HTNs (Hierarchical Task Network), enquanto as redes de Petri hierarquicas foram introduzidas mais recentemente na tese de doutorado Rosi Basbaum (BASBAUM, 2015). A introdução de métodos de tempo real e model checking em redes de Petri foram temas da tese de doutorado de Pedro del Foyo (FOYO, 2009), mas o uso destas técnicas para problemas de planejamento e escalonamento é introduzido no corrente trabalho.

\subsection{Justificativa}

Ao contrário dos problemas modelo, a obtenção do conhecimento do domínio de um problema real de planejamento e escalonamento é uma tarefa difícil, que depende de uma fase inicial caracterizada pela aplicação de métodos de processos da Engenharia do Conhecimento (KENDAL; CREEN, 2007). Temos assim dois problemas: a eliciação do conhecimento do domínio onde se define o problema de planejamento (escalonamento), que chamaremos de domínio de trabalho (work domain); e a especificação do problema de planejamento que se deseja resolver. Os requisitos envolvem a definição do sistema de planejamento e das possíveis ações internas e externas; o conhecimento do domínio efetivo - aquele que de fato interage com o sistema de planejamento (escalonamento) e das restrições que este impõe ao sistema de planejamento. A definição do problema de planejamento completa este quadro. Com o uso de métodos formais para a modelagem e análise destes domínios torna-se mais pragmática e é possível utilizar várias representações, e mudar de uma para outra dependendo do aspecto que se quer analisar. A garantia de problemas formalmente fechados e consistentes pode aumentar o desempenho das técnicas de planejamento inteligente incorporadas nos planejadores (VAQUERO et al., 2012), evitando assim respostas espúrias (impossíveis de conceber ou realizar) ou simplesmente nulas 
(quando o planejador não consegue processar o problema dado).

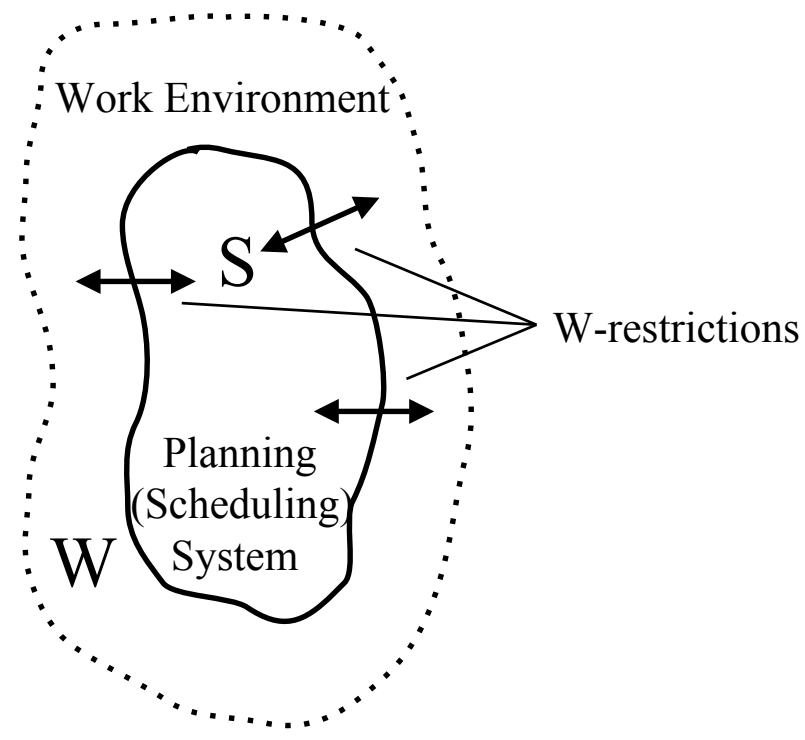

Figura 3 - Relação conceitual entre um sistema de planejamento (planning system, $P s$ ), o ambiente externo que interage com o sistema de planejamento (work environment, $W e$ ), e as restrições de We sobre a dinâmica de $P$ s.

A Figura 3 mostra esquematicamente a relação conceitual entre um sistema de planejamento $(P s)$, a porção do ambiente externo que tem uma influência relevante sobre este sistema, que chamamos de "work environment"(We), e as restrições que este ambiente externo exerce sobre o sistema de planejamento (w-restrictions) ${ }^{1}$, notadamente sobre o ordenamento parcial de ações. O mesmo relacionamento pode ser definido para ambientes que além de planejamento fazem o escalonamento de ações.

Contar com um método mais sistemático para fazer a engenharia de requisitos, ajudará a entender melhor as diversas instâncias - domínio de trabalho, sistema de planejamento, problema de planejamento - enquanto o uso das redes de Petri fornecerá um cenário para modelar a dinâmica do problema, e assim poder validar requisitos expressos em lógica temporal para posterior análise de propriedades, e assim, evitar estados indesejados - como os deadlocks - ou a passagem em estados preferenciais conhecidos na fase de design.

Assim, será fornecido aos projetistas um mecanismo de apoio para a solução de problemas reais, que sobre o ciclo de projeto, permitira a passagem de uma fase inicial com conhecimento incompleto sobre o sistema de planejamento e sua relação com o domínio de trabalho.

As técnicas de planejamento aplicadas a problemas do mundo real, conferem ao processo de análise de requisitos grande relevância como tópico de pesquisa, principalmente porque trata-se de um passo inevitável dentro do ciclo de vida seguido para esses problemas. O presente

1 Usamos o termo w-restrictions para diferenciar estas restrições das restrições internas do sistema, evitando estados indesejáveis, que possam levar a gargalos ou até mesmo a impasses ou situações indesejáveis como aquele causado pela anomalia de Sussman, onde um sistema de planejamento baseado em STRIPS entra em loop infinito. 
trabalho pretende avançar e aprofundar a investigação nesta área, contribuindo para a crescente utilização das técnicas de planejamento automático em problemas reais.

\subsection{Objetivos}

O objetivo geral da presente proposta de tese é formalizar um processo de projeto dentro do escopo do MDE- Model Driven Engineering (CRETU; DUMITRIU, 2014) baseado nas redes de Petri, para a modelagem e análise de modelos de requisitos, usando o ReKPlan como ferramenta de apoio - que depois de revistos e verificados - eventualmente usando o GHENeSys (MIRALLES, 2012) - seriam transferidos em PDDL para planejadores automáticos.

Este seria o método usado na modelagem e análise de requisitos de problemas reais de planejamento.

Um processo de projeto é caraterizado por ser MDE, quando guiados por modelos, permite a tradução de forma automática de uma representação para outra.

Os objetivos específicos são:

- Estudar e avaliar os formalismos para a modelagem e análise de requisitos seguidos pelas ferramentas existentes.

- Comparar o uso do método KAOS em problemas de planejamento com outros formalismos como a linguagem UML (Unified Modeling Language) .

- Propôr um mecanismo de reconhecimento de expressões em LTL a fim de detectar erros ou possíveis inconsistências.

- Propor um algoritmo de tradução desde diagramas KAOS para uma rede GHENeSys, como proposta de sistema de transição, para a descrição do comportamento dos sistemas de planejamento.

- Definir uma linguagem de transferência que facilite a tradução de modelos de requisitos para o modelo de redes de Petri GHENeSys primeiro, e posteriormente para a linguagem PDDL.

A hipótese base da proposta é que com o uso de um método do tipo GORE para representação de requisitos, e o uso das redes de Petri (para a modelagem e análise) como formalismos aplicados no processo de eliciação, modelagem e análise de requisitos -passo inicial do processo de projeto definido para problemas de planejamento automático- é possível melhorar o desempenho e o resultado gerado pelos planejadores implementados no sistema itSIMPLE, mesmo quando este é aplicado a sistemas reais. 


\subsection{Contribuições}

O presente trabalho pretende explorar as possibilidades que oferece o uso de um método enquadrado no processo de engenharia de requisitos para problemas de planejamento e escalonamento, e prevê uma contribuição direta para os processos de projeto que utilizam GORE e na modelagem e verificação formal (com e sem tempo) baseada em Redes de Petri. Espera-se portanto que o que vai ser definido no escopo dos problemas de planejamento (e escalonamento) pode ser generalizado para problemas que admitem um tratamento como transition systems (ou modelados segundo o paradigma estado-transição)

Assim, o trabalho contribuirá também para a análise da aplicação de métodos baseados em diagramas estado/transição (especificamente o uso das redes de Petri) para a resolução de problemas de planejamento, especialmente quando estas técnicas são usadas para prover soluções mais rápidas e flexíveis principalmente nas etapas iniciais do ciclo de vida de um problema desse tipo.

As principais contribuições científicas esperadas são:

- Do ponto de vista teórico/conceitual: Um processo de projeto dentro do escopo do MDE (Model Driven Engineering), em que todo o processo de projeto é baseado em modelos (no caso usando KAOS e redes de Petri, e eventualmente LTL), onde a representação escolhida pode validar/verificar requisitos de um problema previamente modelado, e mostrar que o método proposto de fato ajuda nas etapas iniciais, especialmente para problemas reais de planejamento e escalonamento de médio e grande porte.

- Do ponto de vista teórico/prático: Propor e desenvolver um ambiente integrado para a modelagem e análise de requisitos usando KAOS como método GORE e Redes de Petri como base para formalização de requisitos ${ }^{2}$.

- Do ponto de vista teórico/prático: Propor um algoritmo que fará a tradução por um lado dos diagramas de requisitos em KAOS para sentenças PDDL, e por outro lado para a linguagem PNML aperfeiçoando assim propostas já existentes na literatura. Esta é uma contribuição direta para a área de AI Planning \& Scheduling, no sentido de consolidar a PNML como linguagem de especificação, além do seu papel prático de estender o alcance dos algoritmos de planejamento e escalonamento em problemas reais.

- Do ponto de vista da abertura de novas perspectivas: possibilitar a aplicação de métodos como o System of System (SoS) em Planejamento e Escalonamento.

2 Ferramentas de mercado - que emergiram de grupos de pesquisa -, como o ObjectivER, usam LTL como representação formal, o que não é o mais conveniente para sistemas distribuídos de automação (fábricas, automação predial e residencial, etc. 


\subsection{Metodologia}

A metodologia utilizada no presente trabalho pode ser classificada como pesquisa aplicada, dirigida para a geração de conhecimento e também associada a aplicação prática na solução de problemas específicos, contribuindo concretamente na área de planejamento (escalonamento) automático: i) aplicação de um método na Engenharia de Requisitos sobre um processo de projeto disciplinado, ii) aumentando o potencial da etapa inicial de engenharia de requisitos, que aplicados na solução de problemas reais, possam gerar resultados diretos.

Assim, o primeiro passo empreendido na elaboração da presente proposta de pesquisa, foi realizar uma revisão abrangente sobre o cenário atual das ferramentas atuais para a resolução de problemas de planejamento, assim como as principais tendências em métodos de design e de Engenharia de Requisitos, tendo como pano de fundo a modelagem do conhecimento. Assumiuse como pressuposto que a modelagem e design de sistemas seria feita usando o paradigma estado-transição, o que de fato facilitou a convergência para representações baseadas em grafos e para as redes de Petri na análise de requisitos.

Neste contexto, a presente proposta pretende integrar, por meio do método proposto, os ambientes itSIMPLE e GHENeSys, aproveitando nesse ultimo a possibilidade de inserir hierarquia nas redes de Petri usando somente sub-redes próprias, com comprovado impacto na análise de propriedades de modelos.

\subsection{Organização do Trabalho}

O conteúdo do presente trabalho foi organizado da seguinte maneira:

- Capítulo 2: apresenta a revisão da literatura relacionada ao presente trabalho evidenciando necessidades e oportunidade de pesquisa. São abordados temas como a engenharia do conhecimento em Planejamento Automático, metodologias GORE e o problema de planejamento e escalonamento, a modelagem em KAOS como um desses métodos, a LTL como formalismo para modelar restrições de tempo no método KAOS, e as redes de Petri aplicadas às metodologias GORE bem como sua extensão para as HLPN (High Level Petri Net ).

- Capítulo 3: apresenta o método proposto desenvolvido no sistema ReKPlan, cuja implementação visa contribuir para a solução dos problemas evidenciados no Capítulo 2.

- Capítulo 4: neste capítulo a proposta da tese é aplicada sobre dois estudos de casos: o primeiro satisfaz a definição de problema modelo, o segundo é um problema de manufatura de complexidade intermediária.

- Capítulo 5: apresenta as conclusões e recomendações do trabalho seguidas das referências bibliográficas consultadas e os anexos. 
Este capítulo apresenta uma análise sobre o cenário vigente na área da Engenharia de Conhecimento, especialmente sua aplicação na eliciação dos requisitos em problemas de planejamento e escalonamento. Apresenta-se um breve resumo das abordagens seguidas pelas ferramentas mais destacadas segundo publicações mais recentes na área. Inicialmente, será apresentado um breve histórico da área de atuação, seus principais objetivos e um resumo das principais ferramentas que hoje em dia investem na modelagem e análise de requisitos de problemas de planejamento. Posteriormente serão tratados alguns conceitos básicos das metodologias do tipo GORE, especialmente o KAOS, e sua formalização baseada em lógica linear temporal. Em seguida, é apresentado como representação para sistemas de transição ("transition systems") a rede GHENeSys,uma rede de Petri Unificada proposta neste trabalho como base para a análises de requisitos em problemas de planejamento e escalonamento.

\subsection{O problema de planejamento}

Existem problemas complexos que, por sua natureza e porte, requerem uma capacidade de raciocínio mais elaborada, como a dedução, abdução, raciocínio hipotético, raciocínio baseado em modelo, e aprendizagem. Um sistema baseado em conhecimento é um sistema de software que apoia a representação explícita de conhecimento em algum domínio específico, para poder explorá-lo usando os mecanismos de raciocínio adequados. Entende-se como domínio de um problema de planejamento, todo o conhecimento associado e necessário para sua solução (GHALLAB; NAU; TRAVERSO, 2004).

O planejador é um dos elementos mais importante no planejamento automático, constituindo a parte inteligente central do sistema. Essa inteligência está ligada direitamente ao mecanismo de busca usado e ao conhecimento do domínio da instância do problema. A Figura 4 ilustra os elementos conceituais e a sua correlação no Sistema de Planejamento (GHALLAB; NAU; TRAVERSO, 2004). 


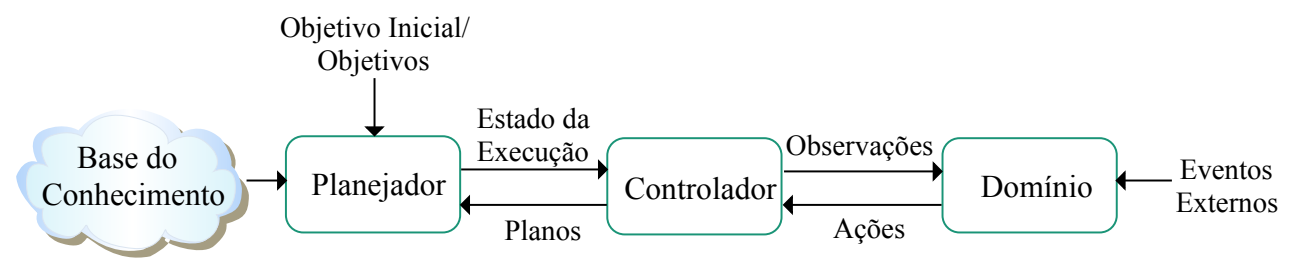

Figura 4 - Diagrama clássico de um Sistema de Planejamento Automático (GHALLAB; NAU; TRAVERSO, 2004).

O conjunto de sensores e atuadores responsáveis por observar e coletar informações e agir em correspondência com a execução da sequência de ações fornecidas pelo Planejador compõem o Controlador, no modelo clássico adotado pela comunidade de planning e exposto na Figura 4.

Entre as aplicações possíveis estão os problemas de manufatura, logística e controle de tráfego aéreo, em que o processo de projeto é dividido em dois elementos segundo (VAQUERO; SILVA; BECK, 2013): $i$ ) aspectos do domínio em que se consideram características essenciais tais como: nome, restrições, operações, ações gerais e propriedades do domínio que são críticas para o sistema; ii) aspectos do problema de planejamento: estado inicial, estado final com os objetos relevantes que compreendem a instância de um problema. A relação entre estes elementos encontra-se na Figura 5. Esta foi a abordagem seguida pelo sistema itSIMPLE original (VAQUERO et al., 2006), agora na sua versão 4.0. Note-se que embora semelhante a proposta deste trabalho segue o apresentado na Figura 3. As diferenças conceituais serão exploradas mais adiante.

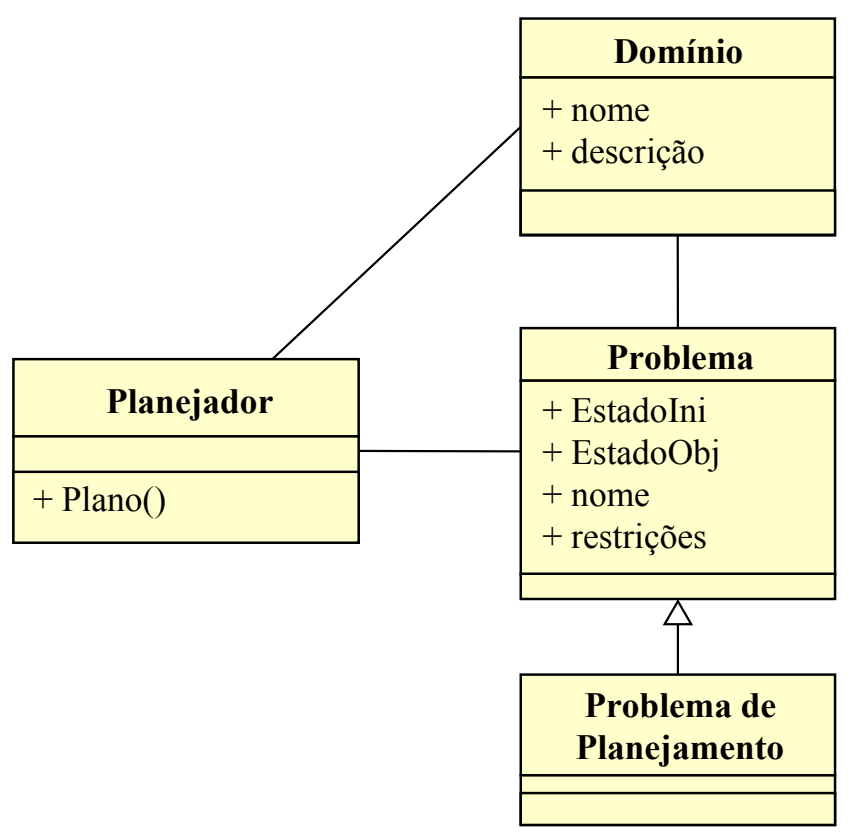

Figura 5 - Esquema geral para ambiente de planejamento segundo (VAQUERO et al., 2006). 


\subsection{Engenharia do conhecimento em Planejamento Au- tomático}

A Engenharia do Conhecimento para Planejamento Automático fundamenta-se nos trabalhos publicados pelo Prof. Thomas Lee McCluskey no início da década de 90 (MCCLUSKEY; PORTEOUS, 1993). Entre os principais objetivos identifica-se o estudo do processo de design para a criação de modelos de conhecimento de alta qualidade e confiabilidade em domínios reais (MCCLUSKEY; PORTEOUS, 2002); e a exploração dos métodos da engenharia de requisitos integradas às técnicas de planejamento automático existentes (VAQUERO; SILVA; BECK, 2013).

Com relação aos planejadores - parte essencial no planejamento automático - o problema apareceu justamente com os planejadores que introduziram hierarquia. Por exemplo, o O-Plan ${ }^{1}$ foi uma das primeiras ferramentas para a aquisição e modelagem de conhecimento de problemas de planejamento sobre uma abordagem orientada a tarefas, cuja distribuição mais atual é em forma de serviço de planejamento acessível pela rede web, e usado em um vasto conjunto de aplicações dependentes do domínio (TATE; DALTON, 2003).

Por outro lado, o SIPE ${ }^{2}$ (MYERS; WILKINS, 1997) introduziu o formalismo ACT, em que um sistema consegue dar resposta a estímulos em tempo real executando a melhor ação possível. Sobre essa abordagem é possível representar todo o conhecimento associado necessário para gerar o plano enquanto eventos externos ocorrem. Ambos os sistemas se propunham já no inicio dos anos 90 a tratar mais formalmente a Engenharia de Conhecimento nos problemas de planning usando métodos de IA.

Tanto O-Plan como o SIPE foram precursores do GIPO, ambiente gráfico integrado com mecanismos para a aquisição e modelagem do conhecimento de aplicações não dependentes do domínio (SIMPSON et al., 2014). O GIPO facilitou a verificação sintática e semântica de modelos, melhorando assim o desempenho dos planos resultantes, e trabalhou na importação e exportação de definições do domínio para o formato PDDL; a integração de algoritmos de planejamento, que eram executados e animados, conferiam um ambiente amigável para os usuários e, a partir da versão III, permitiu a representação gráfica do dinamismo de objetos por meio de máquinas de estados (SIMPSON, 2007).

O itSIMPLE é uma ferramenta mais recente ${ }^{3}$, que seguindo uma abordagem Orientada a Objetos serviu de apoio para que os designers pudessem obter um modelo detalhado do domínio (VAQUERO et al., 2007). A sua maior contribuição foi a introdução do uso da linguagem de modelagem unificada UML para representação de requisitos, usando os diagramas de casos

O O-Plan apareceu oficialmente em uma publicação de K.Currie e Ashton Tate no volume 52, no. 1 da revista Artificial Intelligence de 1991.

2 O SIPE foi proposto na segunda metade dos anos 80, substituido no final desta década pelo SIPE-2.

3 O itSIMPLE foi proposto na dissertação de mestrado de Tiago Stegun Vaquero concluída em março de 2007, e participou pela primeira vez da competição ICKEPS, realizada junto às conferências internacionais de planning e scheduling neste mesmo ano. 
de uso, de classes, de máquinas de estados, temporais (timelines) e de objetos. As classes, propriedades, relações e restrições definem-se no diagrama de classes, permitindo assim modelar as características estáticas do domínio.

A Tabela 1 mostra ambientes de modelagem de domínio seguidos por algumas representações importantes empregadas pelos respectivos métodos de Engenharia de Conhecimento aplicado ao planejamento inteligente.

\section{Tabela 1 - Principais ferramentas e como modelam o domínio} de um problema de planejamento.

\begin{tabular}{cl}
\hline Ferramentas & Modelo do domínio \\
\hline \hline DISCOPLAN & PDDL \\
\hline EUROPA & New Domain Definition Language \\
\hline GIPO & Objetos chamados de sorts \\
\hline FlowOpt & Work-Flow Modeling \\
\hline itSIMPLE & UML \\
\hline JABBAH & Business Process Management Notation \\
\hline ModPlan & PDDL \\
\hline VIZ & Non-Standard Graphical Diagrams \\
\hline
\end{tabular}

Dois destes ambientes usam a linguagem PDDL para fazer a modelagem do domínio de planejamento. Entre os ambientes que não usam UML (Unified Modeling Language) estão o EUROPA, plataforma open-source que modela e analisa modelos do conhecimento de problemas complexos de planejamento e escalonamento, tendo como linguagem de entrada a NDDL (New Domain Definition Language) (BARREIRO et al., 2012) sobre uma estrategia estado/atividade (SMITH; KORSMEYER, 2012); o FlowOpt, que modela processos sobre uma abordagem workflow, simplificando a modelagem e orientando os usuários para a criação de modelos corretos (BART'K et al., 2011); o JABBAH combina a modelagem usando a linguagem BPMN com uma abordagem workflow também (GONZÁLEZ; FERNÁNDEZ; CASTILLO, 2009); e por ultimo o VIZ, que usa uma linguagem gráfica e não-standard simples que permite a descrição de domínios de planejamento (VODRÁZKA; CHRPA, 2010). Todos os ambientes citados permitem a tradução dos modelos do domínio para a linguagem standard PDDL.

O itSIMPLE foi a primeira ferramenta a introduzir técnicas de engenharia de requisitos aplicadas a problemas de planejamento (VAQUERO et al., 2009), em que os requisitos e o conhecimento relevante - egresso dos diferentes viewpoints - envolvidos são representados por meio do diagrama de casos de uso, uma representação semi-formal da linguagem UML (OMG, 2011).

Em seções anteriores mostrou-se como as etapas iniciais para resolver um problema de planejamento são de grande importância no ciclo de design, cuja influência no sucesso das etapas restantes é suficiente para determinar o bom andamento do projeto, isto é, uma boa especificação 
de requisitos é condição necessária (mas não suficiente) para obter um bom design. Além disso, é necessário o uso de métodos formais como forma de representar o conhecimento associado, para assim posteriormente poder verificar os modelos resultantes.

\subsection{Metodologias GORE}

Para entender melhor como um sistema responde às necessidades dos stakeholders( usuários, grupo de pessoas ou organizações que de alguma forma podem influir no sucesso do projeto), resultando em requisitos, é preciso classificar estes requisitos em: funcionais, associados com os serviços a serem prestados; e não-funcionais, relacionados com a qualidade do serviço. Entende-se por requisito uma condição necessária para a obtenção de certo objetivo em um domínio específico, que uma vez modelado e validado pode dar origem a uma especificação: uma descrição mais rigorosa e minuciosa das características do domínio (HORKOFF; YU, 2013).

A Engenharia de Requisitos (RE) é importante ramo da Engenharia de Software e da Engenharia em geral, voltado para o estudo dos métodos que ajudam a determinar os objetivos, as funções e as restrições de um sistema (NUSEIBEH; EASTERBROOK, 2000). Além disso, a RE envolve a relação entre requisitos para resultar em especificações consistentes e fiéis ao comportamento do sistema, na sua evolução ao longo do tempo ou na relação entre famílias de sistemas relacionados (LAPLANTE, 2013). Assim, é possível conhecer pormenores do comportamento do sistema, sua evolução no tempo, e sua relação com outros sistemas através de modelagem formal.

As atividades características da RE são: $i$ ) eliciação dos requisitos: responsável pela aquisição do comportamento pertinente às funcionalidades do sistema e à sua relação com o ambiente em torno; ii) modelagem: descreve as informações dos requisitos através de uma representação específica, que pode ser dividida na modelagem do problema de planejamento a ser resolvido, e na modelagem do mundo que interage com este planejamento, definida como domínio de trabalho (work domain). A análise do domínio ou do conjunto problema/domínio/planejamento consiste em verificar e validar a consistência dos modelos de requisitos (WERNECK; OLIVEIRA; LEITE, 2009).

De acordo com (LAMSWEERDE, 2003) seguindo uma engenharia de requisitos eficiente é possível, além de determinar os objetivos, sua operacionalização em especificações de serviços e restrições, a atribuição de responsabilidades aos agentes (seres humanos, hardware ou software) que se relacionam com os requisitos, e a traceability que associa os requisitos aos agentes que os geraram.

Nos últimos anos, com o aumento na complexidade dos problemas, a clara necessidade de modelar não só requisitos funcionais (ou funcionalidades) mas também os requisitos não-funcionais e os rationales, isto é, respostas ao "por quê?" desses requisitos previamente declarados, levaram a uma nova abordagem: Metodologias GORE (Metodologia Orientada a 
Objetivos), em que os requisitos são modelados em termos de objetivos, como sendo um estado ou condição que um ator ou agente (humano ou não) deseja alcançar (YU, 2011).

Segundo (LAPLANTE, 2013) os objetivos (goals) tem um nível de abstração superior para o negócio, organização, ou sistema; enquanto um requisito especifica como esse objetivo será atingido pelo sistema. Entende-se por sistema, o software e o contexto em que é inserido, incluindo também dispositivos tais como: sensores e atuadores, pessoas, entre outros (consultar Figura 6). Essa coleção de hardware, software, pessoas, instalações e procedimentos organizados geralmente visam a atingir objetivos comuns (BUEDE; MILLER, 2016).

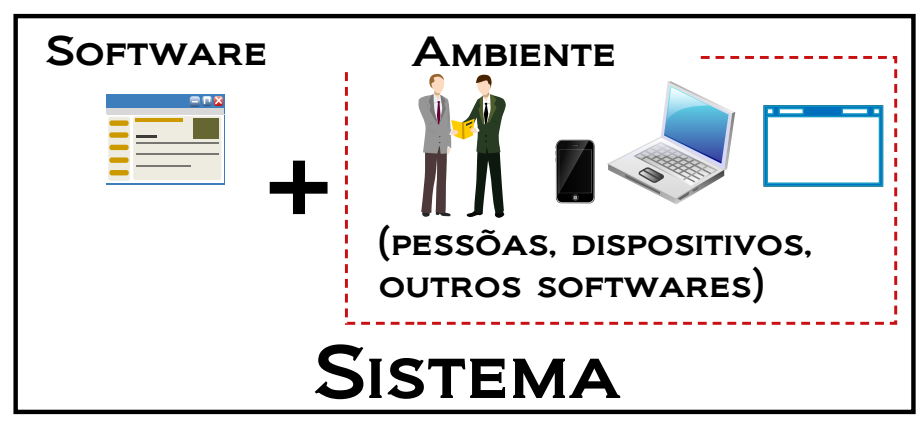

Figura 6 - Perspectiva de sistema segundo (LAPLANTE, 2013).

Ao contrário dos objetivos, as propriedades do domínio são asserções sobre o mundo do problema, tais como as leis físicas. Por exemplo, para um departamento de transportes, um objetivo definido poderia ser "construir a ponte mais segura do mundo", e sendo esta sua principal intenção, estipular requisitos de desempenho, qualificação da equipe de engenheiros e seguir técnicas de construção adequadas, como alguns dos requisitos que permitirão a construção dessa ponte segura.

A eliciação dos requisitos é a base para a solução do problema. Esta deve ser formulada baseada em objetos do mundo real, com um vocabulário simples e compreensível para que seja bem entendida pelos stakeholders (ou qualquer pessoa ou organização que tenha interesse, ou seja afetado pelo projeto). Já para os designers, as especificações do sistema são o objetivo final da fase de modelagem e análise de requisitos agora representados em uma linguagem formal, envolvendo objetos do futuro software. Os agentes - entidades a que são atribuídas responsabilidades para cumprir certos objetivos - podem atingir objetivos do contexto, com todo o conhecimento relevante do domínio, ou objetivos do futuro sistema (LAPOUCHNIAN, 2005).

Em (LAMSWEERDE, 2009) classificam-se os objetivos em duas categorias principais: os funcionais, que conformam modelos operacionais dos serviços a serem oferecidos; e os não funcionais que possuem duas subcategorias: os objetivos de qualidade, que podem atribuir uma métrica à qualidade do serviço, segundo alguns parâmetros (segurança, usabilidade, desempenho, interoperabilidade), e os objetivos de desenvolvimento, relacionados ao processo de desenvolvimento (custos, deadline, variabilidade, manutenção, reusabilidade, entre outros): 


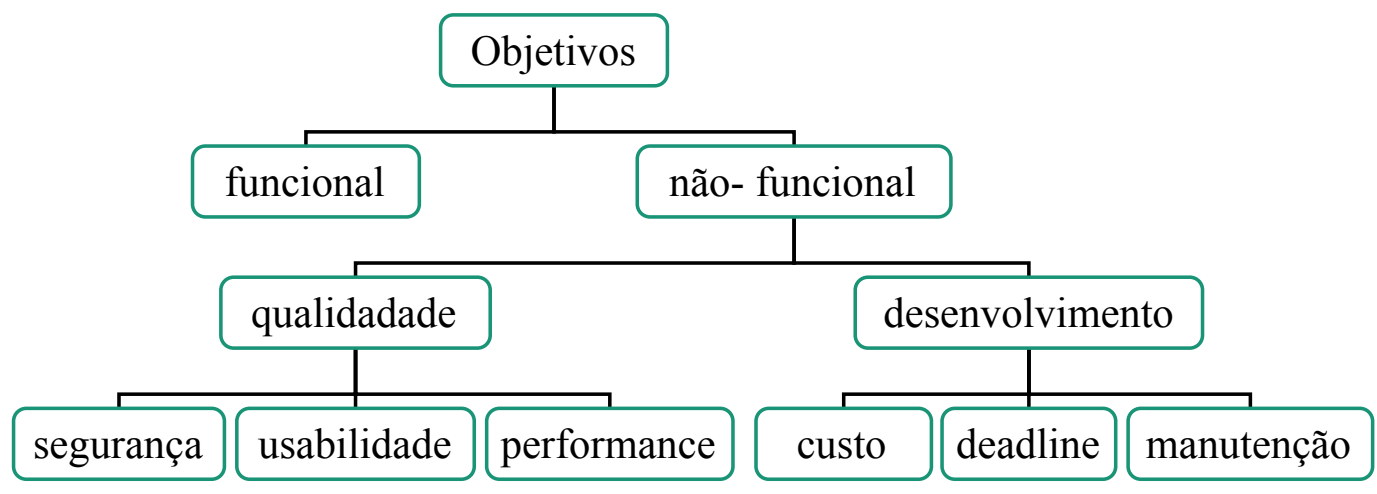

Figura 7 - Classificação dos objetivos segundo (LAMSWEERDE, 2009).

Entre as principais vantagens das metodologias GORE estão: a de fornecer um critério para determinar a completeza na especificação dos requisitos, cumpridos na medida em que sejam atingidos os objetivos que os envolvem; ter um mecanismo chave no gerenciamento de conflitos entre diferentes viewpoints; e fornecer as justificativas (rationales) necessárias, dando resposta ao "por quê?" desses requisitos.

No planejamento automático, a atividade de eliciação (VAQUERO; SILVA; BECK, 2013) consiste na identificação, aquisição, análise e documentação:

- Do conhecimento relevante sobre o problema e do domínio no qual se insere (chamado conhecimento específico);

- Das características e comportamento dos sistemas de planejamento e escalonamento (chamado conhecimento geral ou de contexto)

Para esses problemas é também essencial que o contexto em que o domínio e o problema se situam sejam devidamente analisados, e para isso deve-se utilizar uma combinação de métodos, ferramentas e pessoal (projetistas, especialistas, usuários, stakeholders e outros) organizados seguindo um método de trabalho. O resultado será uma especificação detalhada (informal ou semi-formal) sobre o qual é o problema e uma clara descrição da qualidade dos requisitos (desempenho e restrições de usabilidade).

Em (VAQUERO, 2011) propõe-se as etapas de um processo de projeto para problemas de planejamento e escalonamento [ver Figura 8], em que as etapas iniciais do ciclo de vida caracterizam-se por modelar um conhecimento ainda incompleto do artefato. A maioria das ferramentas consultadas na literatura, tratam a especificação dos requisitos e a modelagem do conhecimento como uma única etapa.

Para esses problemas, a solução final é uma sequencia de ações (plano) que começam em um estado inicial (uma das condições de contorno) e termina em um estado objetivo previamente definido (RUSSELL; NORVIG, 2010). Para modelar estes problemas para os planejadores automáticos, o designer tem que obter um artefato que pode ser usado várias vezes, talvez por 


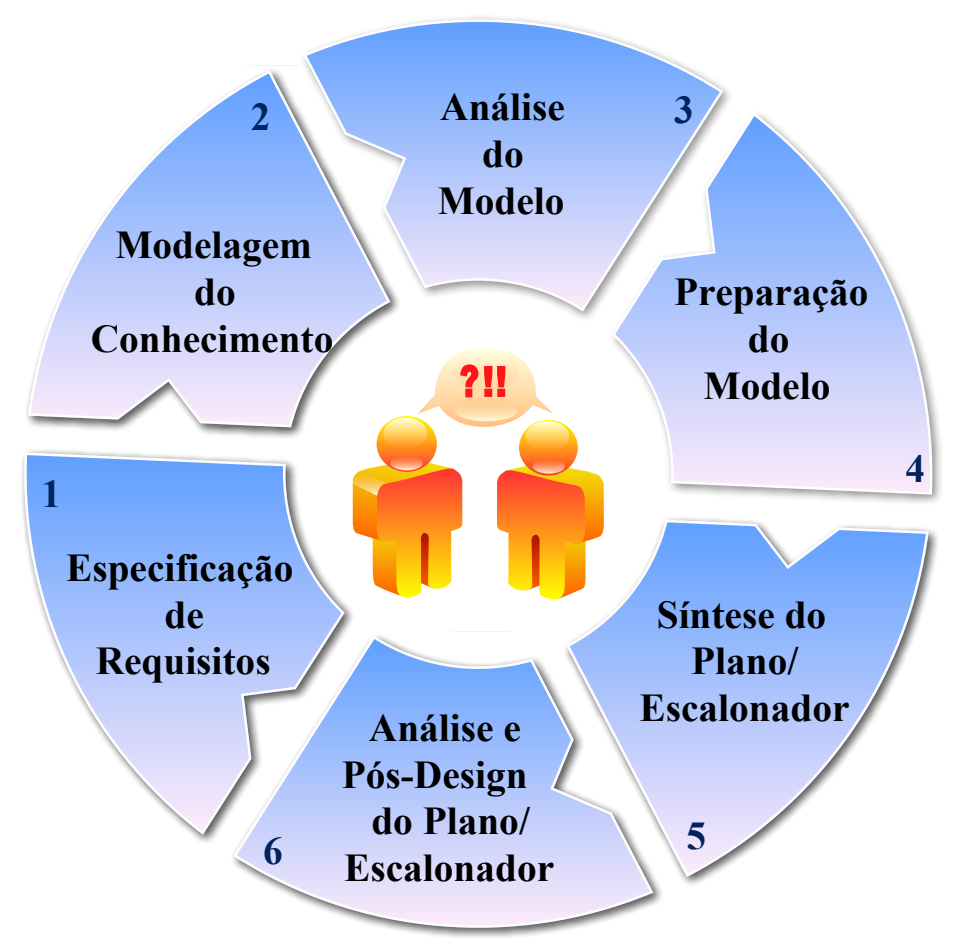

Figura 8 - Etapas do processo de projeto para sistemas de planejamento e escalonamento segundo (VAQUERO, 2011).

muitos usuários e por muitos planejadores, para achar uma sequência de ações mais refinada e otimizada.

O plano, quando utilizado, deve produzir os mesmos efeitos desde que as condições iniciais não sejam alteradas. Por outro lado, não existe necessariamente um único plano satisfazendo as condições iniciais, e há portanto uma segunda pergunta a responder: "qual o melhor plano que resolve o problema?". Assim, o designer, deveria procurar entre os vários planos o que melhor, segundo alguma métrica satisfaz os requisitos do problema. A solução otimizada é no entanto muito difícil de ser encontrada em um tempo que satisfaça os limites impostos por processos de uso prático, e na maioria dos casos (e mesmo para problemas modelo) se considera a primeira solução encontrada. Os métodos Orientados a Objetivos facilitam o balanço entre achar uma solução qualquer e obter uma solução otimizada, embora seu uso em problemas de planejamento e escalonamento não foi plenamente explorada até o momento.

\subsubsection{Método I*}

O método orientado a objetivos I* foi proposto por Eri Yu como parte de sua tese de doutorado em 1994 (YU, 1996). A principal contribuição é sobre como uma abordagem socialintencional auxilia na modelagem, no design e análise de requisitos de um problema. O I* foca a noção de intencionalidade dos atores e na relação desses com outros atores. Um ator é definido como uma entidade ativa que executa certas ações para atingir um ou mais objetivos. Pode ser visto como uma super classe para um agente, posição ou função (LEITE et al., 2007) (consultar 
Tabela 2).

\begin{tabular}{cl} 
Elemento & \multicolumn{1}{c}{ Descrição } \\
Ator & $\begin{array}{l}\text { Representa uma entidade ativa (stakeholders) com } \\
\text { intençães, e que executa ações para atingir os seus } \\
\text { objectivos. }\end{array}$ \\
Função & $\begin{array}{l}\text { Uma abstração de actor com expectativas e } \\
\text { responsabilidades. }\end{array}$ \\
Agente & $\begin{array}{l}\text { Representa um actor humano ou dispositivo com } \\
\text { capacidades especificas que permite-lhe desempenhar } \\
\text { mais de uma Função. } \\
\text { Prupo de responsabilidades que podem ser ocupadas } \\
\text { por um agente. Uma posição pode abranger mais de } \\
\text { uma Função. }\end{array}$
\end{tabular}

Tabela 2 - Classificação dos atores em I*.

Os atores dependem uns dos outros por meio dos recursos a serem fornecidos, de tarefas a serem executadas e dos sub-objetivos a serem atingidos. Para isso o I* fornece dois modelos: o Diagrama de Dependência, para modelar as relações de intencionalidade entre atores por meio de elementos especiais de (consultar Figura 9), e o de Lógica Estratégico, que descreve os processos internos de cada ator de forma detalhada.

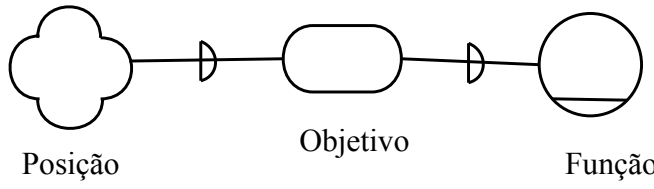

(a) Dependência de Objetivo

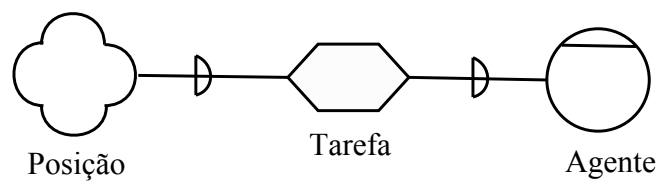

(b) Dependência de Tarefa

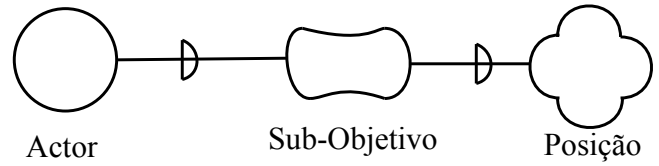

(c) Dependência de Sub-Objetivo

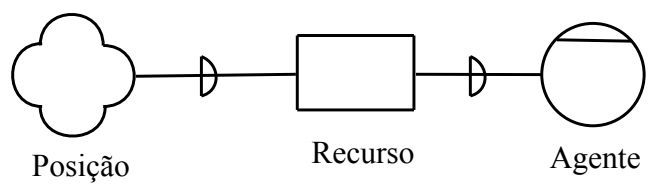

(d) Dependência de Recurso

Figura 9 - Relações de Dependência e os elementos de intencionalidade entre atores em I* (YU, 2011).

Em I* a forma em que os atores interagem e as suas relações de dependências são requisitos essenciais para a modelagem do sistema. A Figura 10 mostra um o Diagrama de Dependência simplificado de um sistema para gerenciamento de eventos extraído de (OLIVEIRA et al., 2006), particularmente o controle da submissão dos artigos.

Neste exemplo identificam-se três atores (Pesquisador, Comitê Organizador e o System Manager), sendo todos representados como atores do tipo Função, pois têm responsabilidades e expectativas sobre o sistema.

Apesar de se tratar de uma metodologia GORE, o fato de não ficar o suficientemente claro quais são os objetivos primários pode ser visto como uma desvantagem, embora possam 


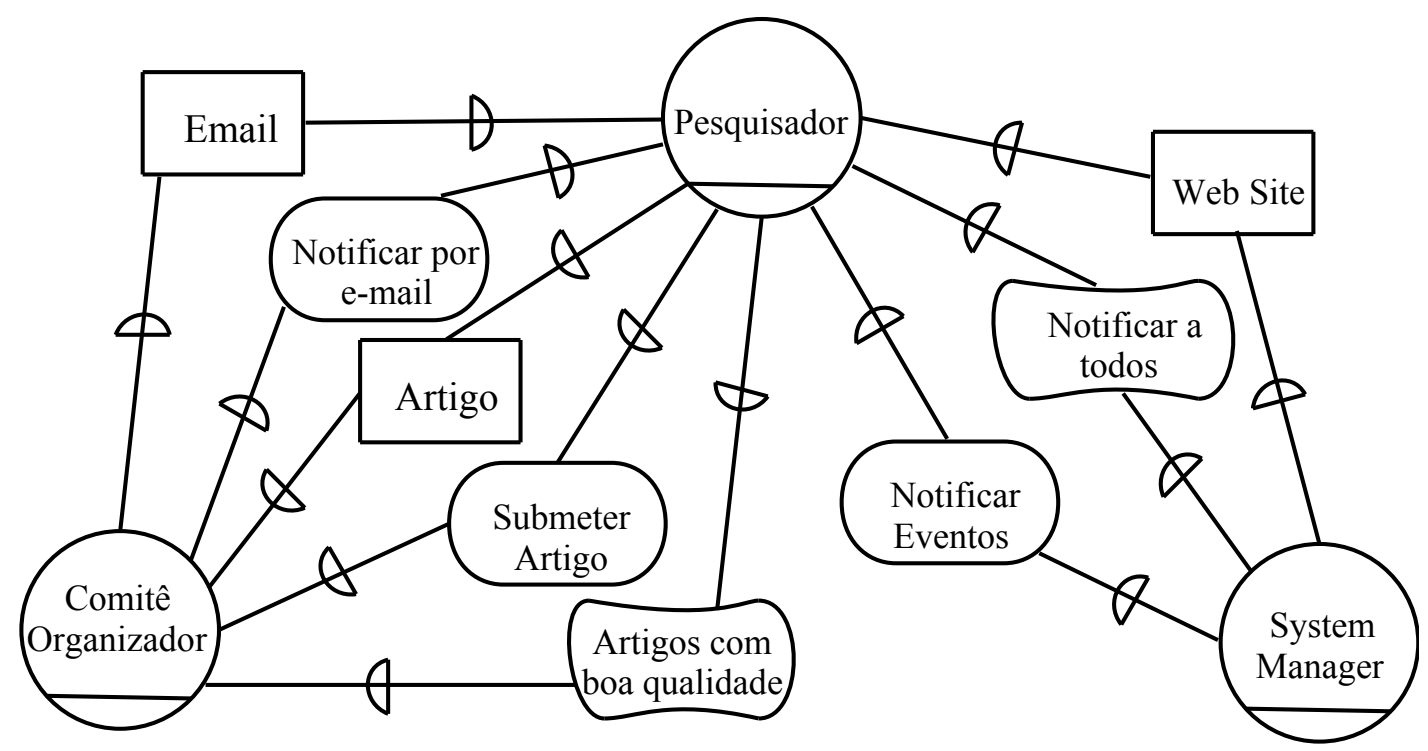

Figura 10 - Diagrama de Dependência simplificado: Sistema de Gerenciamento de Eventos Científicos.

ser identificados por meio de rastreamento entre os elementos de intencionalidade dos atores. $\mathrm{Na}$ próxima seção será introduzida outra abordagem GORE para tratar requisitos: o método KAOS, um dos mais citados na literatura.

\subsubsection{Método KAOS}

O KAOS é outro método de modelagem de requisitos orientado a objetivos desenvolvido pela Universidade do Oregon em parceria com a Universidade de Louvain (PONSARDE; DARIMONT; MICHOT, 2015).

Este modelo já atingiu o mercado através de uma ferramenta desenvolvida pela RespectIT, uma empresa belga criada como spin-off da equipe de Louvin. Portanto já existe uma experiência prática e uma dezena de projetos industriais de grande porte aplicados em diversos setores (RESPECT, 2007), que atestam eficiência do método. Além de fornecer uma linguagem para eliciar requisitos, o método KAOS pretende dar respostas a questões como "Por quê?", “Quem?” e "Quando?” sobre os objetivos previamente declarados (LAMSWEERDE, 2009).

O método envolve uma série de redes semânticas para a modelagem conceitual dos objetivos, hipóteses, agentes, objetos e operações do sistema. Além disso, com o uso da lógica temporal, é possível representar a especificação dos objetivos, dos objetos, e do estado base das operações.

O processo de modelagem em KAOS é divido em dois níveis de representação: um nível gráfico com elementos para modelar conceitos, atributos e relações; e outro nível interno para a representação destes elementos usando o formalismo da lógica temporal linear (LTL).

Entre os diagramas que o KAOS oferece para a análises de requisitos estão: o diagrama de Objetivos (que responde ao "por quê?" e/ou ao "como?"), o diagrama de Responsabilidades 
(que responde ao "quem?"), o diagrama de Objetos (que responde ao "o que?"), o diagrama de Operacionalização (responde o "quando?"). No processo de engenharia de requisitos, técnicas de análise formais ou semi-formais se complementam (em aplicações reais) a fim de fornecer uma garantia maior na correção e integridade dos requisitos do sistema. Especificamente, o KAOS permite a representação dos elementos de todos esses diagramas sobre o formalismo da lógica temporal.

Um objetivo de comportamento captura o conjunto maximal de comportamentos implícitos possíveis, representados como uma sequência de transições em um sistema de transição, portanto, um comportamento poderá violar um objetivo, se não for prescrito entre as especificações formais do objetivo. Em (CAILLIAU; LAMSWEERDE, 2013) propõe-se o uso de LTL (Lógica Linear Temporal) para a formalização dos objetivos, enquanto (LAMSWEERDE, 2013) propõe as classificações “alcançar” ou “manter/evitar” na definição do comportamento associado aos objetivos.

\subsubsection{Lógica Linear Temporal}

A lógica temporal é uma extensão da lógica proposicional, a qual com uma notação matemática intuitiva permite expressar propriedades de um sistema de transição em execução, incluindo novas modalidades temporais (BAIER; KATOEN; LARSEN, 2008)

A abordagem básica do tempo na lógica pode ser tratada como linear ou ramificada. $\mathrm{Na}$ abordagem linear, a noção de tempo é qualitativa e definida sobre um caminho, ou seja, sobre uma sequência de estados em que para cada estado existe apenas um possível sucessor para cada instante de tempo, enquanto na ramificada existe uma ramificação definida por uma estrutura de árvore, em que para um instante de tempo se divide a execução do sistema em sucessivos caminhos alternativos. A logica LTL é baseada na perspectiva de tempo linear, enquanto outros tipos de lógica como a lógica CTL (Computation Tree Logics) aborda uma visão ramificada do tempo.

As modalidades temporais elementares presentes na maioria das lógicas temporais incluem os operadores:

- $\diamond$ “Eventualmente" (eventualmente no futuro).

- $\square$ "Sempre" (Agora e sempre no futuro).

Na Figura 11 mostra-se a semântica associada a esses operadores temporais (KRÖGER; MERZ, 2008).

Segundo (BAIER; KATOEN; LARSEN, 2008) uma fórmula LTL é definida sintaticamente sobre o conjunto AP de proposições atômicas como :

$$
\varphi::=\text { true }|\alpha| \varphi_{1} \wedge \varphi_{2}|\neg \varphi| \bigcirc \varphi \mid \varphi_{1} \cup \varphi_{2}
$$




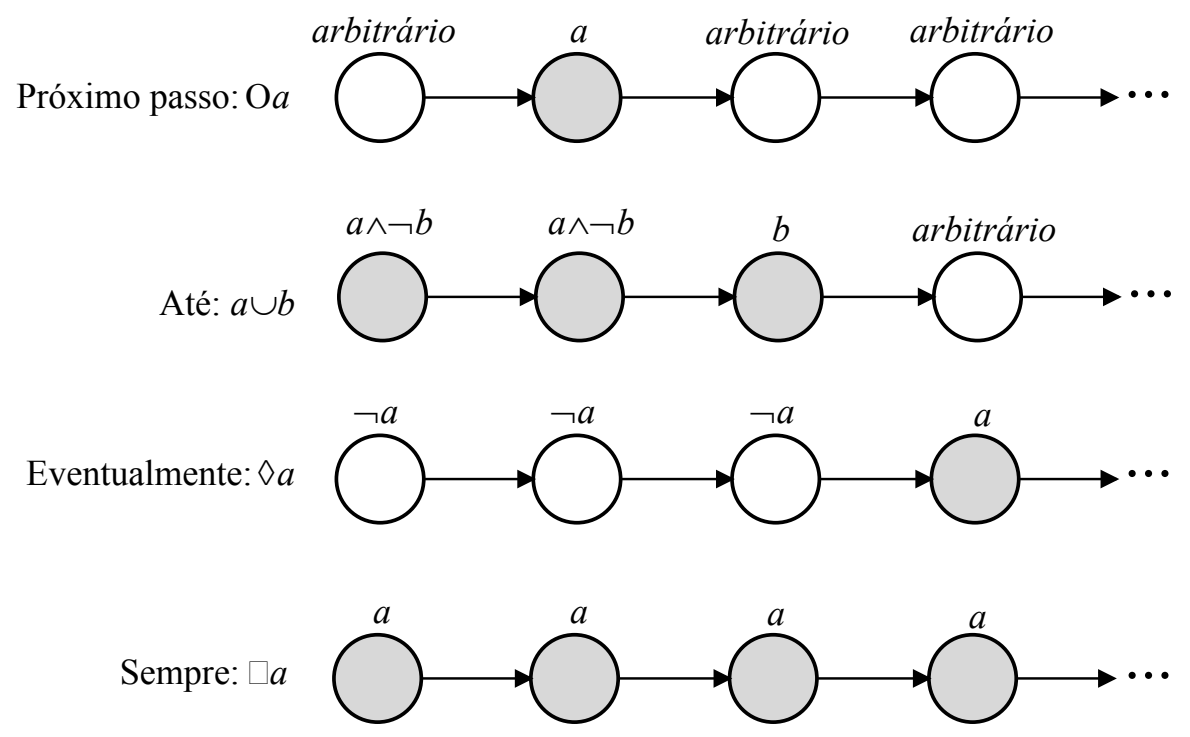

Figura 11 - Semântica dos Operadores Temporais.

- true:simbolo de verdade

- $\alpha$ : uma proposição atômica

- $\varphi_{1} \wedge \varphi_{2}$ :operador conjunção entre as fórmulas $\varphi_{1}$ e $\varphi_{2}$.

- $\neg \varphi$ : operador negação da fómula $\varphi$.

- $\bigcirc \varphi$ : operador “próximo passo"; $\varphi$ é verdadeira no próximo estado.

- $\varphi_{1} \cup \varphi_{2}$ : operador "até"; $\varphi_{2}$ é verdadeira em algum momento e $\varphi_{1}$ é verdadeira em todo estado até atingir esse momento.

Com o formalismo LTL é possível representar propriedades de tempo real sobre a perspectiva de tempo discreto. O operador “próximo passo" $(\bigcirc)$ é redefinido com a seguinte interpretação temporizada:

- $\bigcirc \varphi$ no próximo instante de tempo $\varphi$ se cumpre. Colocado em sequência representa-se:

$$
\bigcirc_{k} \varphi \stackrel{\text { def }}{=} \underbrace{\bigcirc \ldots \bigcirc}_{k-\text { times }} \varphi
$$

Asserções como:

- " $\varphi$ é verdadeira em ao menos $k$ instantes de tempo" podem ser representadas como:

$$
\diamond_{k k} \varphi=\bigvee_{0 \leqslant i \leqslant k} \bigcirc_{i} \varphi
$$


- “ $\varphi$ é verdadeira agora e seguirá sendo durante os próximos $k$ instantes de tempo" podem ser representadas como:

$$
\square_{\leqslant k} \varphi=\neg \diamond \leqslant k \neg \varphi=\neg \underset{0 \leqslant i \leqslant k}{\bigvee} \bigcirc_{i} \neg \varphi
$$

Portanto os objetivos em KAOS têm a seguinte representação formal: $C \Rightarrow \Theta T$, em que $C$ denota uma condição atual, $T$ uma condição destino, e $\Theta$ algum dos operadores $\bigcirc, \diamond, \square, \cup$, com as variantes temporais $\diamond \leqslant k$ e $\square_{\leqslant k}$. Uma expressão da forma $P \Rightarrow Q$ significa que $\square(P \rightarrow Q)$.

O objetivo comportamental "atingir"é representado como $C \Rightarrow \diamond T$, isto é, se cumpre $C$ como condição atual, $T$ eventualmente no futuro vai ser alcançado, enquanto os objetivos comportamentais “manter/evitar" são formalmente definidos como $C \Rightarrow \square A$ (manter), para expressar que se se cumpre $C$ então sempre vai se cumprir $A$; e $C \Rightarrow \neg \square B$ (evitar) para representar que se a condição atual $C$ se cumpre então deve-se evitar que se cumpra $B$ como condição destino (ALRAJEH et al., 2012).

O diagrama de objetivos é representado em um grafo em que os nós representam os objetivos e as arestas a influência de um objetivo sobre outro através de uma relação. O objetivo principal, abstração do problema, representado graficamente por um paralelogramo, pode ser refinado em subobjetivos até modelar requisitos, que são os objetivos mais básicos na hierarquia do diagrama, sempre associados aos agentes.

Graficamente os objetivos, requisitos e expectativas são representados usando paralelogramos. No caso dos requisitos as bordas são mais ressaltadas fazendo o diferencial com o resto, as expectativas são desenhadas usando a cor amarela, enquanto os agentes são representados por hexágonos (consultar Tabela 3).

Os objetivos representados nas folhas da árvore classificam-se em requisitos ou expectativas, e devem sempre estar ligados a um agente (humano ou não). A classificação em requisito ou expectativa é dada pelo tipo de agente ao qual estão ligados. Se o agente é o software a ser desenvolvido, trata-se de um requisito para esse software, enquanto o objetivo é uma expectativa se ele está ligado a um agente do contexto.

O refinamento de um objetivo é a decomposição segundo as exigências ou expectativas associadas às responsabilidades dos agentes (consultar Figura 12).

No diagrama de Objetivos representado na Figura 12 existem três refinamentos:

- $\operatorname{Refs}=\left\{\operatorname{Ref} s_{1}, \operatorname{Ref} s_{2}, \operatorname{Ref} s_{3}\right\}$, em que:

- $\operatorname{Ref} s_{1}(G)=\left\{G_{1}, G_{2}, G_{3}\right\}$ é um E-Refinamento.

- $\operatorname{Refs}_{2}\left(G_{3}\right)=\left\{G_{6}, G_{7}\right\}$ é um Ou-Refinamento.

- $\operatorname{Ref} s_{3}\left(G_{1}\right)=\left\{G_{4}, G_{5}\right\}$ é um E-Refinamento. 


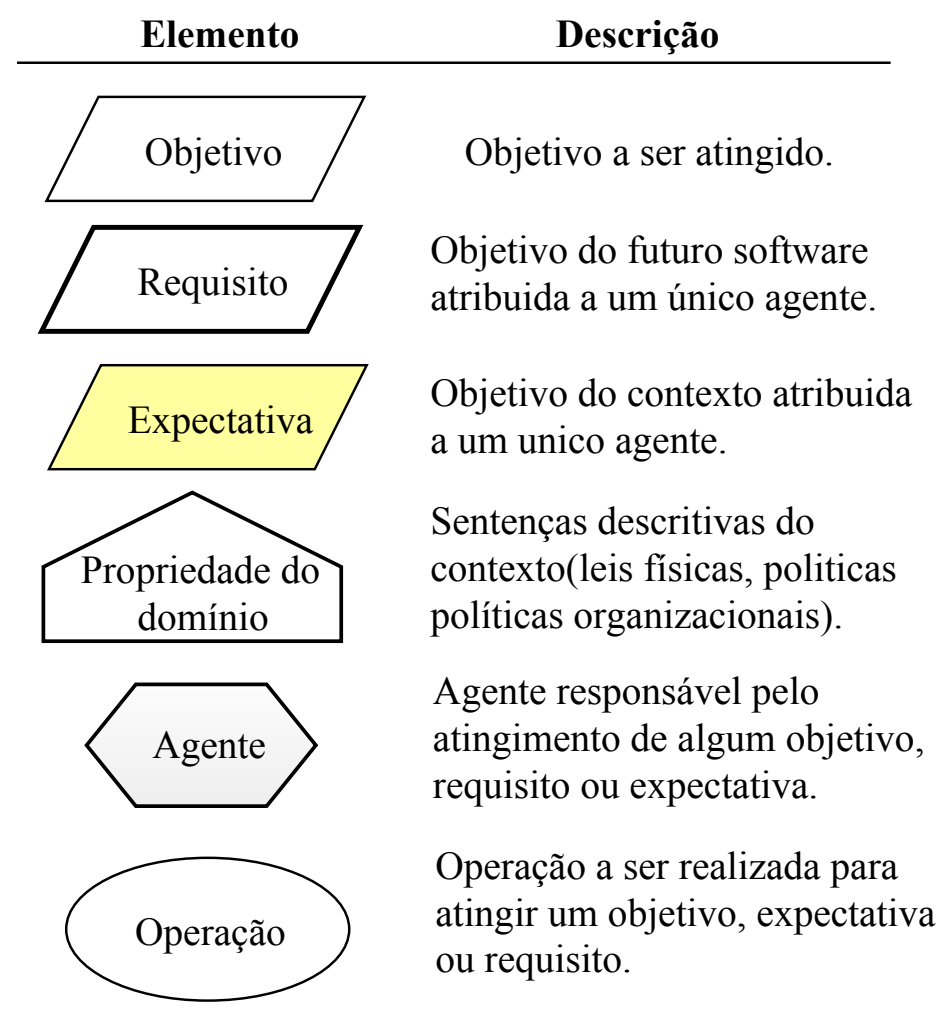

Tabela 3 - Principais Elementos do Diagrama Objetivo de KAOS.

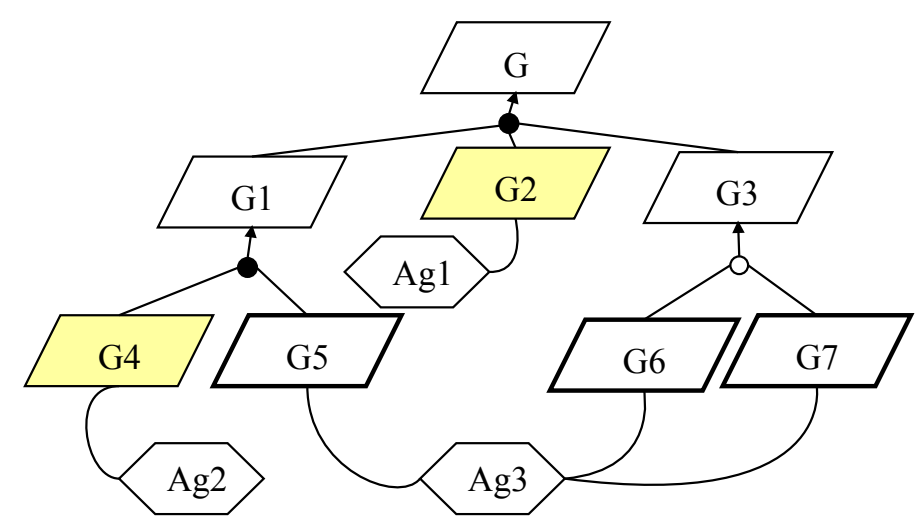

Figura 12 - Refinamento E/OU no modelo de Objetivo em KAOS.

Os sub-objetivos $G_{2}$ e $G_{4}$ são expectativas dos agentes $A g_{1}$ e $A g_{2}$ respectivamente, enquanto $G_{5}, G_{6}$ e $G_{7}$ são requisitos a serem implementados pelo agente $A g_{3}$ (presumivelmente algum software).

Considerando o mesmo exemplo abordado em seções anteriores sobre o gerenciamento de eventos científicos, especificamente o subsistema que controla a submissão de artigos em um prazo definido, na Figura 13 mostra-se o diagrama de objetivos tendo como objetivo funcional primário "Artigos científicos sejam submetidos a tempo quando o período de submissão for aberto". 


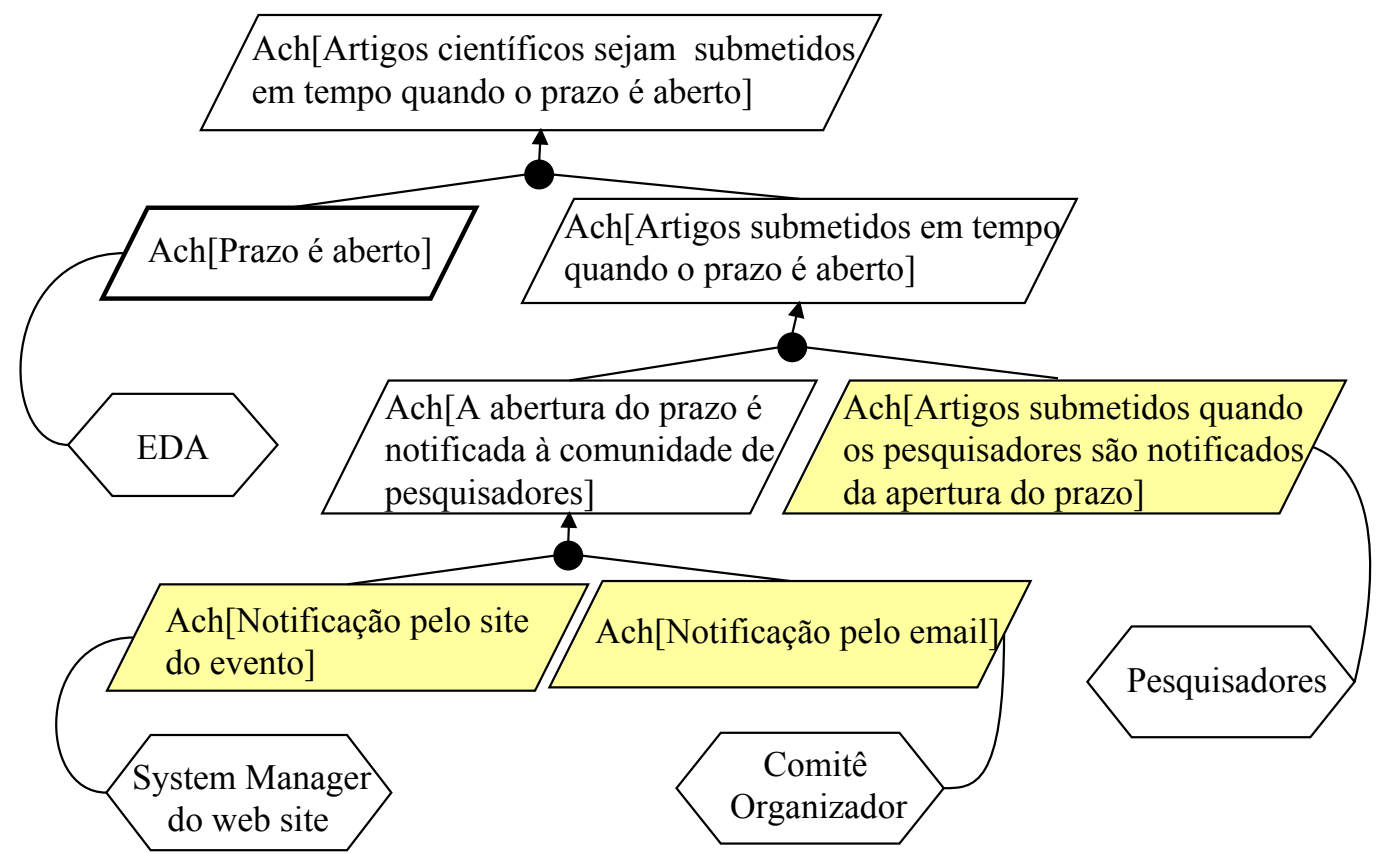

Figura 13 - Diagrama de Objetivos que descreve a submissão de artigos científicos a tempo quando o prazo é aberto.

A representação formal do objetivo "Artigos submetidos depois que os pesquisadores forem notificados da abertura do prazo" baseada em LTL é:

Objetivo Atingir Artigos submetidos quando os pesquisadores são notificados da abertura do prazo

Def. Formal $\forall(p r:$ Prazo,ps: Pesquisadores, $a:$ Artigos $)$ $[$ Conhecem $(p r, p s) \rightarrow \diamond($ Submissão $(a, p s))]$

Outros métodos que seguem uma abordagem orientada a objetivos são GBRAM (POTTS; TAKAHASHI; ANTÓN, 1994), NFR (CHUNG et al., 2012), Goal/Strategy Map (BIDER et $a l ., 2005)$ e o GLR (GRIGOREV; KIRILENKO, 2013). KAOS e I* são os dois mais citados na literatura (WERNECK; OLIVEIRA; LEITE, 2009). Em próximos capítulos a través de um estudo comparativo com o I*, argumentam-se as características que justificam o uso de KAOS na modelagem de requisitos de problemas de planejamento.

Sobre o processo de projeto disciplinado, a modelagem dos requisitos é o primeiro passo para atacar o problema. Contudo, isso não garante que os modelos estejam corretos. Neste contexto, as redes de Petri parecem ser um mecanismo promissor na validação e modelagem do dinamismo do sistema. Na próxima seção introduz-se o estudo desse formalismo, fazendo especial ênfase nas Redes de Petri de Alto Nível especificamente o GHENeSys (MIRALLES, 2012).

\subsubsection{Comparação entre $I^{*}$ e KAOS}

Para escolha de KAOS como método GORE da presente proposta, foi feito um estudo comparativo entre os métodos mais citados. Entre os critérios de comparação, está o tratamento 
dispensado aos requisitos não-funcionais, a relação de dependência entre a modelagem de um sistema e o seu contexto, a facilidade de interpretação, e a base formal do método.

Em KAOS os requisitos não funcionais são tratados com a mesma relevância dos objetivos primários da modelagem, inclusive com o mesmo elemento gráfico. Enquanto que em I* estes requisitos são considerados objetivos mais leves (ou sub-objetivos), com seus correspondentes elementos gráficos para argumentar características qualitativas do problema.

A própria missão do diagrama de Objetivos em KAOS, ajuda a esclarecer a fronteira entre o contexto e o sistema, característica que é impossível de detetar nos dois modelos que I* oferece.

Sobre um mesmo diagrama em KAOS é possível representar os requisitos (objetivos do sistema), as expectativas (objetivos do contexto) e a responsabilidade dos agentes por satisfazelos, assim como também as propriedades do domínio.

Em KAOS fornece-se um diagrama para representar os objetos relacionados com o problema: Diagrama de Objetos. Enquanto em I* estes objetos são representados como recursos, dos quais dependem os agentes.

Apesar de ser uma metodologia GORE, I* é baseado na intencionalidade dos agentes e não nos objetivos do sistema e é portanto um critério mais fraco para definir completeza dos requisitos (exceto na fase inicial do processo de eliciação). Isso leva a defender a hipotese de que o método KAOS enquadra-se melhor na modelagem de sistemas de planejamento e escalonamento (MARTINEZ, 2016).

\subsection{Redes de Petri na Engenharia de Requisitos em pro- blemas de planejamento}

Um sistema de transição (transition system) é caracterizado pela mudança de estado devido à ocorrência de alguma ação, ou outro estímulo, no decorrer do tempo. A representação desta evolução é feita geralmente usando um grafo direcionado em que os nós representam os estados e as arestas transições, para definir modelos semânticos que descrevem o comportamento desses sistemas. Existe uma ampla variedade de formalismos de alto nível usados para a modelagem de sistemas de transição: álgebras de processos, redes de Petri, diagrama de estados, entre outros (BAIER; KATOEN; LARSEN, 2008).

Em um estado representa-se toda a informação e propriedades que determinam o comportamento do sistema em um momento especifico. Para isto, é definido um conjunto de variáveis de estados que ao mudar seus valores permitem construir diferentes abstrações do sistema real. As transições, através da sua execução especificam como o sistema evolui de um estado para outro.

Pelas característica da noção de variáveis de estado, transição, e restrição temporal 
associadas ao problema, nosso foco principal é o formalismo das redes de Petri clássicas, satisfazendo a norma ISO/IEC 15.909 para a modelagem dos requisitos de um problema de planejamento e escalonamento.

\subsection{Redes de Petri}

O formalismo das PN foi criado em 1962 como parte da tese de doutorado de Carl Adam Petri, defendida na Universidade de Tecnologia de Darmstad. O objetivo inicial era prover uma representação sucinta e clara para a comunicação entre processos em sistemas automatizados (PETRI, 1962).

O início do século caraterizou-se pelo surgimento de várias tendências na pesquisa em PN: aqueles que se dedicavam ao formalismo, e sua relação com a Teoria de Grafos e a Teoria de Autômatos (DROSTE; SHORTT, 2002); os que trabalhavam na ampliação do formalismo (HLPN, Redes Híbridas, Redes Estocásticas) (JENSEN; ROZENBERG, 2012) e no seu enquadramento na teoria base; os que se dedicavam ao relacionamento com novas áreas de uso testando assim a abrangência do formalismo (aplicações em workflow management, redes de computadores, sistemas de transporte, etc.) (DIAZ, 2013); os que exploravam a aplicação pratica das redes, ao desenvolvimento de ambientes de software para modelagem, simuladores, jogadores de marcas (DENARO; PEZZE, 2004); e ao desenvolvimento de algoritmos para análise de propriedades entre outras ferramentas (CIARDO.; KINDLER, 2013) .

Hoje em dia, o uso das PN está espalhado por todo o mundo como um paradigma conceitual multidisciplinar abrangendo a modelagem, análise lógica, avaliação de desempenho, otimização paramétricas e controle dinâmico, e nas diferentes etapas do ciclo de vida de sistemas dinâmicos a eventos discretos (SILVA, 2013).

Entre as áreas de aplicação estão: modelagem conceitual e análise de sistemas dinâmicos, sistemas de banco de dados distribuídos, programação concorrente e paralelismo, sistemas de controle flexíveis de manufatura, sistemas de eventos discretos, sistemas de computação, dataflow, sistemas tolerantes a falhas, circuitos assíncronos, compiladores e sistemas operacionais, linguagens formais e programas lógicos (MURATA, 1989).

Basicamente, uma PN é um grafo bipartido, simples, conexo e não nulo, composto de lugares (graficamente representados por círculos); transições (representadas por barras); arcos, usados somente para conectar lugares a transições e transições a lugares (os arcos podem ter associados pesos: $1,2,3, \ldots$ ); e marcas associadas aos lugares, e utilizadas para definir o estado da rede (representadas por círculos pequenos de cor preto) (ver Figura 14). 


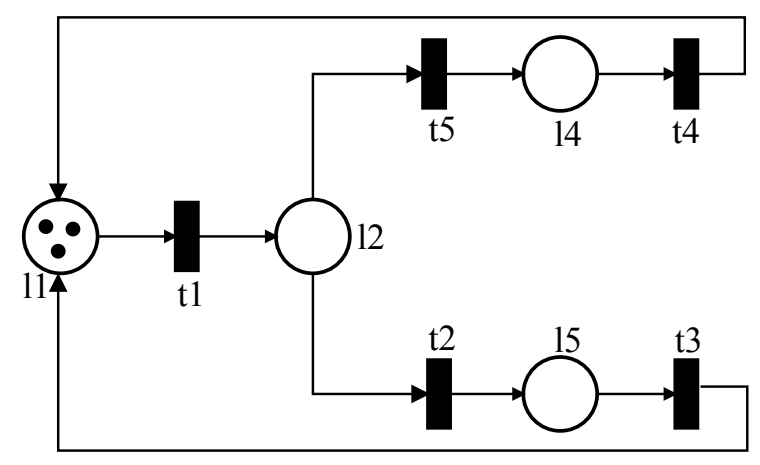

Figura 14 - Exemplo de uma rede de Petri.

\subsubsection{Definição formal das PNs}

De acordo com (MURATA, 1989), formalmente, uma rede de Petri é definida como uma 5-tupla $P N=\left(P, T, F, W M_{0}\right)$ em que:

- $P=\left\{p_{1}, p_{2}, p_{3}, \ldots, p_{m}\right\}$ é o conjunto finito de lugares;

- $T=\left\{t_{1}, t_{2}, t_{3}, \ldots, t_{m}\right\}$ é o conjunto finito de transições;

- $F \subseteq(P \times T) \cup(T \times P)$ é o conjunto de arcos (relação de fluxo);

- $W: F \rightarrow\{1,2,3, \ldots\}$ é a função de peso;

- $M_{0}: P \rightarrow\{0,1,2,3, \ldots\}$ é a marcação inicial da rede.

Onde $P \cap T=0$ e $P \cup T \neq 0$.

A execução da Rede de Petri caracteriza-se por contínuos disparos das transições que a compõem. Para entender melhor o processo de disparo de uma transição, denotaremos por $\operatorname{Pre}\left(t_{i}\right)$ ao conjunto de lugares de entrada ligados à transição $t_{i}$, e a $\operatorname{Pos}\left(t_{i}\right)$ ao conjunto de lugares de saída. No exemplo representado na Figura 15 (a), Pre $(t)=\{l 1, l 2\}$ e Pos $(t)=\{l 3, l 4\}$. Uma transição se diz habilitada se os lugares em Pre tem marcas associadas, e essas podem ser acrescentadas nos lugares de Pos uma vez executado o disparo. No exemplo da Figura 15 (a), a transição $t$, não é habilitada por $l 2$ não ter marca associada. Já na Figura 15 (b) a transição é habilitada, e ao disparar-se marcas de $l 1$ e $l 2$ são removidas e acrescentadas em $l 3$ e $l 4$ (Figura 15 (c)). O número de marcas que podem ser removidas e acrescentadas é estabelecido pelo peso associado aos arcos que ligam à transição com os lugares em Pre e Pos respectivamente.

\subsubsection{Principais propriedades das redes de Petri}

A seguir são apresentadas as principais propriedades das redes de Petri (MURATA, 1989), cuja análise pode ser de interesse quando aplicada ao processo de engenharia de requisitos para problemas de planejamento sobre métodos orientada a objetivos. 


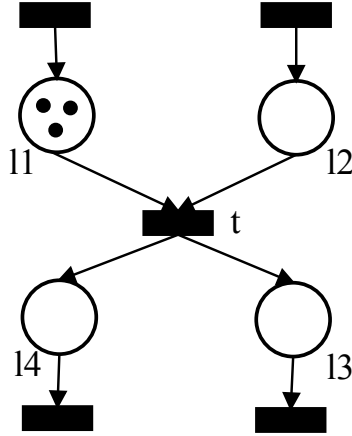

(a)

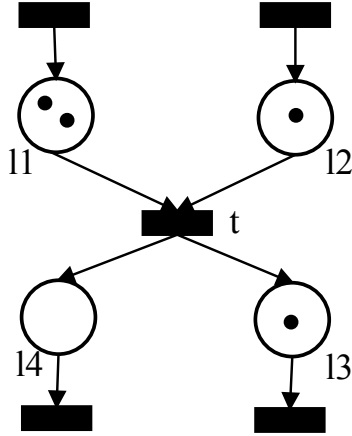

(b)

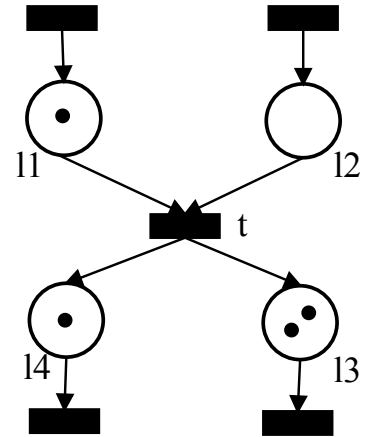

(c)

Figura 15 - (a) Transição $t$ não é habilitada, (b) $t$ habilitada, (c) rede resultante depois de disparar-se $t$.

- Alcançabilidade (Reachability): assumindo $M_{0}$ marcação inicial de uma rede $N$. Uma marcação $M_{n}$ é alcançável se existe uma sequencia de transições que quando disparadas a partir de $M_{0}$ tem $M_{n}$ como estado final. Alguns algoritmos respondem à seguinte pergunta: " $M_{n}$ é alcançável a partir de $M_{0}$ ?". Contudo, estes algoritmos são, no mínimo, NP-hard.

- Limite de marcas: a rede $P N=\left(P, T, F, W, M_{0}\right)$ se diz k-limitada se o numero de marcas em cada lugar $p$ não excede $k$, considerando todos os estados da rede resultantes a partir $M_{0}$.

- Vivacidade: propriedade que está estreitamente relacionada com a ausência total de deadlocks na rede. A rede $P N=\left(P, T, F, W, M_{0}\right)$ é viva, se para qualquer marcação $M_{n} \in R\left(M_{0}\right)$, existe alguma transição que poderá ser disparada.

- Cobertura: uma marcação $M$ na rede $P N$ é dita coberta, se existe $M^{\prime} \in R\left(M_{0}\right)$ tal que $M^{\prime}(p) \geq M(p)$, em que define-se $M(p)$ como o número de marcas no lugar $p$.

- Assincronismo: quando um lugar possui mais de uma marca disponível, mas somente uma pode ser disparada pela transição. É necessário estabelecer uma ordem para a passagem das marcas.

- Conflito estrutural: quando duas o mais transições com lugares de entrada em comum, entram em uma disputa não determinística por recursos (representados pelas marcas).

- Hierarquia: quando uma região da rede (sub-rede) é substituída por apenas um lugar ou transição.

- Paralelismo estrutural: dado pela existência de transições paralelas ou concorrentes sem um lugar de entrada comum. 


\subsection{Redes de Petri de Alto Nível (HLPN)}

A característica fundamental das HLPN, é a possibilidade de poder especificar atributos nas marcas, que passam a ser elementos de um domínio ou tipo específico. Assim, o fluxo de informação pela rede não só se limita à presença ou não de marcas nos lugares, pois podem conter dados que os caracterizam.

As transições tornam-se elementos modificadores das marcas, podendo gerar marcas de tipos diferentes daqueles dos lugares de entrada. Os dois formalismos básicos encontrados na literatura sobre as redes de alto nível são:

- As redes Predicado/Transição (PrT-nets), em que a marcação dos lugares é representada por conjuntos (tuplas) de marcas distinguíveis sobre uma linguagem de primeira ordem. $\mathrm{Na}$ verdade, as marcas constituem uma extensão dos predicados. Inscrições, expressas usando fórmulas lógicas, podem ser associadas com algumas ou todas as transições da rede; os arcos podem ser etiquetados com funções que representam a soma de um conjunto de variáveis que é calculado sobre as marcas (REISIG, 2012).

- As redes Coloridas (CPN) extensões das redes Lugar/Transição associam cores com as marcas. A cor é a definição de um tipo, o que permite a distinguibilidade de classes de elementos que pertencem a uma mesma categoria estrutural. Uma CPN pode ser transformada numa rede Lugar/Transição, portanto as rede Lugar/Transição são um caso especial de redes CPN. Entretanto, um número infinito de cores confere às CPNs o mesmo poder de representação das máquinas de Turing, o que permite que qualquer sistema computável possa ser modelado utilizando esta abordagem (JENSEN, 2013).

Os dois formalismos são equivalentes quanto ao poder computacional, o que significa que qualquer conceito, algoritmo ou teorema que é aplicável para um modelo, é aplicável para o outro. A formalização das CPNs é mais simples e apropriada para a análise matemática de sistemas complexos, e uma diferença entre estas abordagens reside no formalismo subjacente: as CPNs são definidas utilizando tipos, variáveis e funções de forma similar a das linguagens de programação, enquanto a definição das PrT-nets é baseada em notações algébricas permitindo a representação, por exemplo, de somas formais de tuplas contendo variáveis associadas com os arcos da rede.

As redes CPNs (JENSEN, 2013) são até agora as de melhor aceitação na comunidade acadêmica, pela sua definição mais elegante (MIYAMOTO; KUMAGAI, 2005), e as apresentaremos com mais detalhes na presente revisão. 


\subsubsection{Redes de Petri Coloridas}

O formalismo das CPNs foi proposto originalmente por Jensen em (JENSEN, 1981) como uma alternativa de rede de alto nível, e fortemente influenciadas pela proposta de Genrich e Lautenbach (GENRICH; LAUTENBACH, 1979). O nome vem pela possibilidade das marcas poderem carregar dados e consequentemente serem distinguíveis umas das outras A diferença principal na proposta original de Jensen em relação às PrT-nets era o método proposto para o cálculo das invariantes da rede. A Figura 16 mostra o modelo de um protocolo de comunicação simples modelado sobre uma CPN.

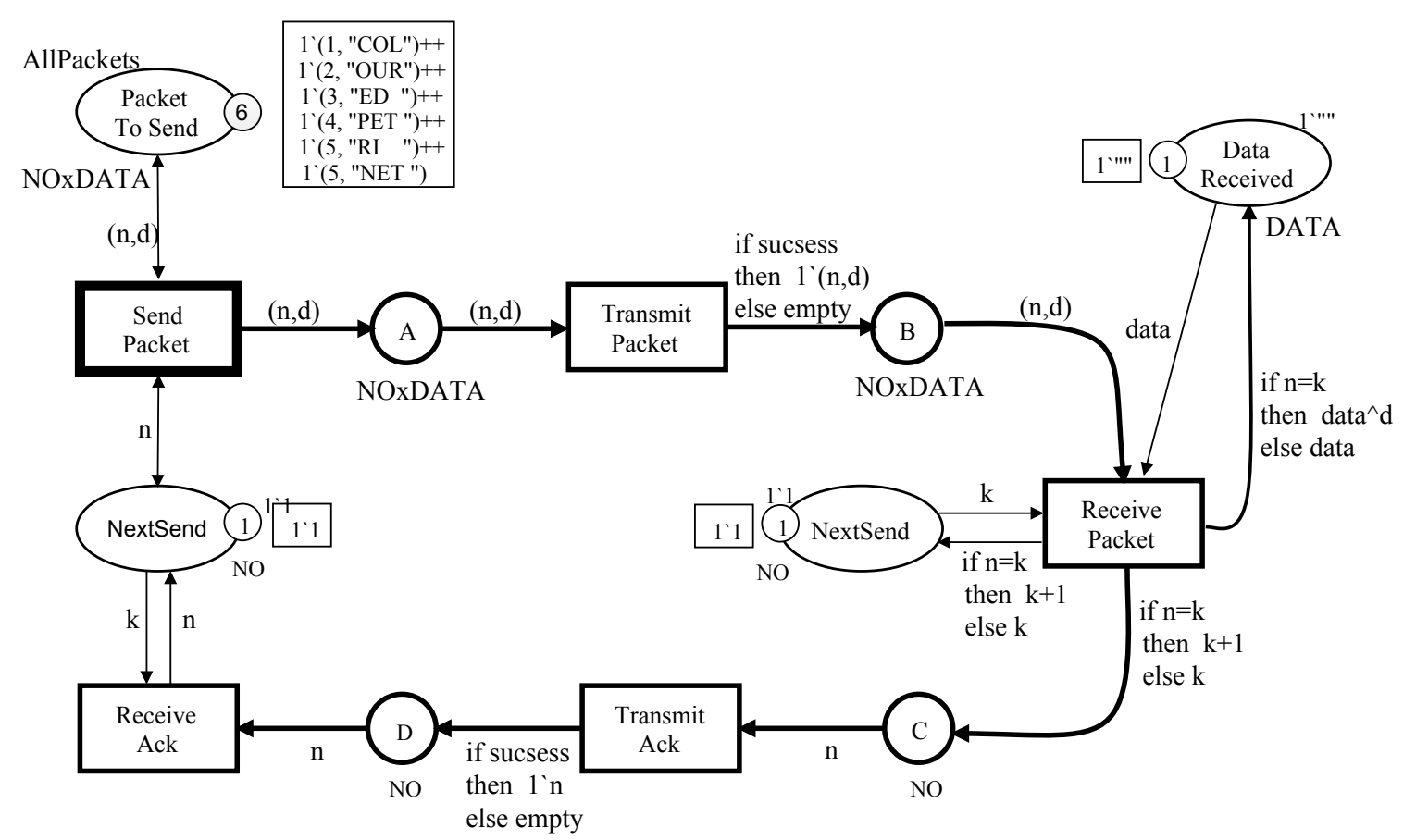

Figura 16 - Modelo de um protocolo de comunicações básico utilizando CPN (JENSEN; KRISTENSEN; WELLS, 2007).

Uma primeira aproximação proposta por (JENSEN, 1981) permitia utilizar somente conjuntos de cores simples com pouca cardinalidade, por exemplo, um conjunto enumerado com uma quantidade fixa de processos. $\mathrm{O}$ formalismo foi evoluindo até permitir a representação de conjuntos de cores bem mais complexos (JENSEN, 1993) em que os conjuntos de cores podem representar uma lista com milhares de entradas envolvendo atributos de tipos diferentes (JENSEN; KRISTENSEN; WELLS, 2007).

O formalismo de representação usado é o CPN ML, que é uma linguagem de programação funcional baseado no Standar ML (HARPER, 2011) permitindo a declaração de variáveis, dos conjuntos de cores, e a definição de inscrições nos elementos da redes: lugares, arcos e transições.

Com uso das CPNs é possível uma representação modular de um sistema, sendo este um conceito hierárquico: um módulo pode ter vários submódulos e módulos novos podem ser criados a partir da composição de módulos existentes. Assim, é possível a representação de 
vários níveis de abstração no modelo, assim como o desenvolvimento top-down e bottom-up. As figuras 17 e 18 mostram os módulos hierárquico criados a partir do exemplo do protocolo simples mostrado na Figura 16.

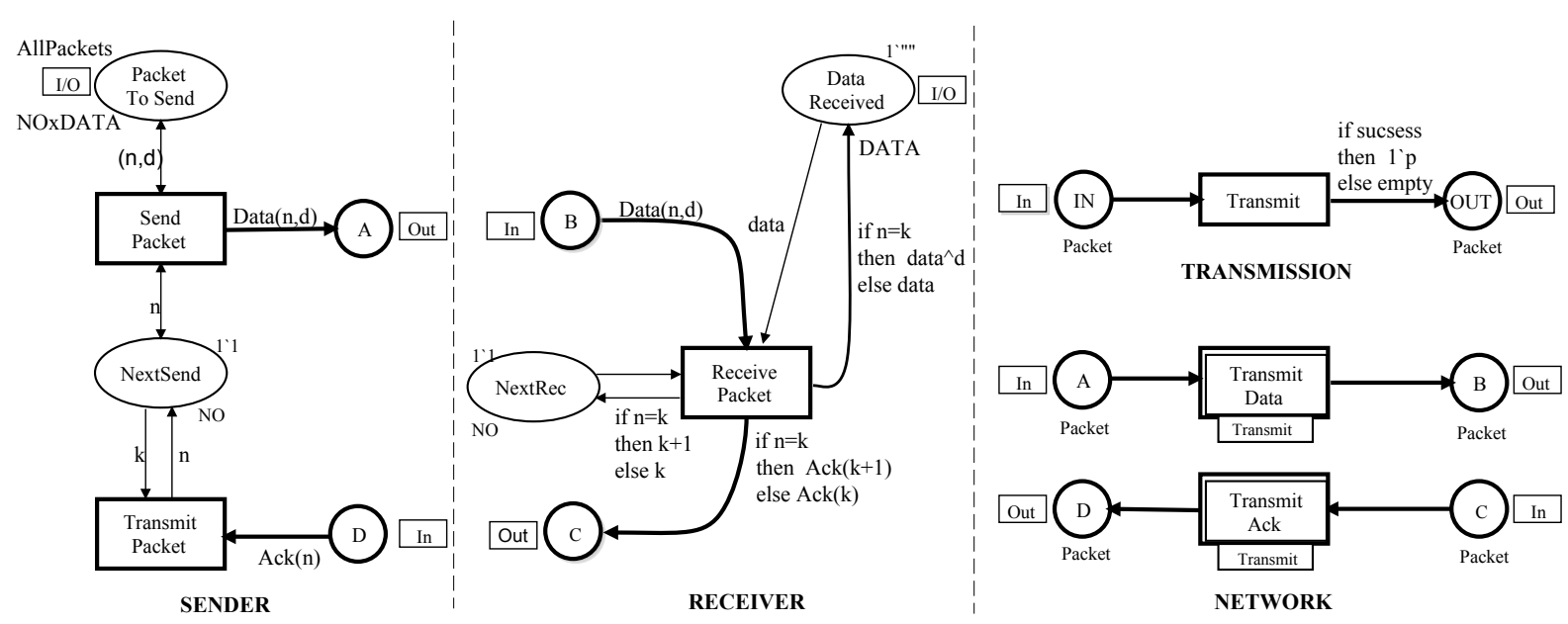

Figura 17 - O modelo do protocolo simples divido em módulos (JENSEN; KRISTENSEN; WELLS, 2007).

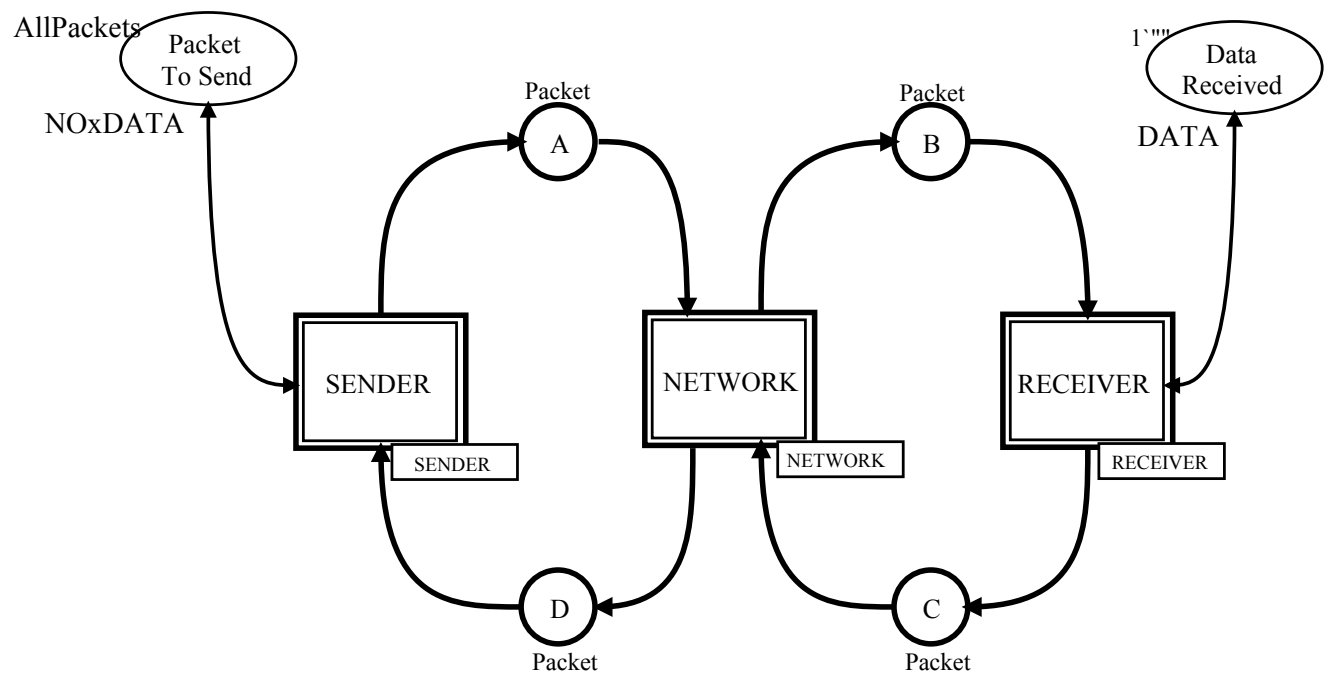

Figura 18 - O rede hierarquica top-level do modelo do protocolo simples (JENSEN; KRISTENSEN; WELLS, 2007).

\subsubsection{A rede GHENeSys}

A rede GHENeSys foi inspirada nas ideias apresentadas em (SILVA; MIYAGI, 1995)(SILVA; MIYAGI, 1996) para modelagem estruturada, tratando de modo formal a inclusão de extensões, e foi finalmente desenvolvida e formalizada em (FOYO, 2001) como trabalho de dissertação de mestrado, que forneceu como resultado uma PN estendida com conceitos de orientação ao objetos e dotadas de mecanismos de abstração - por meio de uma definição de hierarquia e da inclusão do tempo como variável - sobre uma abordagem estruturada, associada ao encapsulamento introduzido pelos objetos. 
A proposta inicial da rede GHENeSys foi ter uma representação integrada e formal (com um modelo semântico bem definido) para as extensões das redes de Petri, que foram normatizadas na ISO/IEC 15.909-3. Assim, a rede passou a ser definida pela estrutura da ISO/IEC 15.909-1 que define a rede de Petri clássica e a High Level Petri Net (HLPN) sua versão dobrada e de alto nível e as extensões (como a hierarquia, gates, pseudo-boxes, e tempo) introduzidas de modo a seguirem o formalismo básico (MIRALLES, 2012).

Existem três elementos chaves na definição da rede GHENeSys que permitem a modelagem de um amplo de escopo de sistemas, tais como os sistemas de controle centralizado, hierárquico, hierárquico modificado e distribuído. Trata-se da definição de pseudo-lugares, a hierarquia e a abordagem orientada a objetos.

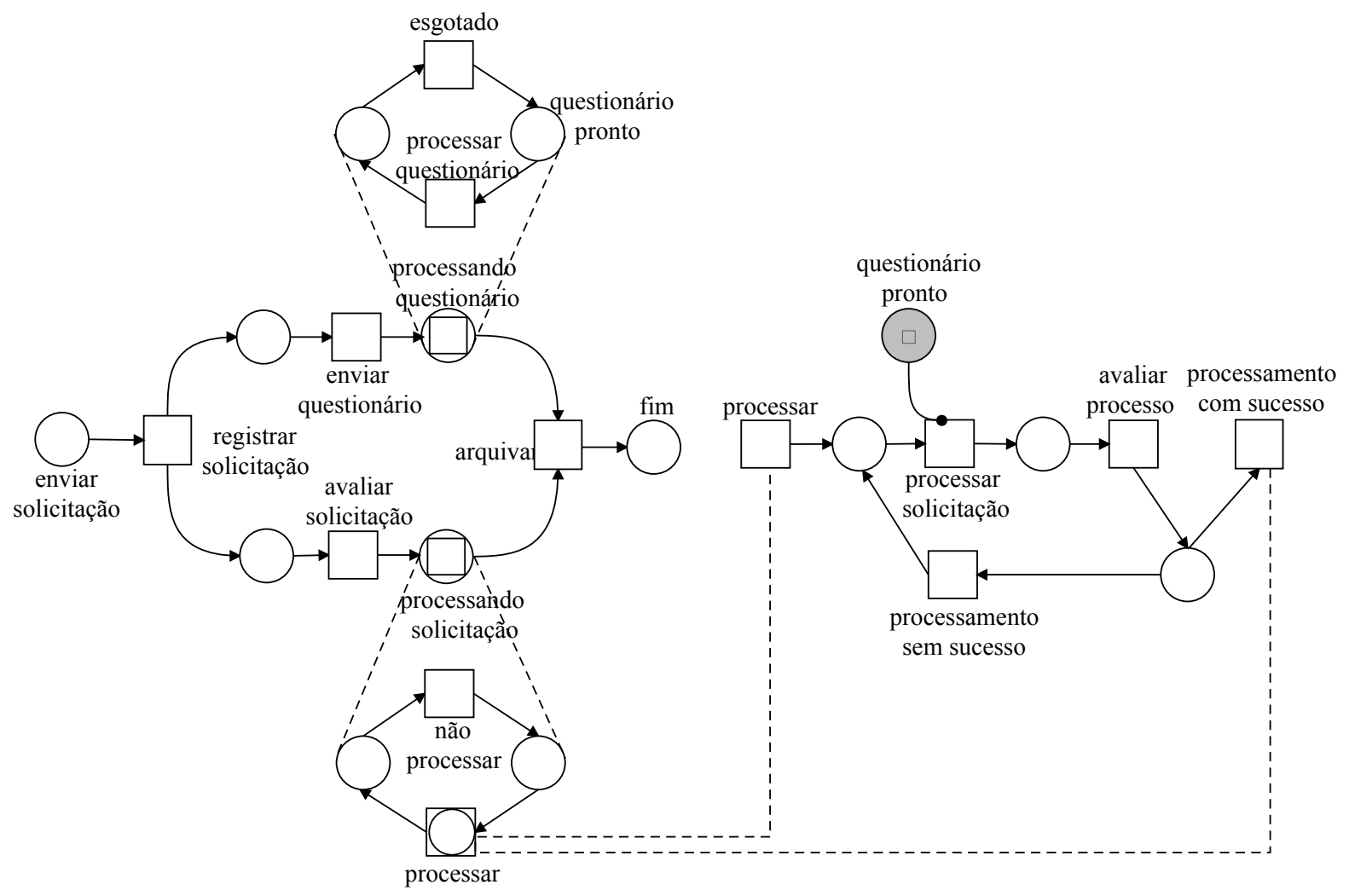

Figura 19 - Exemplo da hierarquia na rede GHENeSys (MIRALLES, 2012).

- Pseudo-lugares: modelam a transferência de informação entre diferentes partes do sistema, facilitando assim a modularização e estruturação do processo de síntese da rede; além disso, modelam a interação com o contexto, representando informações de eventos observáveis e previsíveis.

- Hierarquia: em GHENeSys a base da hierarquia é definida por sub-redes que gozam de propriedades especiais: têm borda homogênea, isto é, todos os elementos que possuem ligação com elementos de fora da sub-rede são do mesmo tipo, lugares ou transições; só existem dois destes elementos, um de entrada e outro de saída, denotando um sistema 
próprio. Com estas propriedades, os elementos macros permitem preservar as propriedades estruturais e de comportamento da rede global. A rede pode ser construída a partir de elementos simples ou macros sobre os diversos níveis de abstração formando uma agregação de elementos reutilizáveis, apoiando assim, o processo de modelagem e design de sistemas. Na figura 19 é mostrado um exemplo de uma rede GHENeSys hierárquica.

- Abordagem orientada a objetos: os elementos são definidos como objetos ativos enquanto as marcas como objetos passivos (sem definição de métodos). A rede base formada pela agregação dos objetos é também um objeto, e as sub-redes são representadas por elementos macros que podem ser reutilizáveis em outros modelos. Essa vantagem permite atenuar o problema de explosão de estados, comum na modelagem de sistemas reais de médio e grande porte.

A abordagem orientada a objetos, que já fornece uma estrutura hierárquica disciplinada, facilita a reutilização de modelos bottom up, enquanto a modelagem conceitual é feita por refinamentos. Assim, é possível obter uma fusão dos métodos top down e bottom up usando o esquema orientado a objetos.

A seguir explora-se com mais detalhe a proposta com base nos conceitos definidos neste capítulo. 


\section{3}

\section{REKPLAN: ENGENHARIA DE REQUISITOS USANDO KAOS PARA PROBLEMAS DE PLANEJAMENTO}

O presente capítulo apresentará uma proposta de uma nova disciplina de projeto para o tratamento geral de Engenharia do Conhecimento na fase inicial dos projetos de planejamento automatizado. A nova disciplina irá ser aplicada em problemas modelos ou em situações reais. Estamos portanto falando da etapa de eliciação de requisitos (para o problema de planejamento) e conhecimento (relacionado com o que chamamos de work domain), formando o domínio de planejamento (planning domain); a modelagem e análise deste domínio de planejamento para resultar em uma especificação (ainda em PDDL), que poderá ser repassada para um planejador automático. Em especial, o processo de análise, validação e verificação será feito usando redes de Petri, e em especial o sistema GHENeSys.

Portanto recapitulando a proposta de objetivos do Capítulo 1, propomos um método baseado em modelos KAOS, Redes de Petri e LTL, acelerando o processo de formalização, o que não é tão direto na versão atual do itSIMPLE.

A noção de completeza vem do KAOS, e é então trabalhada nos modelos formais, seja em Redes de Petri ou em LTL. A validação é feita em Redes de Petri por um algoritmo de análise de propriedades (SALMON; FOYO; SILVA, 2014) durante o processo de eliciação e depois de ter um modelo dinâmico constituído.

A contribuição desta proposta começa portanto pela inserção de KAOS e sua justificativa, no processo de preparação do conhecimento, aqui dividido entre o problema de planejamento e o ework domain, compondo o domínio de planejamento ${ }^{1}$. A antecipação da formalização é uma proposta presente em quase todos os trabalhos do D-Lab, e não é contribuição específica deste trabalho mas foi seguido, mantendo aparentemente o mesmo formato do itSIMPLE original, mas

$\overline{1}$ Estes conceitos receberam um outro tratamento e uma formulação mais definida neste trabalho 
deve-se inserir aqui a crítica feita ao processo original que de fato usava State Charts, embora pudesse sintetizar uma rede clássica Place/Transition. Neste trabalho um algoritmo foi proposto para converter o modelo KAOS diretamente para GHENeSys.

A contribuição final é prospectiva e resultado das anteriores: a possibilidade de trabalhar no contexto de Systems of Systems, isto é, fazendo sistemas de planejamento menores que poderão se compor no futuro em um sistema mais complexo. No entanto, cada componente é um sistema completo com métodos e operação próprios, que não dependem dos demais.

A síntese da contribuição compõe o que chamamos de sistema MDE ReKPlan, ou, Requirements Engineering using KAOS for Planning, mostrado na Figura 20. Nesta figura podemos ver o sistema guiado por modelos que é iniciado pelo diagrama KAOS, que tem uma versão XML denominada KML (KAOS Markup Language) que descreve univocamente os diagramas. Um mapeamento pode ser feito em XML de KML para GNML (GHENeSys Markup Language) e daí podemos sintetizar uma rede de Petri GHENeSys (a definição padrão da rede Place/Transition) para fazer a análise baseada em propriedades. Todo o processo de conversão, assim como as versões XML do KAOS e da GHENeSys (KML e GNML) são contribuições operacionais deste trabalho, dado que são importantes para disciplina de projeto proposta.

A conversão inversa, da representação em redes de Petri para KAOS pode ser feita $(K M L \rightarrow G N M L)$, de modo a incorporar na documentação básica todos as possíveis mudanças geradas no processo de análise. Portanto KAOS é a representação padrão para o domínio de planejamento.

Usando a noção de completeza já mencionada podemos discernir quando o modelo está pronto para seguir adiante e um algoritmo foi desenvolvido para mapear das instruções em LTL do diagrama de objetivo em KAOS para a linguagem PDDL, que é a base para o planejamento automático.

Neste trabalho propomos usar efetivamente as redes de Petri com uma rede unificada, a GHENeSys, que reproduz a rede P/T definida na norma ISO/IEC 15.909-1, mas também incluir extensões de hierarquia, gates, pseudo-boxes e extensões temporais, inseridas na ISO/IEC 15.9093. A síntese da especificação formal em PDDL é feita à partir também de uma contribuição parcial, com a criação da GNML, isto é, a Ghenesys Markup Language, sobre a PNML, que compõe a norma ISO/IEC 15.909-2. Assim, é possível gerar a especificação formal em PDDL diretamente, a partir da análise do sistema.

O resultado, que vai ser descrito com mais detalhes adiante, é um processo geral - que vale para qualquer tipo de problema - e que é também escalável, podendo se adaptar mais facilmente a problemas reais de grande porte.

A aplicação das técnicas de planejamento inteligentes a problemas reais requerem um processo mais robusto do que aquele aplicado na solução de problemas acadêmicos. Problemas reais devem seguir um projeto disciplinado com base na Engenharia do Conhecimento, cuja etapa 


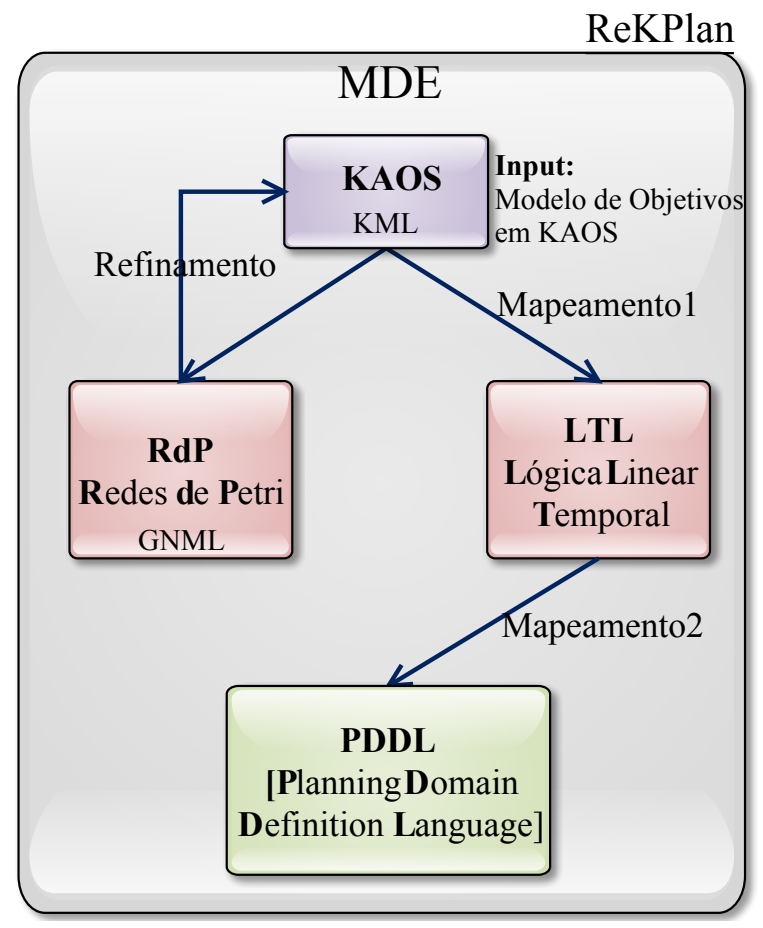

Figura 20 - MDE proposto em ReKPlan.

inicial é composta pela Especificação de Requisitos e a Modelagem do Conhecimento, que é base da proposta aqui apresentada. Outros problemas podem ser resolvidos mais facilmente, mas, os estudos mostram que mesmo nestes casos mais simples temos situações em que um plano não pode ser gerado, dependendo do método usado pelo planejador. Assim, ter um processo de projeto mais robusto pode ser bastante útil também nestes casos.

Este é um tema emergente, motivado principalmente pela crescente demanda de novas ferramentas que apoiem a solução de problemas de planejamento reais. Entretanto, novas abordagens escaláveis devem também funcionar com problemas modelo e de interesse acadêmico, apresentando os mesmos resultados.

O design de problemas de planejamento deve resultar em um modelo consistente e convergente, logicamente aceitável e livre de contradições que derive de uma rede de Petri simples, harmonizando todos os viewpoints dos agentes envolvidos. Entre as propriedades a serem analisadas estão a vivacidade, invariantes de lugar e transição, equidade entre outras.

Durante a etapa de Engenharia de Requisitos podem ser feitos ajustes nos modelos de referência como um processo de retroalimentação após uma análise da dinâmica do sistema em PN, de modo a gerar de forma automática possíveis refinamentos do modelo do conhecimento inicial. Além disso, a proposta proverá um método diretamente voltado para a Engenharia de Requisitos, auxiliando assim a obtenção de soluções com um menor custo computacional e com com uma qualidade superior, considerando todas as características sugeridas pelos diferentes viewpoints envolvidos no sistema. O ambiente proposto é apresentado a seguir. 


\subsection{O ReKPlan}

O ReKPlan - Requirements Engineering for Planning Problems- é uma das novas ferramentas com a mesma função das estudadas no Capítulo 1 que apoia o processo de modelagem e análise de domínios em problemas de planejamento, ajudando a minimizar possíveis problemas durante o ciclo de vida de projetos reais de planejamento. $\mathrm{O}$ foco principal do ReKPlan são as fases de eliciação de requisitos, modelagem e análise em que são levados em consideração os principais viewpoints dos diferentes stakeholders.

Com o uso do ReKPlan, é possível especificar e analisar domínios de problemas baseados no método Orientado a Objetivo KAOS que combinado com outras linguagem conhecidas como a PDDL por um lado e a PNML por outro lado permitem fazer a Engenharia de Requisitos em problemas de planejamento.

O ambiente foi desenvolvido em Java integrando o KAOS para modelar domínios de problemas de planejamento nas fases iniciais; integra o uso de Redes de GHENeSys para a análise desses requisitos desde o ponto de vista dinâmico. Por outro lado permite a tradução para PDDL que serve de entrada para que os planejadores possam gerar para um problema dado o plano resultante.

O software é independente de qualquer técnica de planejamento existente, ou seja, a modelagem e verificação não depende de um planejador específico, embora podem ser usado os já incorporados no itSIMPLE como ferramenta auxiliar para obter como saída a solução de um problema deste tipo.

O ReKPlan conta com uma interface gráfica (GUI) amigável com base no diagrama de objetivos de KAOS, projetada para ser simples e agradável, visando a disponibilizar aos designers mudanças de contextos entre projetos de forma fácil e rápida e a obtenção de instruções PDDL de forma automática e direta.

Sobre a interface o designer pode acessar a cada um dos projetos projetos abertos simultaneamente, assim como a todos os diagramas e seus respectivos elementos (objetivos, agentes, refinamentos, etc) através do painel "Explorador de Projetos".

O ReKPlan fornece uma visão global de cada projeto, propiciando um acesso rápido a cada um dos elementos que conformam cada diagrama do projeto.

O painel de "Visualizador de Diagramas", permite que o designer trabalhe com o Diagrama de Objetivos associado a cada projeto, representando cada um dos elementos gráficos que fornece KAOS e acessando a cada uma das propriedades a través do painel "Propriedade dos Elementos" de forma flexível e permitindo também a modificação das características do elemento selecionado, seja um objetivo, uma expectativa, requisito ou um agente.

Na Figura 21 mostra-se uma visão geral desta interface com cada um dos diferentes paneis. 


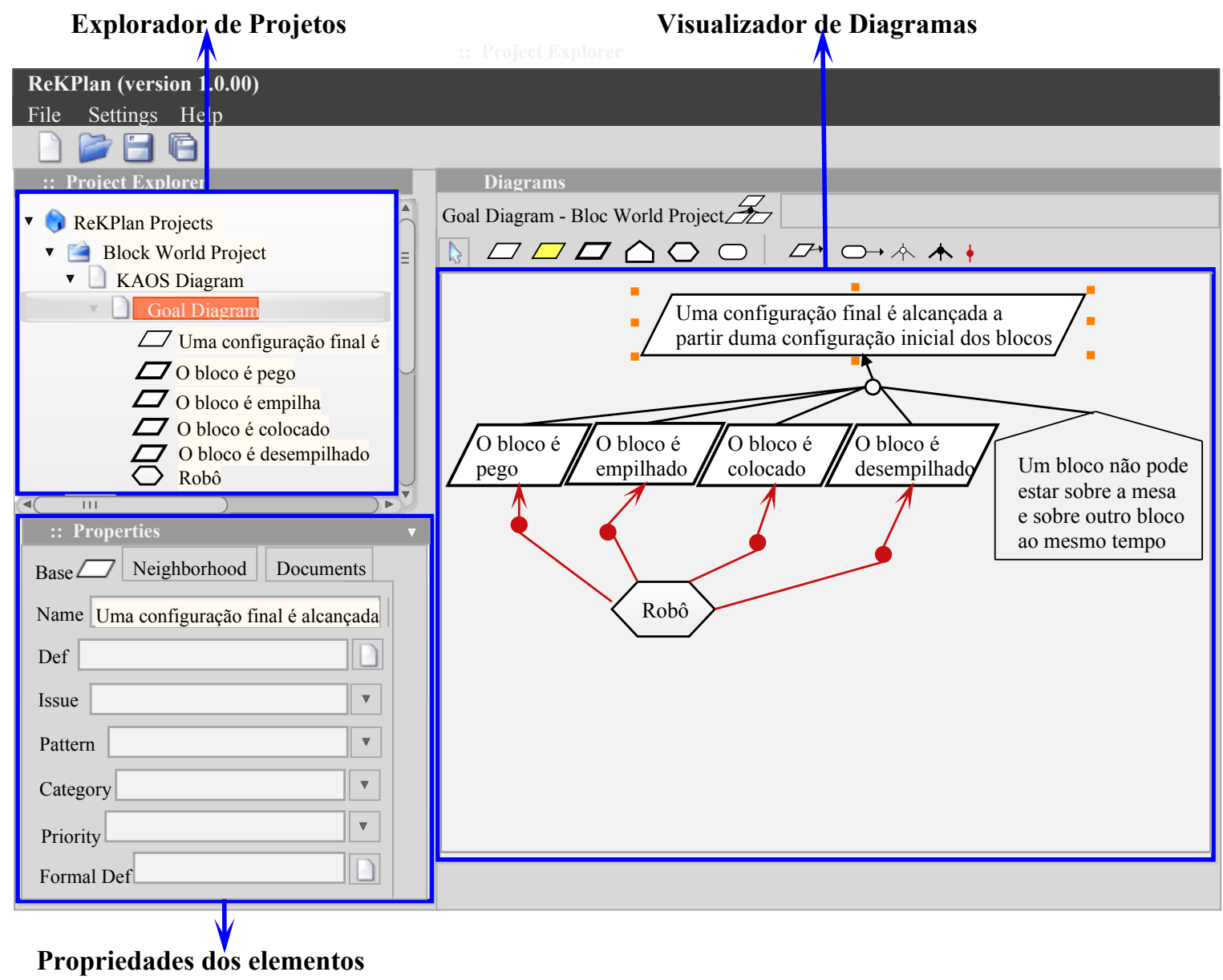

Figura 21 - Ambiente de Análise e Modelagem do ReKPlan.

\subsection{Arquitetura do ReKPlan}

Já foi explorado em capítulos anteriores como a missão da Engenharia de Requisitos é apoiar por meio de seus métodos, na identificação dos requisitos de um sistema.

Um dos mecanismos mais usados é a linguagem UML (Unified Modeling Language), praticamente convertido em padrão nos últimos anos dentro da industria do desenvolvimento do software. Contudo, este enfoque atualmente não fornece nenhum suporte formal explícito para a fase de requisitos sobre um processo de projeto disciplinado.

A modelagem dos requisitos na UML, segue uma abordagem Orientada a Objetos. Existem algumas dificuldades no mapeamento desses requisitos em entidades inferiores, toda vez que eles representam aspectos que chegam a traspassar as fronteiras de uma classe no nível de design. Por outro lado, os requisitos não funcionais, não contam com representações gráficas, limitando-se a serem representados como restrições do sistema em forma de sentenças OCL (Object Constraint Language) associadas a cada classe do Diagrama de Classes.

Neste cenário surge o ReKPlan (Requirement Engineering using KAOS for Planning Problem) que envolve: $i$ ) A fase de modelagem, análise e documentação dos requisitos, baseado 


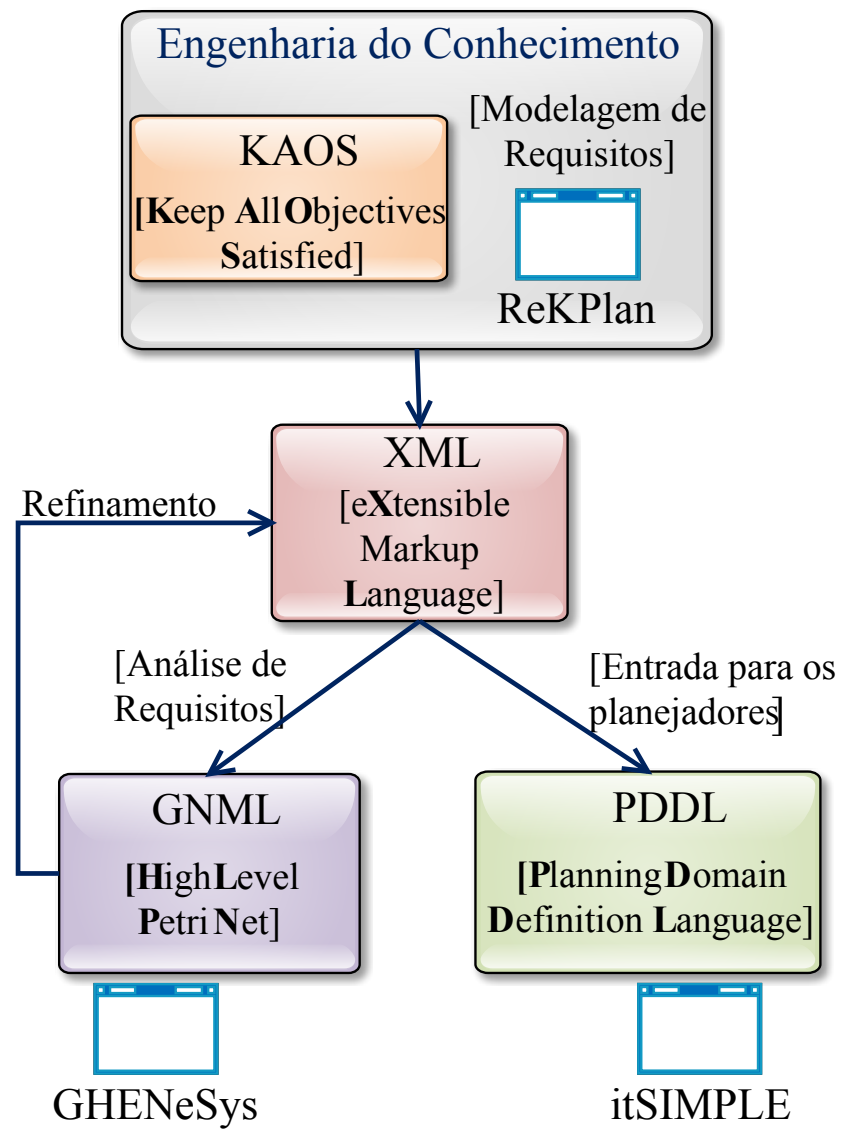

Figura 22 - Linguagens integradas no ReKPlan.

no uso de KAOS ; ii) a tradução e transferência desses diagramas para uma rede de Petri, para seu posterior analise no sistema GHENeSys; e iii) a geração automática de sentenças PDDL para um posterior processamento com algum dos planejadores incorporados no itSIMPLE. Na Figura 22 ilustra-se o esquema das linguagem integradas nesse ambiente, em que um aspecto importante é o uso da linguagem XML como elemento integrador com o resto das linguagem: KAOS, GNML (Petri Net), XPDDL (linguagem para a entrada dos planejadores).

A Figura 23 mostra uma panorâmica global do projeto no processo de construção do modelo do conhecimento, do domínio de trabalho e do problema de planejamento. $\mathrm{O}$ framework tem como complemento a analise feito da rede de Petri como modelo unificado em GHENeSys (MIRALLES, 2012), e a verificação de propriedades.

Na primeira fase do design que contempla o passo 1 Criar e desenvolver o modelo do domínio de planejamento, os resultados são os diagramas de KAOS, o que levará a delimitar o domínio do sistema da instância do problema de planejamento. O refinamento desses objetivos direciona ao designer até a obtenção dos requisitos do futuro sistema de planejamento.

Esses diagramas são traduzidos em redes de Petri de Alto Nível para que sejam analisadas e detetadas possíveis inconsistências. Para isto auxiliara-se do GHENeSys na análise das propriedades da rede de Petri resultante (passo 4), e por outro lado dar resposta ao problema de 


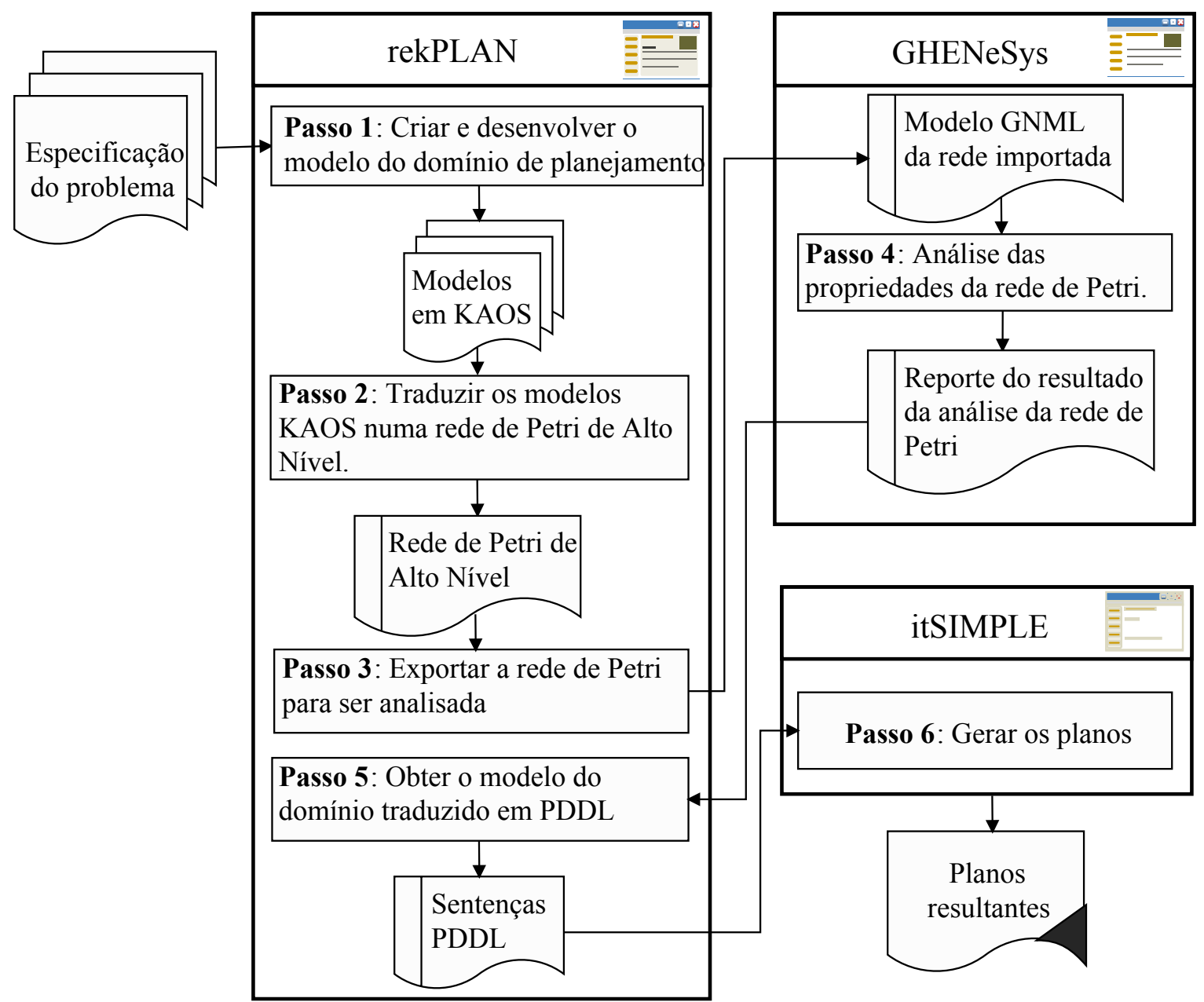

Figura 23 - Framework ReKplan para a Engenharia de Requisitos complementado com o uso das Redes de Petri para a análise.

planejamento por meio do uso da algum dos planejadores incorporados no itSIMPLE (passo 6). Associado a cada objetivo pode haver um conjunto de objetos e operações, que conjuntamente com o modelo de responsabilidade completam o modelo de conhecimento do problema. Os diagramas devem ser corretos sintaticamente e ser exportáveis para o formato KML. Basicamente, a meta dessa primeira fase é a detenção de contradições e possíveis conflitos (característica implícita na filosofia de KAOS como formalismo) entre os diferentes objetivos ou viewpoints dos envolvidos. A segunda fase é encarregada da detenção de inconsistências mais profundas dentro da dinâmica do plano, que inclui informações importantes (restrições, heurísticas de solução, entre outras) que acrescentadas ao modelo podem alterar o performance dos planejadores, já seja em relação à qualidade dos planos que se geram, bem como o tempo de processamento.

A transferência de uma fase para outra deve ser de forma automática, oferecendo aos designers uma perspectiva geral e bem detalhada da solução do problema. 


\subsubsection{Modelagem de um problema usando KAOS}

Uma das principais vantagens que oferece o itSIMPLE como ambiente integrado para a resolução de problemas reais de planejamento, é a possibilidade de modelar os problemas usando um conjunto de diagramas UML como o Diagrama de Caso de Uso, o de Classes, de Estados e o de Objetos (VAQUERO et al., 2009). Contudo, por meio da resolução de estudos de caso - principalmente problemas reais - na sua maioria publicados no ROADEF Challenge (NGUYEN, 2005), pode-se constatar a existência de fissuras na recopilação de informação para construir o modelo do conhecimento representado sobre esses diagramas.

Neste contexto questiona-se o uso da linguagem UML para a modelagem de requisitos, sendo nosso alvo a implementação de um mecanismo mais eficiente na representação otimizada do conhecimento associado a um problema de planejamento. Para isto, é importante levar em conta que as aplicações de planejamento estão divididas no domínio da aplicação e no problema de planejamento em si; portanto o primeiro passo é a identificação dos requisitos do domínio, para assim convergir numa entrada adequada dos algoritmos de planejamento até a geração do plano resultante.

Como é necessário a identificação dos objetos do sistema de planejamento, KAOS oferece essa possibilidade associando a cada objetivo declarado um conjunto de objetos derivados da sua definição formal, sendo assim um mecanismo que garante a completitude do modelo do conhecimento, implicando unicamente todos as objetos necessários para descrever o domínio e o problema de planejamento.

Também é possível representar gráfica e semanticamente um conjunto de operações associadas aos objetivos de comportamento, as relações dessas operações com os objetos e agentes previamente definidos no diagramas de Objetos e Responsabilidade respectivamente. Com esta proposta não somente é possível constatar o dinamismo implícito em alguns objetivos, bem como estipula-se uma clara divisão do domínio de trabalho com o problema de planejamento; o modelo é flexível ante possíveis alterações, permitindo assim a reutilização em novas instâncias do problemas sobre uma nova estrutura, talvez com mais ou novos elementos e com a atuação de novos atores.

Atualmente o itSIMPLE usa o Diagrama de Casos de Uso para a descrição do problema (VAQUERO et al., 2012). Contudo, existem vários estudos que o consideram um diagrama redundante e muito semelhante a uma descrição textual de um problema. Em (IRWIN; TURK, 2005), demonstra-se a falta de rigor e consistência na representação de um problema usando esse diagrama, e são muitos os trabalhos que acreditam que trata-se de um diagrama ineficiente na modelagem de requisitos (SIAU; LEE, 2004). Por outra parte, os defensores do diagrama carecem de evidências de que se seja o melhor mecanismo na comunicação entre projetistas e stakeholders (pessoas que de alguma forma podem influir no sucesso do projeto).

Em oposição, com o conjunto de diagramas da presente proposta, obtém-se uma repre- 
sentação concisa, sintática e semanticamente bem formada do problema. Apesar disso, não é possível ainda validar o modelo do conhecimento como um todo, situação que pode ser corrigida, se a partir dessa primeira representação o problema é sintetizado numa única rede de Petri.

A fase de modelagem em KAOS permitirá a detenção de eventuais erros sintáticos e alguns erros semânticos por meio da análise do diagrama de Operações, uma vez traduzidas as operações associadas a objetivos de comportamento para redes de Petri individuais.

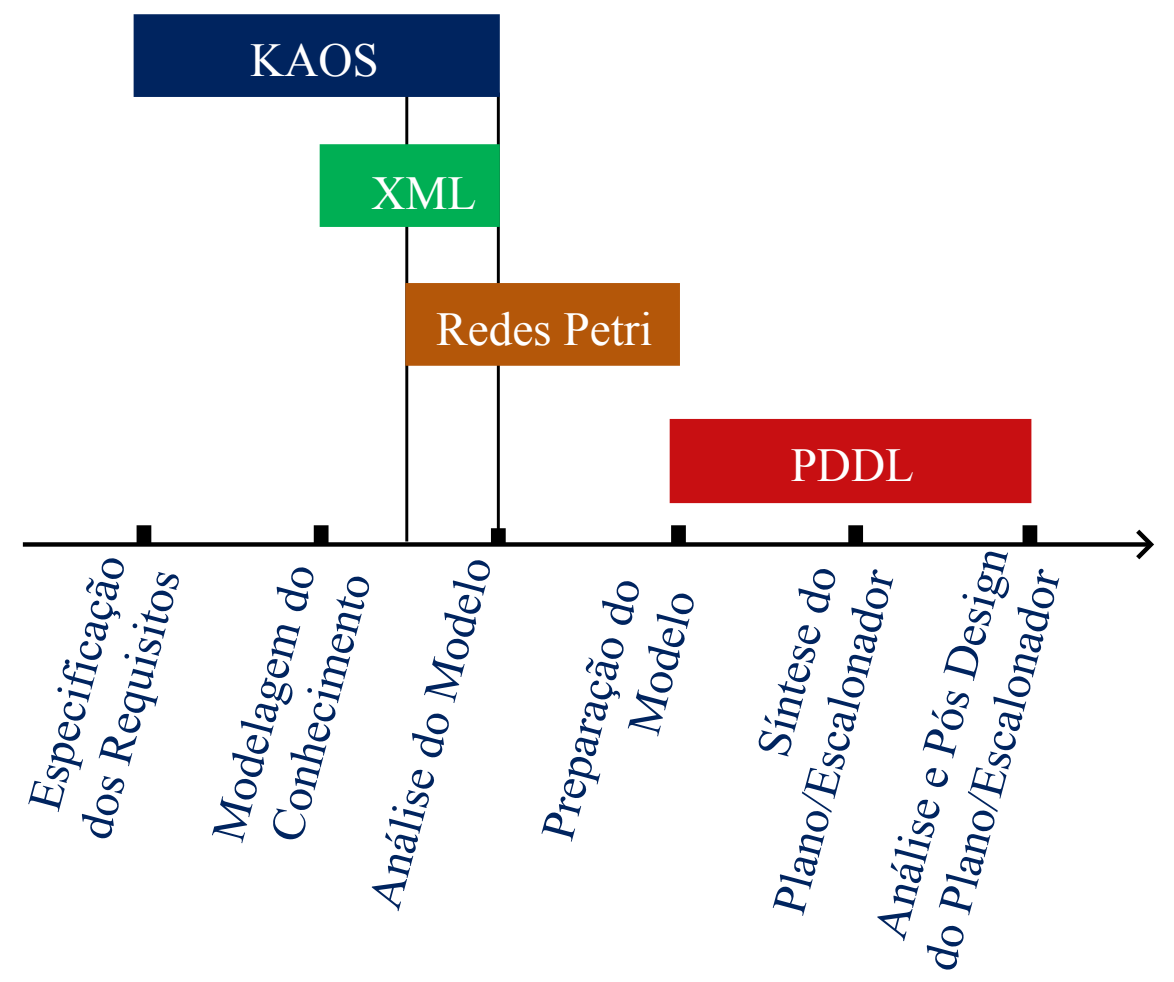

Figura 24 - Proposta inserida no ciclo de processo de projeto proposto por (VAQUERO, 2011).

Posterior ao análise feita, é gerado o código PDDL, artefacto de entrada às seguintes fases do processo de projeto para este tipo de problemas. A Figura 24 mostra uma outra perspectiva da proposta em relação a como é inserida durante as fases de Especificação de Requisitos e Modelagem do Conhecimento no processo de projeto para problemas de planejamento proposto por (VAQUERO, 2011).

\subsection{Análise de Requisitos usando redes de Petri}

As redes de Petri na área de planejamento automático vem sendo muito usadas para melhorar o performance dos planejadores, especificamente em diminuir o espaço de estados de busca do planejador automático (HICKMOTT et al., 2007). Entretanto, existe pouca referência na literatura sobre seu uso na modelagem e análise de requisitos em problemas de planejamento. O impacto de seu uso é ainda maior, pela crescente tendência de querer aplicar técnicas de planejamento na resolução de problemas reais, o que muda significativamente o cenário da 
pesquisa em planejamento, pois deve-se definir em primeiro lugar um processo de projeto para problemas deste tipo, e em segundo lugar conferir uma maior importância às fases iniciais deste processo.

Por outro lado, o uso das redes de Petri é bastante promissor ao reduzir o ciclo de melhoria dos planos até atingir um estado aceitável; na verificação e validação do modelo do conhecimento de um problema dado, pois permite obter uma representação global do sistema permitindo além, a representação da dinâmica das ações. Na Figura 24 mostra-se como pode ser inserido o uso deste formalismo dentro do processo de projeto.

O itSIMPLE na sua versão atual, uma rede de Petri é obtida a partir de cada Diagrama de Estado associado a cada classes do diagrama de Classes (VAQUERO et al., 2012). Essa abordagem limita-se somente a mostrar o ciclo de vida dos objetos e os métodos das classes definidos como transições da rede. Não é possível gerar uma rede única para fazer a análise do sistema como um todo, e constatar a interação entre vários objetos.

O uso de KAOS redefine a proposta atual do itSIMPLE para a modelagem e análise de requisitos, e propõe o uso das redes de Petri, transcrevendo o diagrama de Objetivos para uma rede de Petri GHENeSys, pode ter ou não associado sub-redes de Petri lugar-transição descrevendo as operações associadas a objetivos de comportamento. Uma vez definida a rede, pode verificar-se a existência de conflitos mais diretos e triviais, como a presença de deadlocks; fazer a análise semântica das propriedades comportamentais e estruturais da rede; e por ultimo a análise de invariantes, da matriz de incidência e equação de estados, e do grafo de cobertura da rede.

Com o uso das redes de Petri como ferramenta gráfica e base matemática, é possível representar atividades dinâmicas e concorrentes de sistemas (SILVA, 2013), o que justifica seu uso nos diagramas anteriormente citados. Especificamente para o diagrama de Operações se definirá quais estados cada objetivo atingirá pela execução das operações envolvidas, e verificar quais sequências de ações são disparadas. Entretanto, restaria definir o método de tradução para essa rede de Petri e incorporá-lo ao ReKPlan como ferramenta.

\subsubsection{Traduzindo o diagrama de Objetivo em KAOS para GNML}

O formato de transferência que permite o intercâmbio de modelos de sistemas feitos em diferentes ferramentas de edição, análise e simulação de PN é o PNML,e é definido na segunda parte da norma 15909-2 com base na linguagem XML (NAJM; PRADAT-PEYRE; DONZEAU-GOUGE, 2006). No caso da presente proposta, para o resultado de aplicar o Passo 2 do framework representado na Figura 23 é usado a GNML, esquema PNML para o mapeamento de elementos da HLPN GHENeSys (MIRALLES, 2012). Na Tabela 4 podem ser consultados esses elementos do modelo GNML com seus correspondentes atributos.

Convenientemente a Tabela 5 mostra a proposta de elementos KML como linguagem de 


\begin{tabular}{|c|c|c|}
\hline Classe & Elemento GNML & Atributos \\
\hline SubNet & $<$ subNet $>$ & $i d:$ IDRef(Net) \\
\hline ArcType & $<$ ArcType $>$ & \\
\hline Place & $<$ place $>$ & \\
\hline NodeType & $<$ NodeType $>$ & \\
\hline PSeudoPlace & $<$ PSeudoPlace $>$ & $i d:$ ID \\
\hline MacroPlace & $<$ macroPlace $>$ & $i d:$ ID \\
\hline MacroTransition & $<$ macroTransition $>$ & $i d:$ ID \\
\hline IsMarked & $<$ isMarked $>$ & \\
\hline External & $<$ external $>$ & \\
\hline ArcType & $<$ subNet $>$ & \\
\hline MasterElement & $<$ masterElement $>$ & \\
\hline MacroElement & $<$ macroElement $>$ & \\
\hline Refined & $<$ refined $>$ & \\
\hline isWellBehabed & $<$ isWellBehaved $>$ & \\
\hline SubNetId & $<$ subNetId $>$ & \\
\hline
\end{tabular}

transferência em KAOS com os seus pares em GNML. A estrutura integra para um documento de transferência desse tipo pode ser consultada no Apêndice A.

\begin{tabular}{|c|c|c|c|}
\hline KAOS & KML & GNML & GHENeSys \\
\hline Objetivo & $<$ goal type $=$ 'primary'> & \multirow{3}{*}{$<$ place $>$} & \multirow{3}{*}{ Lugar } \\
\hline Expectativa & <goal type='expectativa'> & & \\
\hline Requisito & $<$ goal type='requirement'> & & \\
\hline Agente & $<$ agent $>$ & \multirow{2}{*}{$<$ pseudoPlace $>$} & \multirow{2}{*}{ Pseudo Lugar } \\
\hline $\begin{array}{l}\text { Propriedade } \\
\text { do domínio }\end{array}$ & $<$ domProperty $>$ & & \\
\hline Refinamento AND & $<$ andRefinament $>$ & \multirow{2}{*}{ arcType } & \multirow{2}{*}{ Arco habilitador } \\
\hline Refinamento OR & <orRefinament> & & \\
\hline
\end{tabular}

Tabela 5 - Mapeamento do Modelo KML de KAOS para elementos GNML de GHENeSys

O Algoritmo 1 é o proposto para traduzir os elementos do Diagrama de Objetivos em KAOS para a rede GHENeSys. 


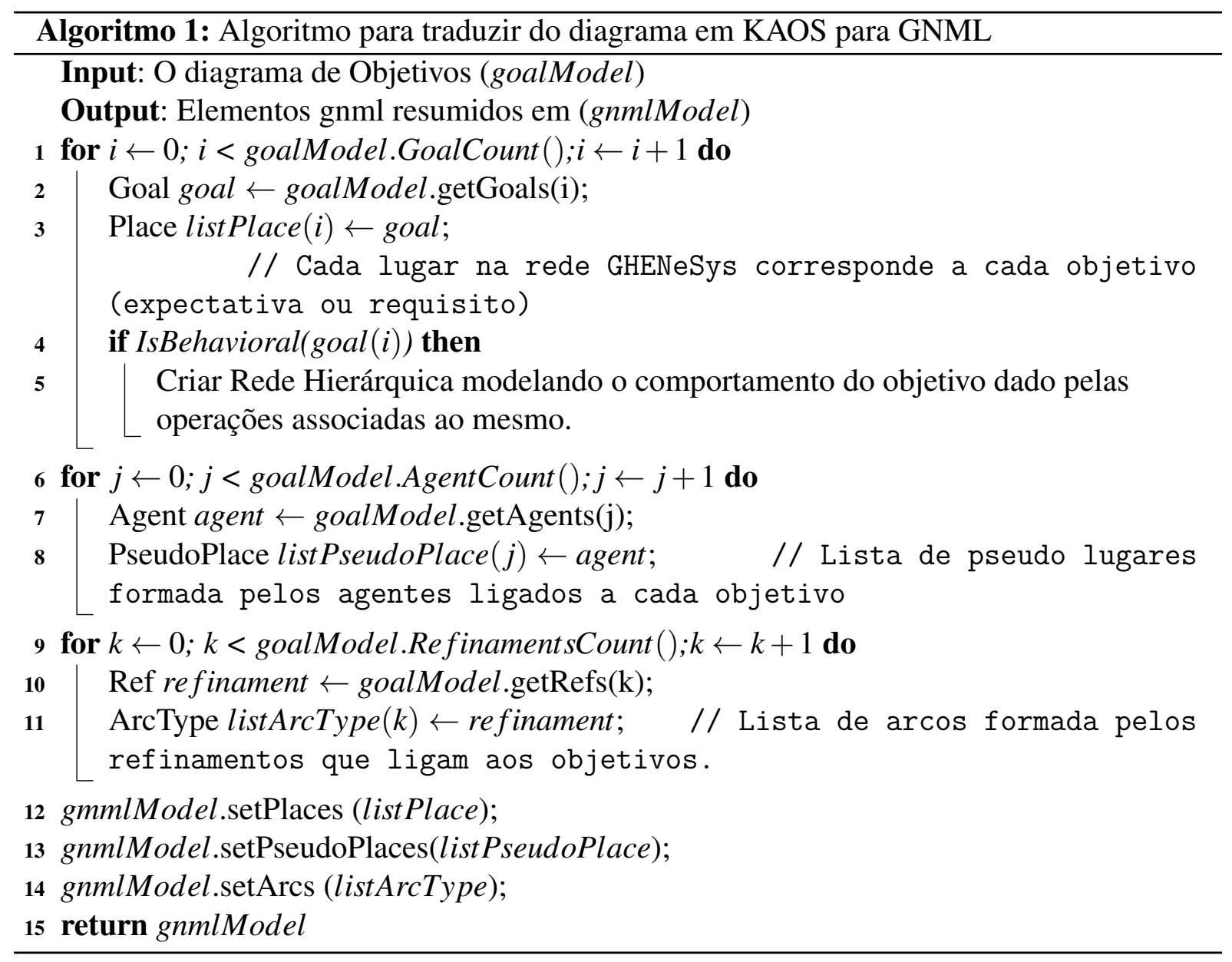

Em termos de elementos gráficos, na Tabela 6 mostra-se como pode ser traduzido para uma rede GHENeSys desde o Diagrama de Objetivo, e como exceto para os objetivos representados por lugares (com a mesma interpretação que nas redes de Petri elementares ), o resto dos elementos do diagrama de Objetivos podem ter associado elemento de rede GHENeSys como:

- Pseudo lugares (PseudoPlace), para representar lugares com marcação persistente, usados principalmente para modelar Agentes responsável pelo atingimento ou não de um objetivo, assim como para representar Propriedades do Domínio;

- Arcos habilitadores (ArcType) para ligar esses Pseudo lugares com transições;

- Elementos Macro lugares (MacroPlace) para os objetivos de comportamento, que podem ter associado um conjunto de operações (modeladas no diagrama de Operacionalização KAOS);

- Sub-redes de Petri lugar/transição modelando o dinamismo das operações ligadas aos objetivos comportamentais, tornando assim a rede hierárquica. 


\begin{tabular}{|c|c|}
\hline Elemento KAOS & Elemento GHENeSys \\
\hline $\begin{array}{c}\text { Objetivo de } \\
\text { Comportamento }\end{array}$ & \\
\hline Requisito & \\
\hline $\begin{array}{c}\text { Propriedade do } \\
\text { domínio }\end{array}$ & \\
\hline Agente
\end{tabular}

Tabela 6 - Tradução dos elementos do diagrama de Objetivos para uma rede GHENeSys.

Já para a modelagem dos refinamentos (E/OU), na Tabela 7 mostra-se as correspondentes estruturas da rede GHENeSys associadas a este tipo de representação.

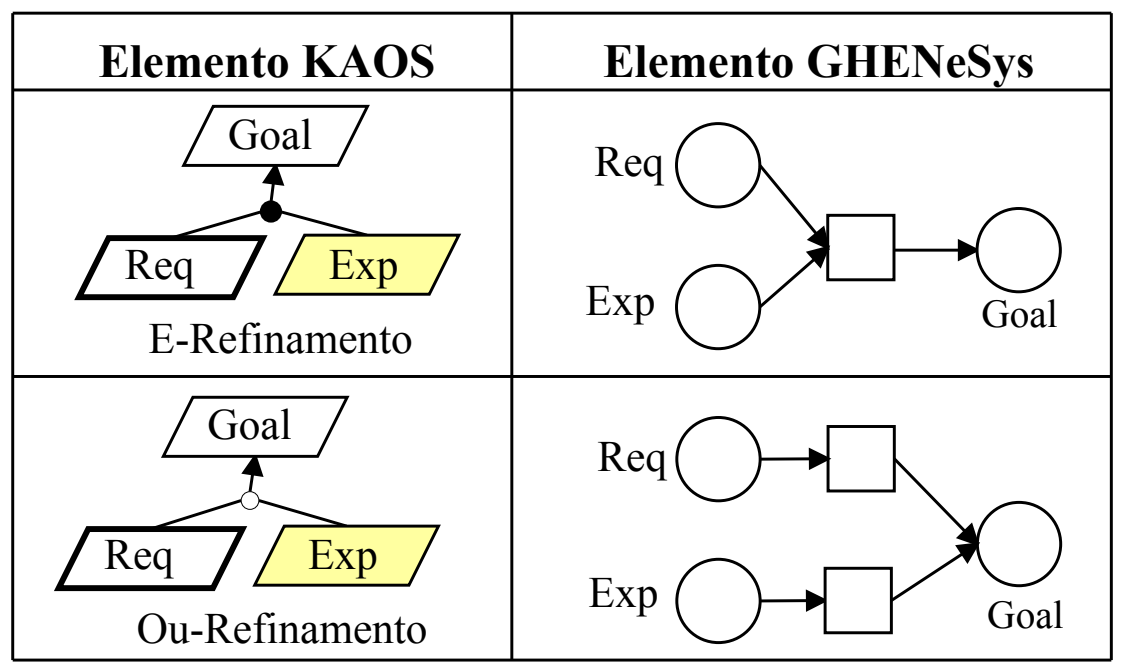

Tabela 7 - Tradução dos refinamentos E/Ou para estruturas da rede GHENeSys.

É importante ressaltar que o processo de refinamento exige de regras ou padrões que apoiam aos engenheiros do conhecimento na hora de modelar os objetivos de um sistema. Em (LAMSWEERDE, 2004) introduz-se alguns desses padrões como são: Refinamento por Etapas, Dirigido por Casos, Dividir e Conquistar, entre outros. O refinamento proposto a ser usado é o Dirigido por Etapas, em que os subobjetivos definem sucessivas etapas intermédias (dependentes cada uma da anterior), sendo que, a partir da condição atual é possível chegar a uma etapa em que a condição objetiva é atingida (CAILLIAU; LAMSWEERDE, 2013). 
Os primeiros resultados no processo de tradução foram introduzidos em (MARTINEZ; SILVA, 2015a) em que é proposto o mapeamento gráfico das estruturas topológicas modeladas em GHENeSys para um Refinamento Por Etapas dos objetivos em KAOS (consultar a Figura 25).

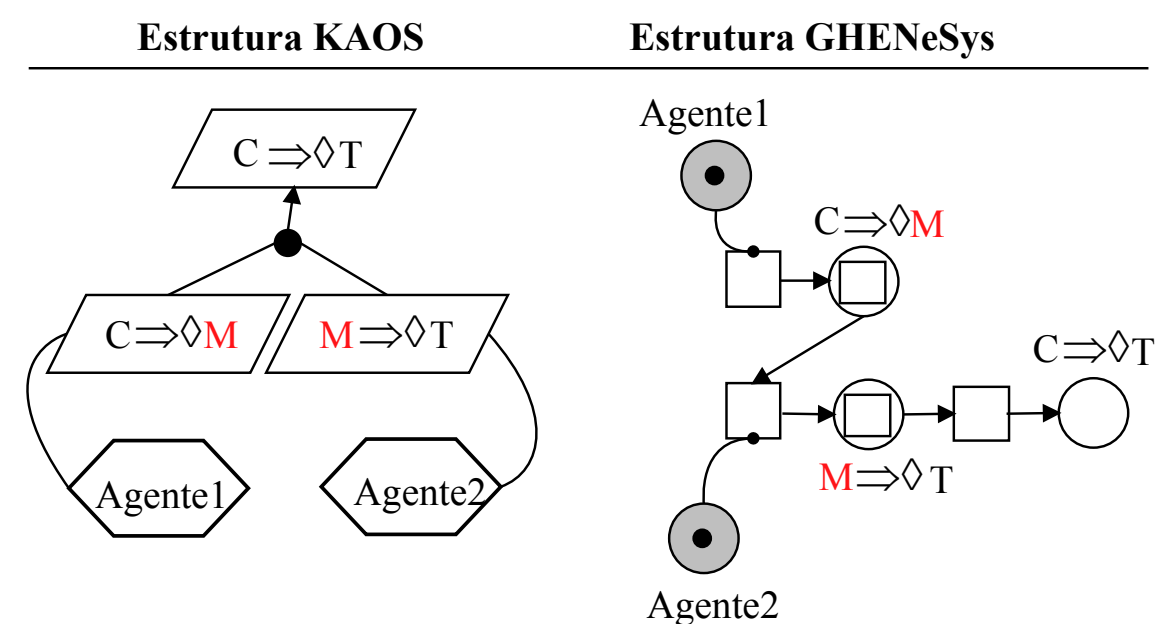

Figura 25 - Tradução do padrão de Refinamento por Etapas para uma estrutura de rede GHENeSys

\subsubsection{Traduzindo desde o diagrama de Objetivo em KAOS para PDDL}

Como foi analisado em capítulos anteriores, os planejadores precisam de uma descrição em PDDL para que possam iniciar o processo de resolução do problema de planejamento. $\mathrm{O}$ ReKPlan como ambiente, permite a exportação do modelo do domínio em KAOS para a PDDL. A descrição do sistema de planejamento divide-se em dois elementos essenciais: descrição do domínio e uma descrição do problema.

Baseado nesse enfoque, o Algoritmo 2 fornece um modelo do domínio em PDDL com uma estrutura geral bem definida com sete passos importantes. O objetivo geral é a obtenção elementos essenciais da linguagem como : predicados, tipos, restrições, etc. 


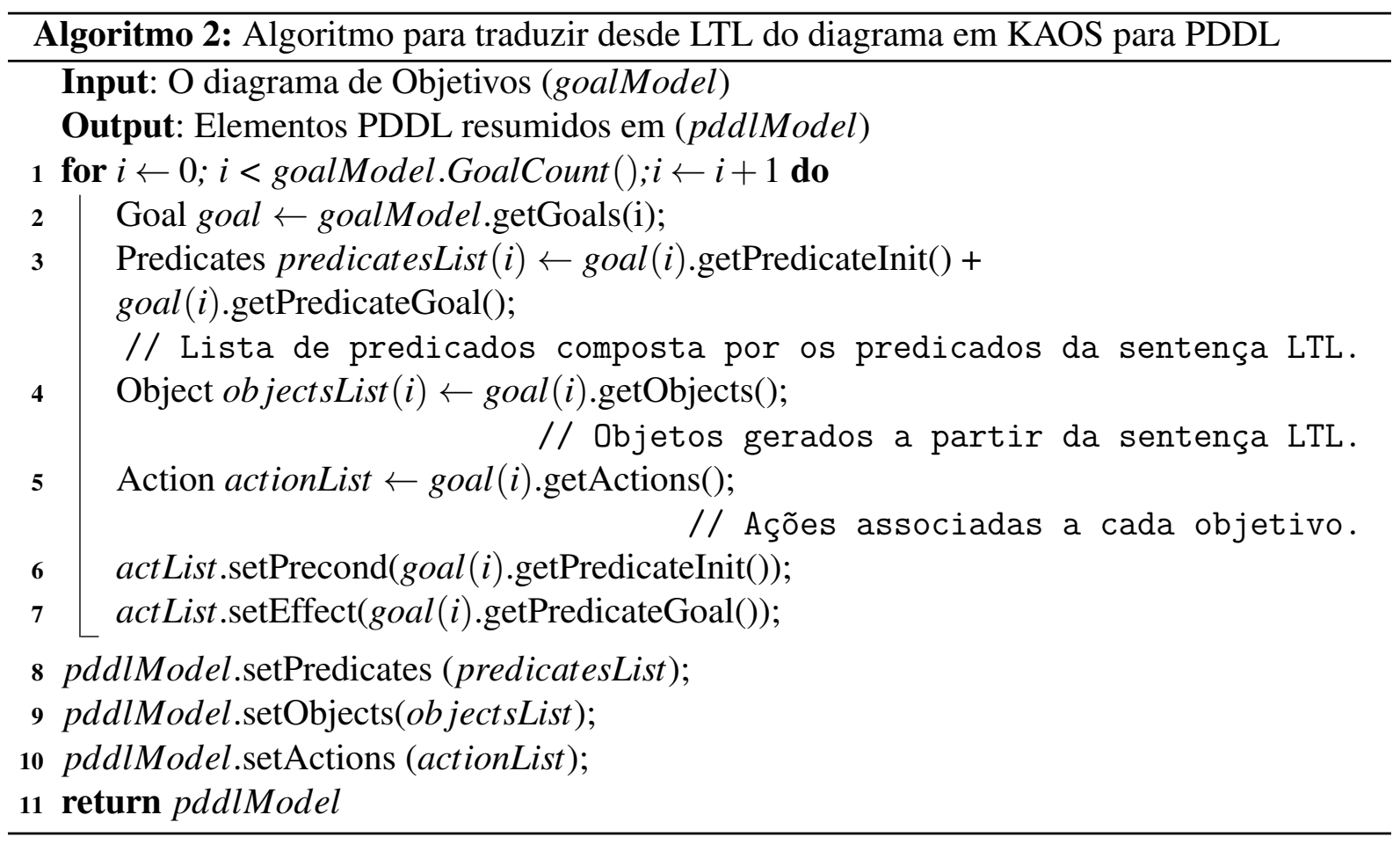

\subsubsection{Disciplina de Projeto para a Engenharia de Requisitos usando KAOS}

A seguir é apresentada detalhadamente a disciplina de projeto que deve ser usada para gerar o modelo do conhecimento, resultado da Engenharia de Requisitos para problemas de planejamento. Os passos são:

1. Análise do Domínio, que envolve a definição e refinamento de objetivos, propõe-se especificamente dois diagramas: Objetivos Funcionais e Objetivos Não Funcionais caso precise.

a) Delimitar o sistema de planejamento do domínio do problema.

b) Analisar as responsabilidades de atingir objetivos sendo atribuídas para os agentes do sistema.

2. Derivar os objetos do sistema:

a) Sistema de planejamento: Objetos essenciais para cada objetivo comportamental.

b) Obter o diagrama de Objetos do sistema todo.

3. Operacionalização e análise dinâmico do sistema:

a) Identificar os objetos de entrada e saída para cada operação associada aos objetivos de comportamento. 
b) Definir restrições para cada operação.

4. Síntese do modelo de comportamento:

a) Traduzir o diagrama de Objetivos KAOS para a rede GHENeSys e fazer a análise correspondente.

b) Gerar as redes de Petri envolvendo as operações associadas a cada objetivo de comportamento.

No próximo capítulo, serão apresentados estudos de casos que avaliam a eficiência do método, comparado com outras abordagem como o proposto por (BASBAUM, 2015) baseados no uso da UML em sua versão 2.4 . 
Nesta seção são apresentados dois estudos de casos que refletem os resultados de aplicar o método proposto. Dois domínios de problemas foram escolhidos. O primeiro é um problema clássico de planejamento simples: $O$ Mundo Dos Blocos e o segundo é um problema de manufatura com complexidade intermediária proposto pelo ROADEF 2005 (NGUYEN, 2005): Montagem Seqüencial de Carros.

\subsection{Problema Mundo dos Blocos}

Um dos problemas mais conhecidos na área de Planejamento Automático: o Mundo dos Blocos, é muito usado na ilustração dos principais conceitos teóricos e práticos dos sistemas de planejamento. Basicamente, o problema consiste em determinar um plano que leve a um sistema, desde uma configuração inicial para uma configuração final de blocos sobre uma mesa. Para isso, conta-se com um braço mecânico que facilita o movimento dos blocos.

Conforme descreve a disciplina de projeto proposta, o primeiro passo é a construção do diagrama e refinamento dos objetivos. Baseado nas características do Mundo dos Blocos, a Figura 26 mostra o Diagrama de Objetivos. O objetivo primário do problema é "Uma configuração final é alcançada a partir de uma configuração inicial dos blocos", em que existem cinco sub-objetivos resultantes do refinamento, como sendo aqueles estados que uma vez atingidos, contribuem como o cumprimento do objetivo primário. Eles são: "O bloco é pego", "O bloco é empilhado", "O bloco é colocado", ou "O bloco é desempilhado". O refinamento é de tipo ou-refinamento, pois para que qualquer uma configuração de blocos seja eventualmente atingida, é possível com o cumprimento de algum desses sub-objetivos.

Foi visto no Capítulo 2, a estrutura em LTL que pode ter associado cada objetivo, e como esta instrução está formada por dois elementos importantes: o estado atual e o estado objetivo. Assim, a pergunta a ser respondida na hora de definir um objetivo é: "Qual estado é 


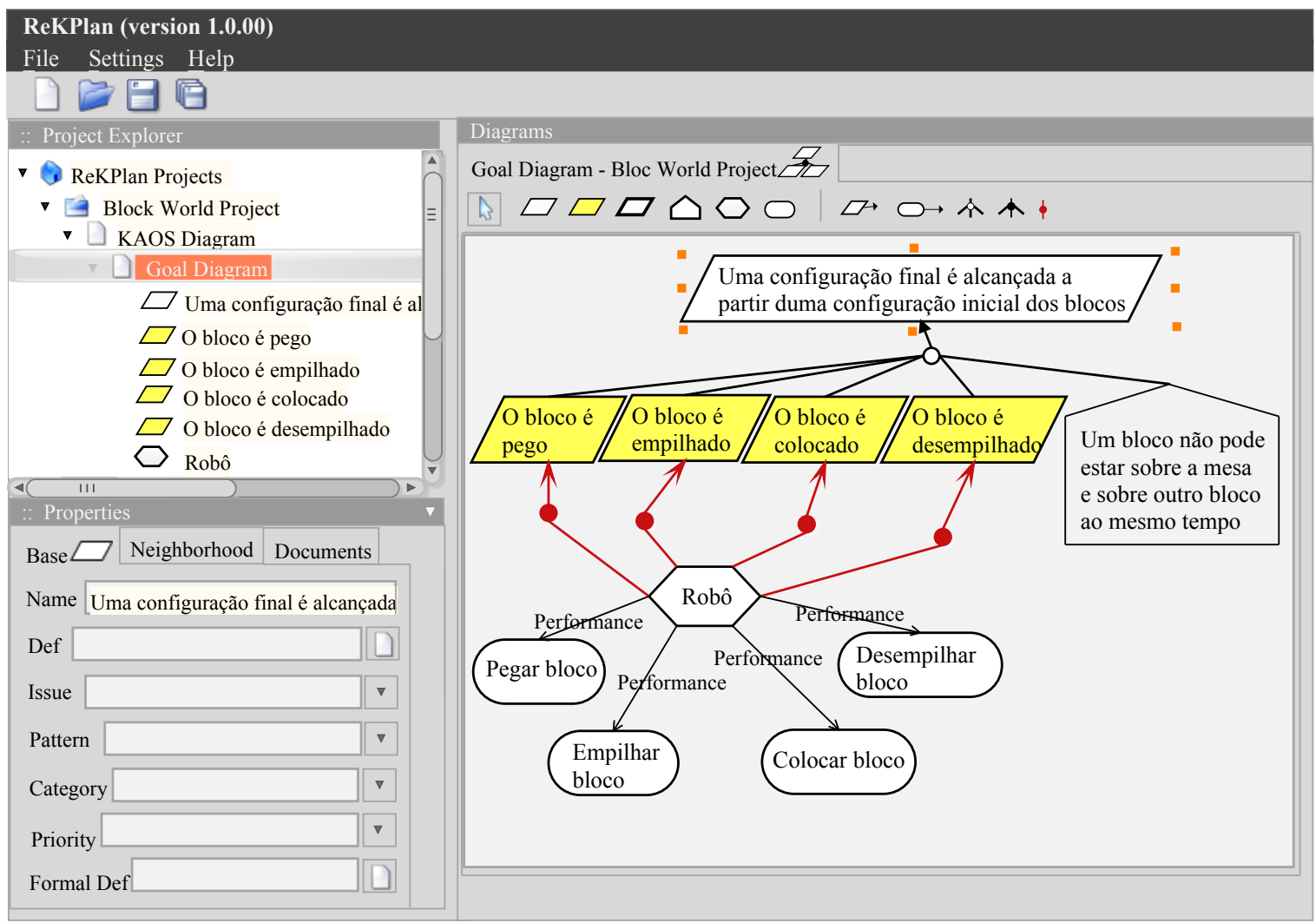

Figura 26 - Diagrama de Objetivos do problema do Mundos dos Blocos em ReKPlan.

atingido a partir do estado atual com o cumprimento do objetivo?". Seguindo esse raciocínio foi construído o diagrama mostrado na Figura 26 feito na ferramente ReKPlan -proposta no presente trabalho- em que o responsável do cumprimento dos objetivos é o Robô, modelado como agente do diagrama, e que deverá realizar certas operações para atingir os objetivos.

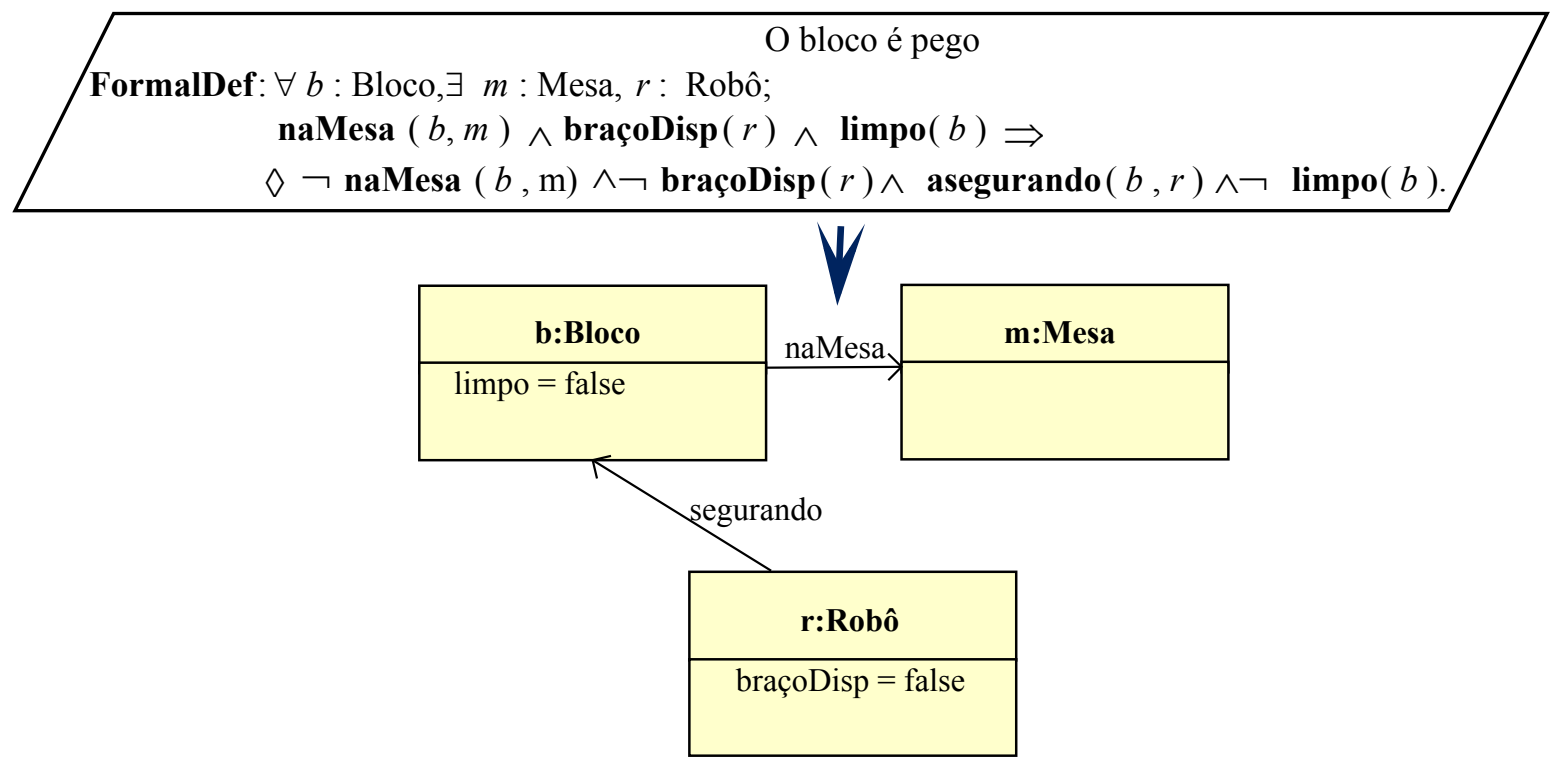

Figura 27 - Geração dos objetos envolvidos no objetivo "O bloco é pego". 


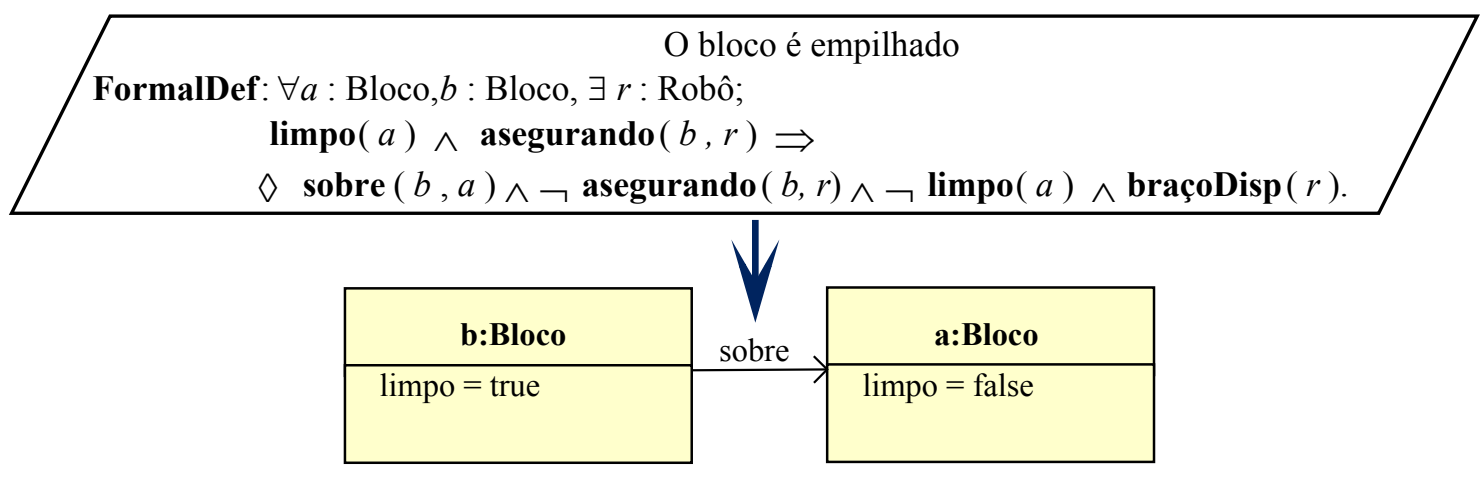

Figura 28 - Geração dos objetos envolvidos no objetivo "O bloco é empilhado".

Outros dos passos da metodologia é a obtenção da visão estrutural do sistema por meio dos objetos derivados de cada objetivo. Nas Figuras 27 e 28, representam-se os objetos originados da definição formal LTL para os objetivos “O bloco é pego" e "O bloco é empilhado”. Os objetos referenciados por mais de um objetivo não são re-declarados no diagrama de Objetos, por exemplo, para o objetivo "O bloco é empilhado", na figura representa-se os objetos a:Bloco e $b$ :Bloco sendo que o objeto Robô devia se representado também, mas como foi previamente modelado para o objetivo "O bloco é pego" então não precisaria ser gerado novamente.

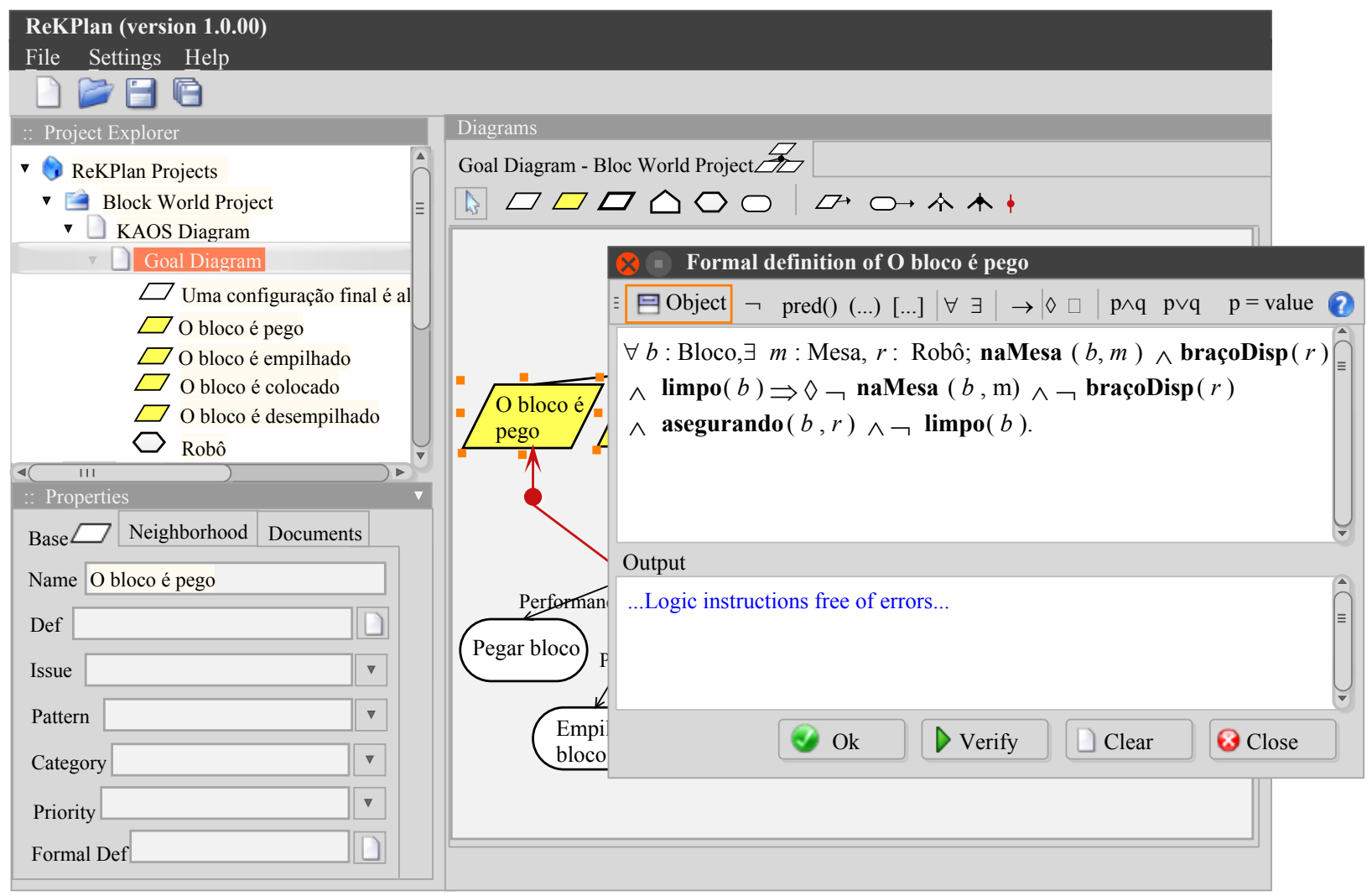

Figura 29 - Asistente incorporado ao ReKPlan para análise de instruções LTL Mundo dos Blocos.

O ReKPlan incorpora um assistente (ver Figura 29) que permite aos designers a especificação de instruções LTL como definição formal dos objetivos comportamentais. Para isto, foi 
criada uma gramática e desenvolvido um parser que além de identificar cada um dos elementos LTL das expressões, deteta possíveis erros sintáticos e semânticos, garantindo assim a correta e estrita tradução para instruções PDDL (consultar Apêndice C).

Embora o KAOS como método propõe um diagrama de Objetos gerados a partir da declaração em LTL, a presente proposta visa a obter de forma automática o diagrama de classes do sistema a partir desses objetos como processo inverso, assim é possível obter uma visão estrutural geral do sistema [ver Figura 30].

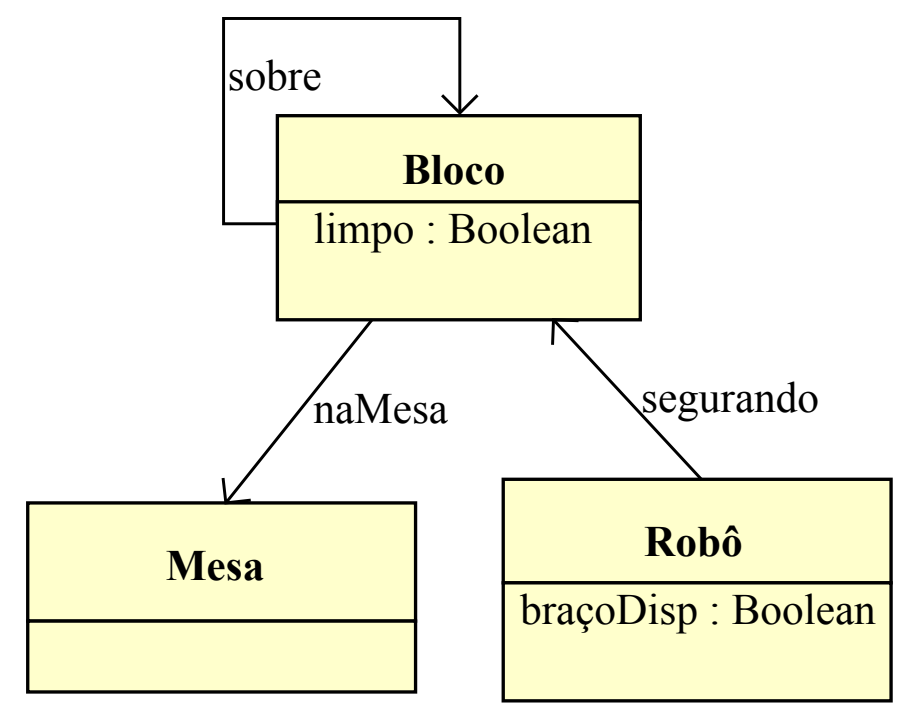

Figura 30 - Diagrama de Classes do problema Mundo dos Blocos.

O resumo dos objetivos em KAOS para o problema Mundos dos Blocos com a sua formalização usando LTL pode ser consultado na Tabela 8.

Tabela 8 - Sentenças LTL associadas a cada objetivo do Diagrama de Objetivos do problemas do Mundo dos Blocos.

\begin{tabular}{|c|c|c|}
\hline & Objetivo & Sentenças LTL \\
\hline 1 & O bloco é pego & $\begin{array}{l}\forall b: \operatorname{Bloco}, \exists m: \text { Mesa, } r: \text { Robô; } \\
\operatorname{naMesa}(\mathrm{b}, \mathrm{r}) \wedge \text { braçoDisp }(\mathrm{r}) \wedge \operatorname{limpo}(\mathrm{b}) \Rightarrow \\
\diamond \neg \operatorname{naMesa}(b, m) \wedge \neg \operatorname{braçoDisp}(\mathrm{r}) \wedge \operatorname{segurando}(\mathrm{b}, \mathrm{r}) \wedge \neg \operatorname{limpo}(\mathrm{b})\end{array}$ \\
\hline 2 & O bloco é empilhado & $\begin{array}{l}\forall a: \text { Bloco, } b: \text { Bloco, } \exists r \text { :Robô } m: \text { Mesa; } \\
\operatorname{limpo}(\mathrm{b}) \wedge \text { segurando }(\mathrm{a}, \mathrm{r}) \Rightarrow \\
\diamond \text { sobre }(\mathrm{a}, \mathrm{b}) \wedge \neg \operatorname{segurando}(\mathrm{a}, \mathrm{r}) \wedge \neg \operatorname{limpo}(\mathrm{b}) \wedge \operatorname{braçoDisp}(\mathrm{r})\end{array}$ \\
\hline 3 & O bloco é colocado & $\begin{array}{l}\forall b \text { :Bloco, } \exists m \text { :Mesa, } r \text { :Robô; } \\
\operatorname{segurando}(b, r) \Rightarrow \\
\diamond \neg \operatorname{segurando}(b, r) \wedge \operatorname{limpo}(b) \wedge \operatorname{braçoDisp}(r) \wedge \operatorname{naMesa}(b, m) ;\end{array}$ \\
\hline 4 & O bloco é desempilhado & $\begin{array}{l}\forall a: \text { Bloco, } b: \text { Bloco, } \exists r \text { :Robô, } m: \text { Mesa; } \\
\text { sobre }(\text { a,b }) \wedge \operatorname{limpo}(\text { a }) \wedge \text { braçoDisp }(\mathrm{r}) \Rightarrow \\
\diamond \neg \text { braçoDisp }(\mathrm{r}) ; \wedge \neg \operatorname{sobre}(\text { a,b }) \wedge \neg \operatorname{limpo}(\text { a }) ;\end{array}$ \\
\hline
\end{tabular}


O passo 3 do Algoritmo 2 permite a obtenção dos predicados com os seus tipos em PDDL seguintes a partir das sentenças LTL:

\begin{tabular}{lr} 
KAOS (LTL) & \multicolumn{1}{c}{ Predicados PDDL } \\
\hline naMesa(x,r) & (:predicates (naMesa ?x ?m) \\
limpo(x) & (limpo ?x) \\
bracoDisp(r) & (bracoDisp ?r) \\
sobre(x,y) & (sobre ?x ?y) \\
segurando(x.r) & (segurando ?x ?r))
\end{tabular}

Em que $x$ e $y$ são objetos de tipo bloco, $r$ de tipo robô e $m$ de tipo mesa.

Como resultado de aplicar do passo 4 ao 7 do Algoritmo 2 a geração das ações em PDDL a partir das sentenças LTL da Tabela 8 resultaria em:

\begin{tabular}{ll}
\multicolumn{1}{c}{ Ações } & Predicados PDDL \\
\hline (:action pegar & :parameters (?b -bloco ?m- mesa ?r -robo) \\
Pegar bloco & (precondition (and (naMesa ?b ?m) (braçoDisp ?r) (limpo ?b)) \\
& :effect (and (not (naMesa ?b ?m)) (not (braçoDisp ?r)) \\
& (:action empilhar \\
& :parameters (?a -bloco ?b -bloco ?r -robo) \\
& :precondition (and (limpo ?b) (segurando ?a ?r)) \\
& :effect (and (sobre ?a ?b) (not (segurando ?a ?r)) (limpo ?a) \\
Empilhar bloco & (braçoDisp ?r)) \\
\hline (:action colocar & :parameters (?b -bloco ?m -mesa ?r -robo) \\
:precondition (segurando ?b ?r) \\
:effect (and (not (segurando ?b ?r))(limpo ?b) (braçoDisp ?r) \\
(naMesa ?b ?m))
\end{tabular}

Seguindo esse raciocino, no Apêndice B podem ser consultados o domínio e o problema expressado em PDDL do Mundos dos Blocos. 


\subsubsection{Teste com planejador de um problema simples}

Com o objetivo de levar um problema até a etapa Síntese do Plano Escalonador abordada no Capítulo 2 sobre o processo de projeto seguido para problemas de planejamento, decidiu-se modelar um problema simples do Mundo dos Blocos, e assim poder testar sobre um plano as instruções PDDL geradas a partir da presente proposta. O processo de modelagem dos estados Inicial e Objetivo para um problema simples sobre este domínio, envolve o uso da ferramenta itSIMPLE (VAQUERO et al., 2012) resultando nos modelos representandos na Figura 31.

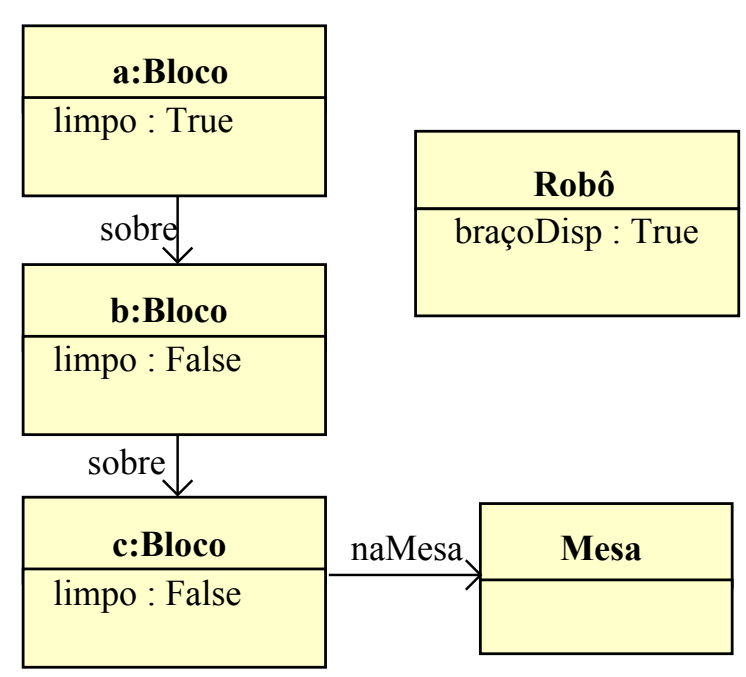

(a)

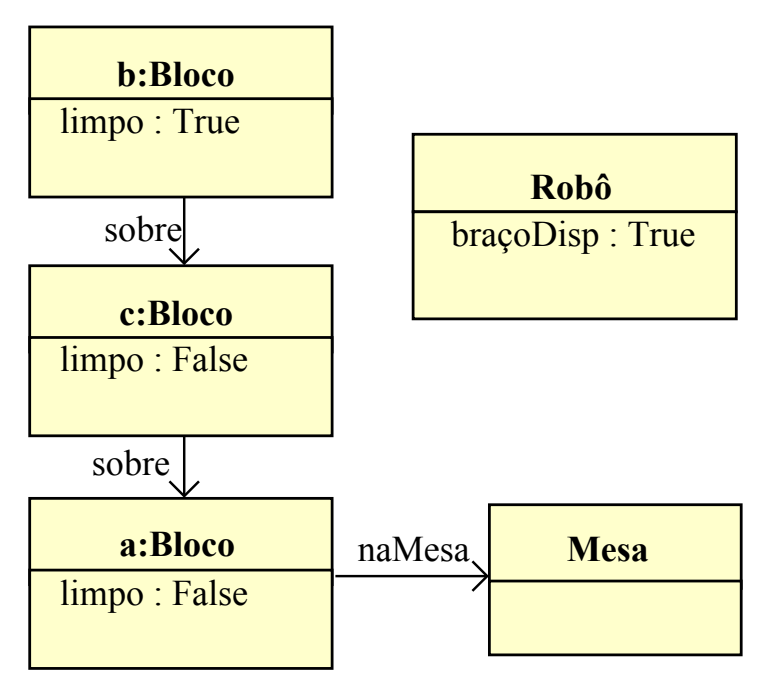

(b)

Figura 31 - (a) Estado Inicial e (b) Estado Objetivo de um problema simples do Mundo dos Blocos.

Para esta etapa experimental, usou-se o planejador Metric-FF proposto por (HOFFMANN, 2011) resultando na seguinte saída:
step 0: DESEMPILHAR A B R
3: COLOCAR B M R
6: PEGAR B M R
1: COLOCAR A M R
4: PEGAR C M R
7: EMPILHAR B C R
2: DESEMPILHAR B C R 5: EMPILHAR C A R

\subsubsection{Análise do Modelo do Domínio}

Uma das etapas do método proposto é Síntese do Modelos de comportamento que envolve o processo de tradução do diagrama de Objetivos em KAOS para a rede GHENeSys e fazer a análise correspondente.

A rede GHENeSys resultante do processo de aplicar o Algoritmo 1 para que em uma posterior etapa possa ser realizado a análise de propriedades e identificar possíveis estados o condições não desejadas é mostrada na Figura 32.

Com o uso de técnicas de análise de árvore de alcançabilidade aplicados na rede concluiuse: 
- É livre de deadlock (a rede é viva).

- Todas as marcações são atingíveis a partir da marcação inicial, portanto a rede é alcançável.

- Ao ser a árvore de alcançabilidade finita, então a rede é finita.

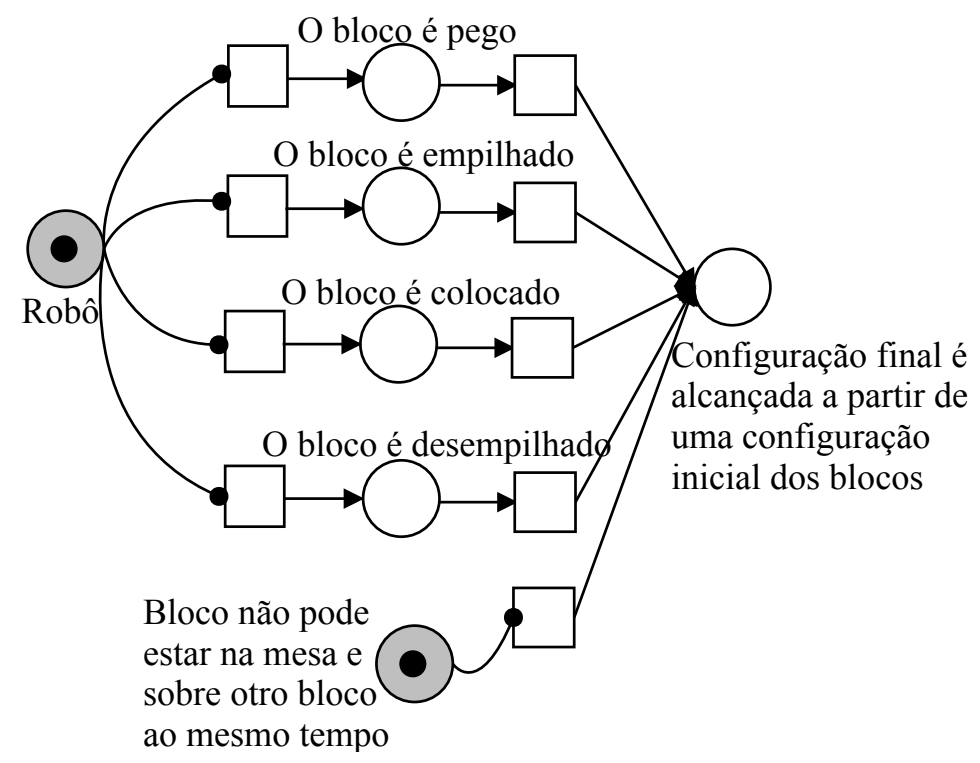

Figura 32 - Rede GHENeSys do problema do Mundo dos Blocos.

Em termos de cardinalidade, caso deseja-se modelar a quantidade de blocos especificados em uma outra instância do problema, será declarado um lugar Blocos cujos tokens descrevem esses blocos, e que estará direitamente ligado às transições que finalizam em cada uma dos lugares que modelam os objetivos do sistema. A Figura 33 mostra o caso para um problema com três blocos.

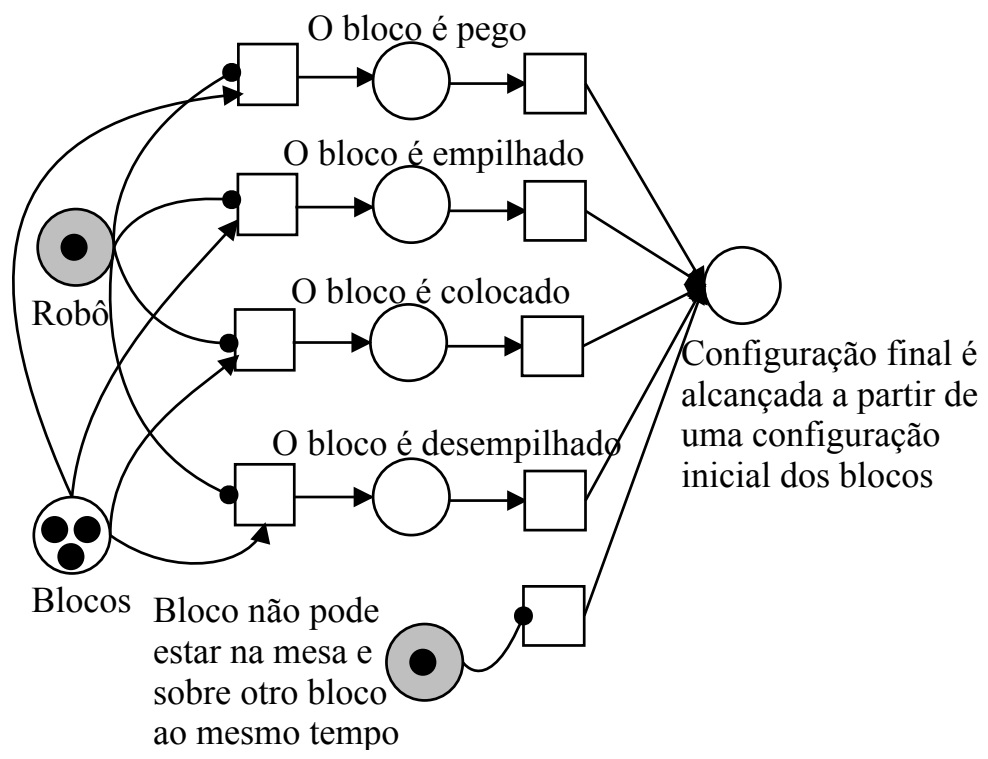

Figura 33 - Rede GHENeSys do problema do Mundo dos Blocos com três blocos. 


\subsection{ROADEF 2005 - Montagem Seqüencial de Carros}

O problema consiste em controlar a produção diária de uma fábrica de carros que tem dois objetivos principais: atribuir um dia de produção a cada veículo encomendado, de acordo com a capacidade da linha de produção; e por outro lado gerenciar a ordem em que os carros devem ser colocados na linha de produção satisfazendo o maior número de requisitos sobre os processos de transporte, carroçaria, pintura e montagem. O presente domínio de planejamento inspira-se em um dos desafios apresentados em uma grande competição chamada Roadef Challenge em sua quarta edição proposto pela empresa Renault (NGUYEN, 2005).

A fábrica estabelece os pedidos diários a serem atendidos com base na capacidade da linha de produção. Existe um processo de escalonamento dos veículos na hora de ser colocados na linha de produção para cada dia de produção e respeitando restrições dos pedidos. A ordem em que é estabelecida a sequiência diária dos veículos na linha de produção tem um efeito direto no rendimento da fábrica e na qualidade dos veículos. Entretanto uma disposição inapropriada da seqüência resultaria em um fluxo de trabalho desbalanceado, perda de tempo e baixa produção.

Trata-se de um domínio de planejamento, que abrange características interessantes tais como, o gerenciamento de recursos, otimização, escalonamento, minimização de custos, entre outras.

O principal objetivo no processo de modelagem é poder avaliar o método proposto neste trabalho e previsivelmente levantar futuras melhorias para a ferramenta ReKPlan na modelagem dos objetivos de problemas reais, a análise das propriedades do modelo representado em redes de Petri; e a geração de instruções PDDL a serem executadas por planejadores.

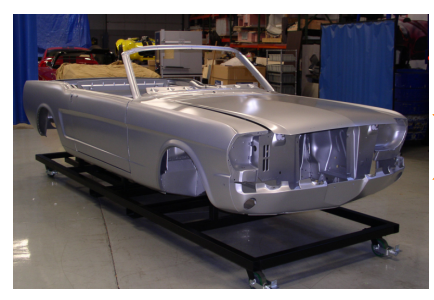

Body Shop

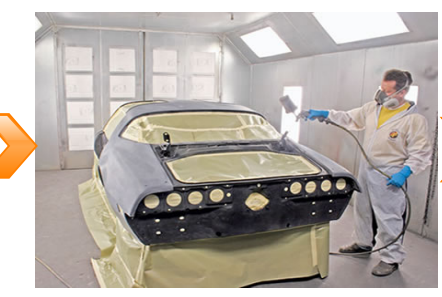

Pintura

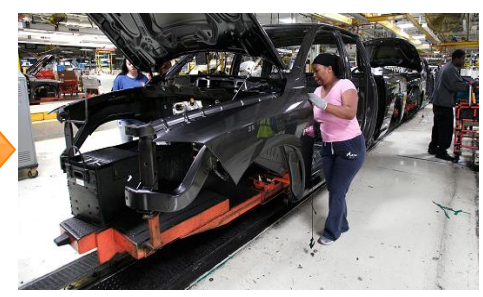

Montagem

Figura 34 - Áreas do domínio Montagem Seqüencial de Carros.

Para este estudo de caso, focaliza-se nos requisitos das áreas de pintura e montagem dos carros, devido a que a primeira etapa não incide na seqüencia diária dos veículos na linha de produção.

A modelagem do problema proposta segue uma abordagem Orientada a Serviços em que cada estado pelo qual que passa o carro dentro da linha de manufatura é feita sobre uma 
arquitetura PSA (Product Service Architecture) (MARTINEZ; SILVA, 2015b). Assim, existe uma área de pintura que como serviço oferecido resulta em que os carros estejam pintados e uma área de montagem para a montagem dos carros.

A seguir é introduzido a modelagem em itSIMPLE seguindo a abordagem atual formulada em (BASBAUM, 2015).

\subsubsection{Modelagem do domínio usando o itSIMPLE}

O itSIMPLE - umas das ferramentas citadas no Capítulo 2- é um Ambiente Integrado de Modelagem e Análise de Domínios de Planejamento Automático proposto pelo Design Lab, laboratório de pesquisa da Universidade de São Paulo (USP), que pretende minimizar os problemas encontrados durante o ciclo de vida de projeto para problemas reais de planejamento, com especial ênfase nas fases iniciais.

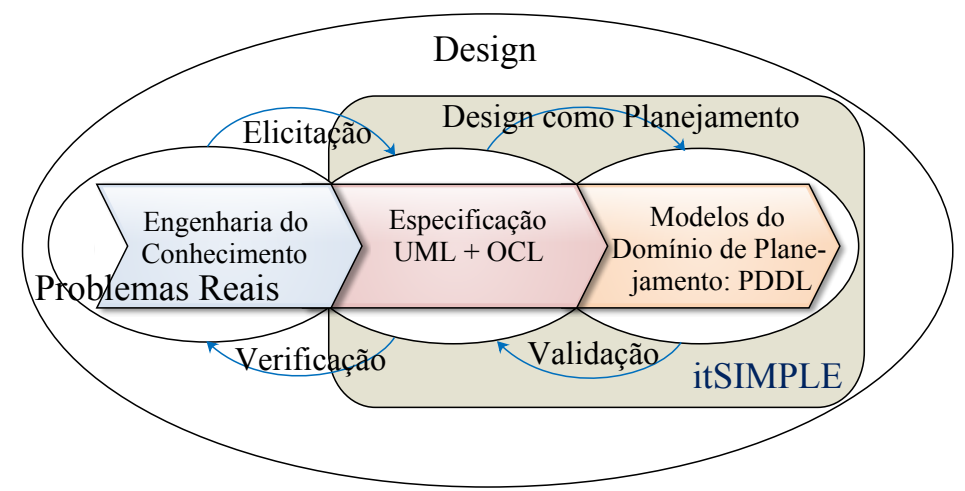

Figura 35 - itSIMPLE : Dos requisitos de um problema de planejamento até instruções PDDL.

A resolução de um grande número de problemas usando itSIMPLE, aumentou a importância das etapas iniciais do processo de modelagem, caracterizada pela elicitação dos requisitos expressados informalmente para uma combinação de linguagens como UML (Unified Modeling Language) e OCL (Object Constraint Language), e posteriormente como parte do design, levados para modelos do domínio em PDDL (Planejamento Domain Definition Language), servindo assim de entrada para vários planejadores (consultar Figura 35).

Em (BASBAUM, 2015) (BASBAUM; MARTINEZ; REINALDO, 2016) essa abordagem é estendida com a introdução da hierarquia com o uso do Diagramas de Classes e um Diagrama de Eventos Comportamental para modelar o domínio do problema de planejamento como um todo.

Para completar o modelo, é preciso a definição da instância do problema com outros dois diagramas: um diagrama com os objetos iniciais do estado inicial e o diagrama com os objetos do estado objetivo.

A modelagem do domínio do problema de manufatura no itSIMPLE que inclui o diagrama de classes é mostrado na Figura 36, enquanto o Diagrama de Estado Comportamental é 
mostrado na Figura 37.

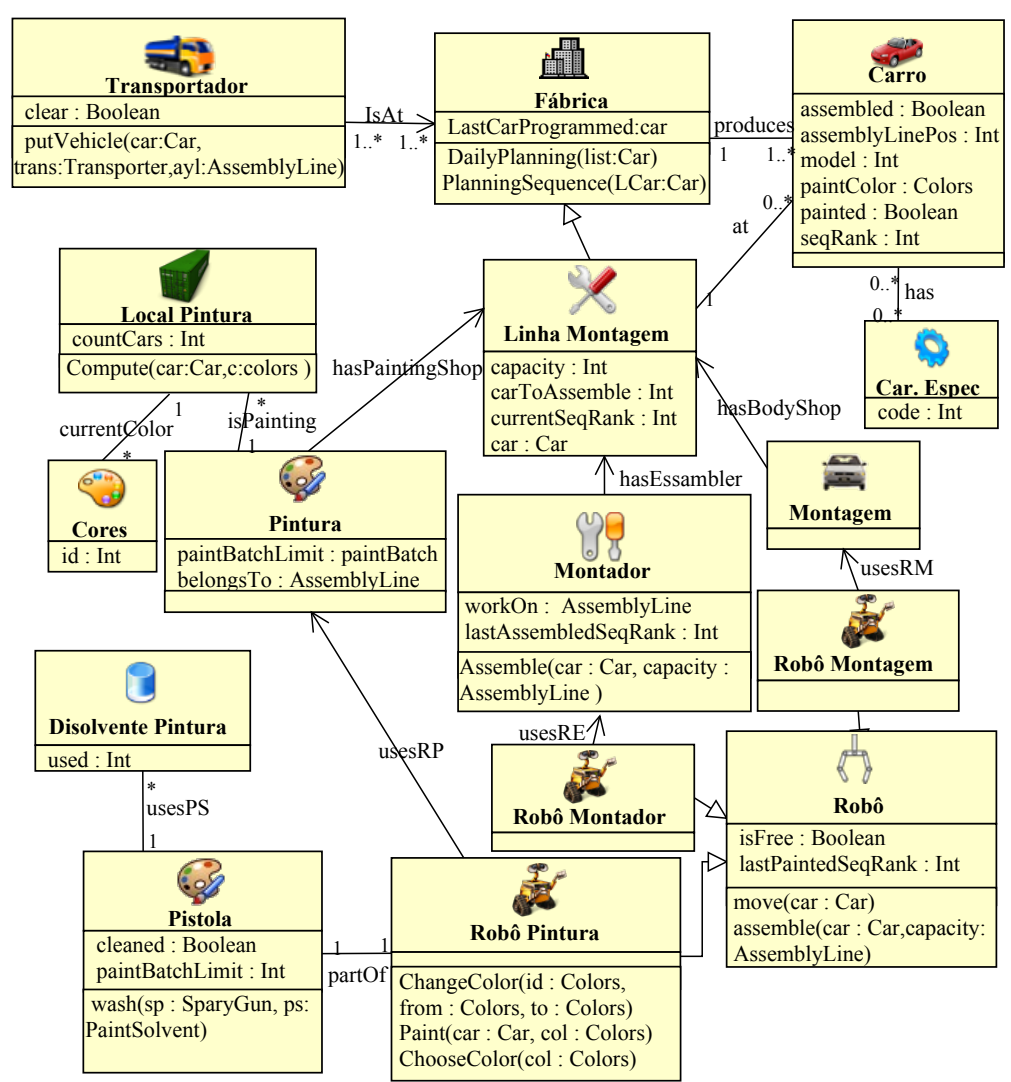

Figura 36 - Diagrama de Classe do domínio de manufatura ROADEF 2005 segundo (BASBAUM, 2015).

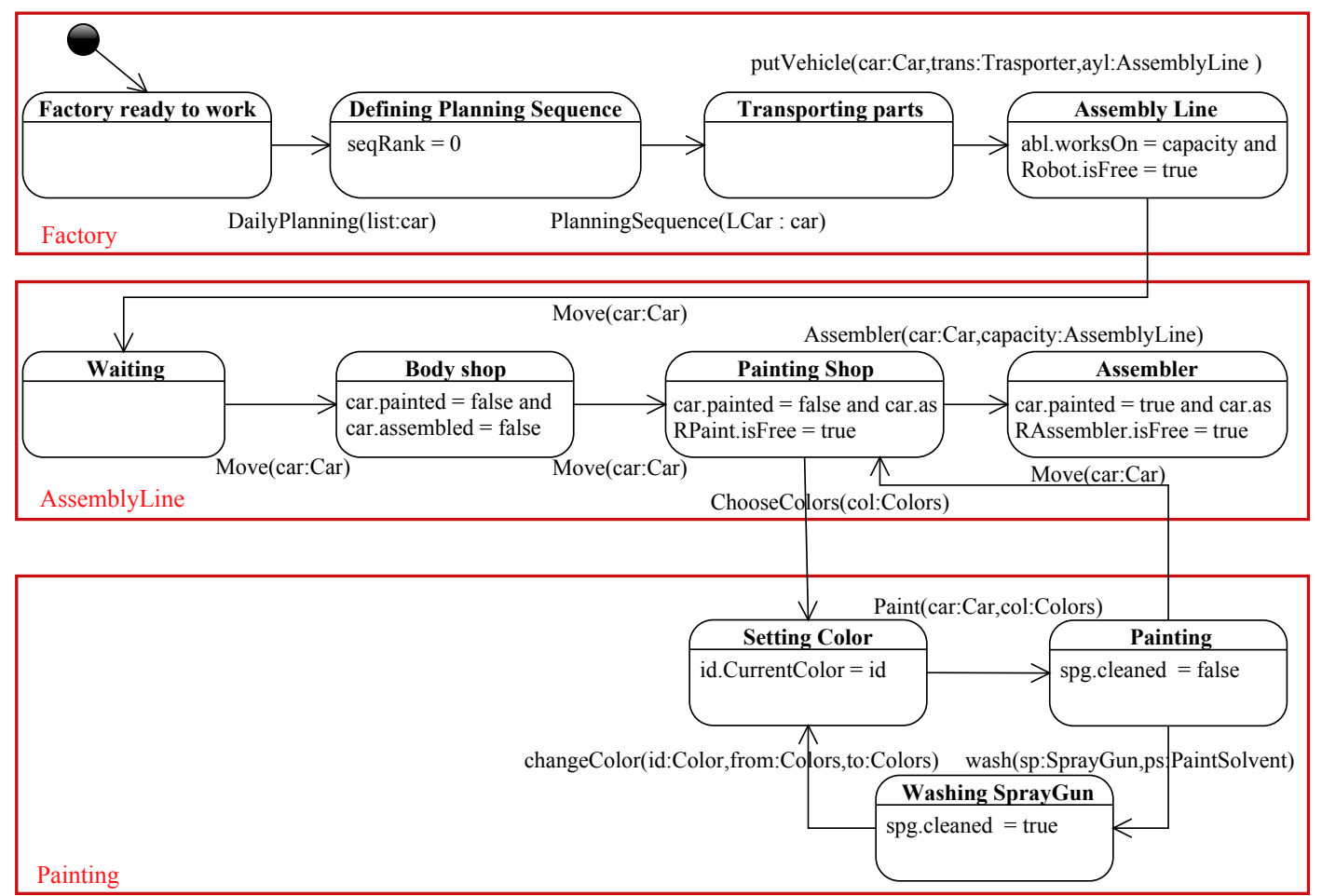

Figura 37 - Diagrama de Estados Comportamental para o domínio de manufatura ROADEF 2005 (BASBAUM, 2015). 
A versão atual do itSIMPLE (4.0), gera uma rede de Petri para cada um desses diagramas de Estados, fato que ignora poder analisar numa primeira aproximação o sistema como um todo, incluindo o futuro sistema de planejamento a ser implementado assim como o contexto com todos os seus elementos relevantes.

Além de (BASBAUM, 2015) propôr o uso de um único diagrama de Estado Comportamental, propõe-se um algoritmo de tradução para a geração de uma única rede de Alto Nível, expressando características de hierarquia a serem tratadas por planejadores hierárquicos que ficam fora do escopo da presente proposta.

A seguir, é apresentado a modelagem do processo de fabricação, usando o ReKPlan, com um objetivo primário "Pedido pronto para entrega quando uma ordem foi recebida". Além disso, é apresentado o diagrama de Objetivos, os objetos associados a cada objetivo, e por ultimo a rede GHENeSys gerada com seu correspondente análise.

\subsubsection{Modelagem do Domínio usando ReKPlan}

Como parte da proposta, o diagrama de Objetivos de KAOS para este estudo de caso é apresentado na Figura 38, em que define-se como objetivo primário do sistema, que um pedido de carros esteja pronto toda vez que a solicitação foi recebida pela fábrica. A partir desse objetivo e aplicando para o refinamento a técnica Dirigida por Etapas (DARIMONT; LAMSWEERDE, 1996; LAMSWEERDE, 2004), geram-se novos sub-objetivos que descrevem as etapas do processo de produção de carros: que sejam pintados e posteriormente montados na área de montagem.

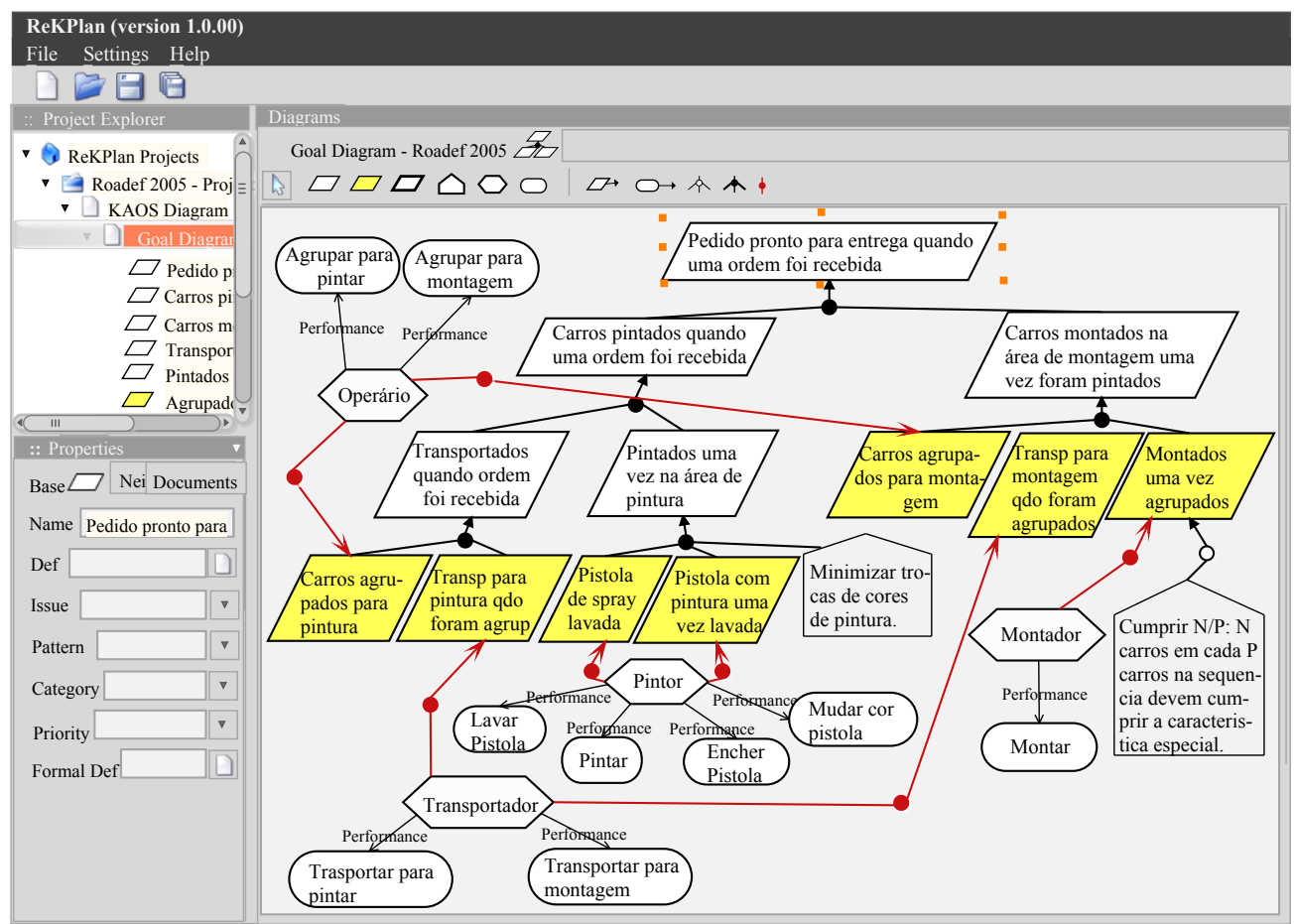

Figura 38 - Diagrama de Objetivo para o estudo de caso de manufatura: Montagem Seqüencial de Carros. 
O refinamento termina quando sub-objetivos (folhas do diagrama) ficam ligados diretamente a agentes do sistema. Os agentes modelados são o Transportador, dedicado ao transporte de um lote de carro de uma área para outra; o Montador, responsável pela montagem dos carros; o Pintor responsável pela pintura; e um agente Operário que classifica e agrupa os carros em cada etapa, bem seja pelo critério quantidade de carros que podem ser pintados conforme disponibilidade da pintura na pistola para pintar, ou pelas característica especiais que alguns carros devem cumprir antes de serem montados.

A Área de Montagem deve cumprir o requisito de que alguns carros possam ter algumas características especiais extras ao processo de montagem: teto solar, tipos de rodas especiais, ar acondicionado, entre outras. Esses carros devem ser devidamente colocados na linha de montagem evitando assim sobrecargas. O requisito é caracterizado pelo razão $N / P$ que é definida para cada característica especial: $P$ carros de $N$ na seqüência devem possuir tal característica. Por exemplo: para a característica "Ar acondicionado", sendo razão $N / P=1 / 4$ significa que não deve haver mais de um carro em qualquer sequiência de 4 carros na ordem de montagem com ar acondicionado incorporado como característica especial. No Diagrama de Objetivos usou-se "Propriedades do domínio" ligada ao objetivo Montados uma vez agrupados, e assim representar este comportamento como uma sentença descritivas do sistema ou politica que deve cumprir o domínio.

Nas Figuras 39 e 40 mostram-se como podem ser gerados objetos a partir da definição formal em LTL para os objetivos "Carros montados na área de montagem uma vez foram pintados " e "Carros pintados na área de pintura quando a fábrica recebe uma solicitude ". Os objetos referenciados por mais de um objetivo não são re-declarados no diagrama de Objetos, por exemplo, para o objetivo "Carros pintados na área quando uma solicitação foi recebida”, na figura modelam-se os objetos ps de tipo PistolaSpray, cor de tipo Cor, ap de tipo Área de Pintura, e pintor de tipo Pintor, sendo que o objeto $c$ de tipo Carro devia se modelado também, mas como foi previamente declarado para o objetivo "Carros montados quando foram pintados", não precisa ser declarado novamente. 


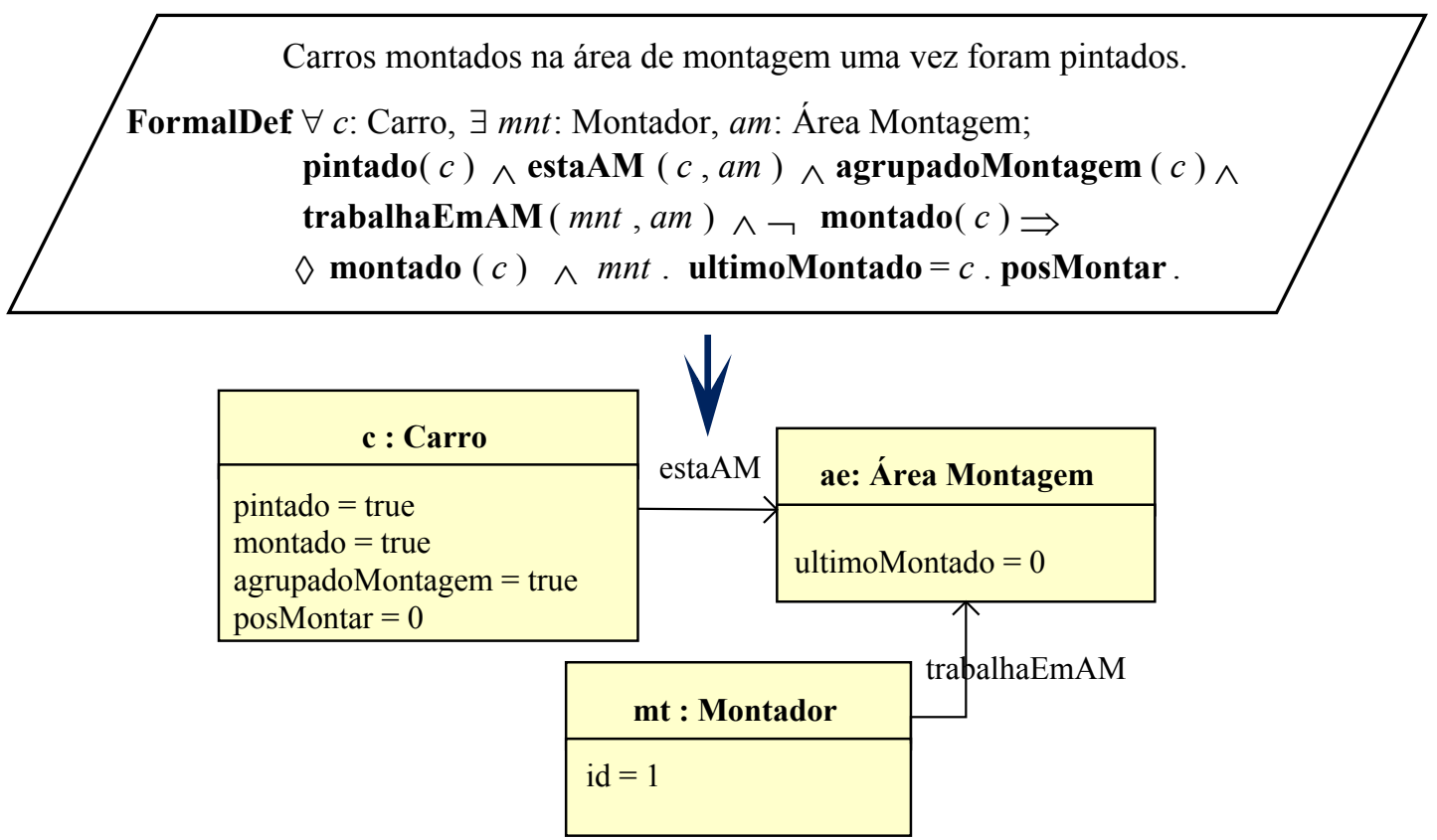

Figura 39 - Geração dos objetos do objetivo "Carros montados na área de montagem uma vez foram pintados".

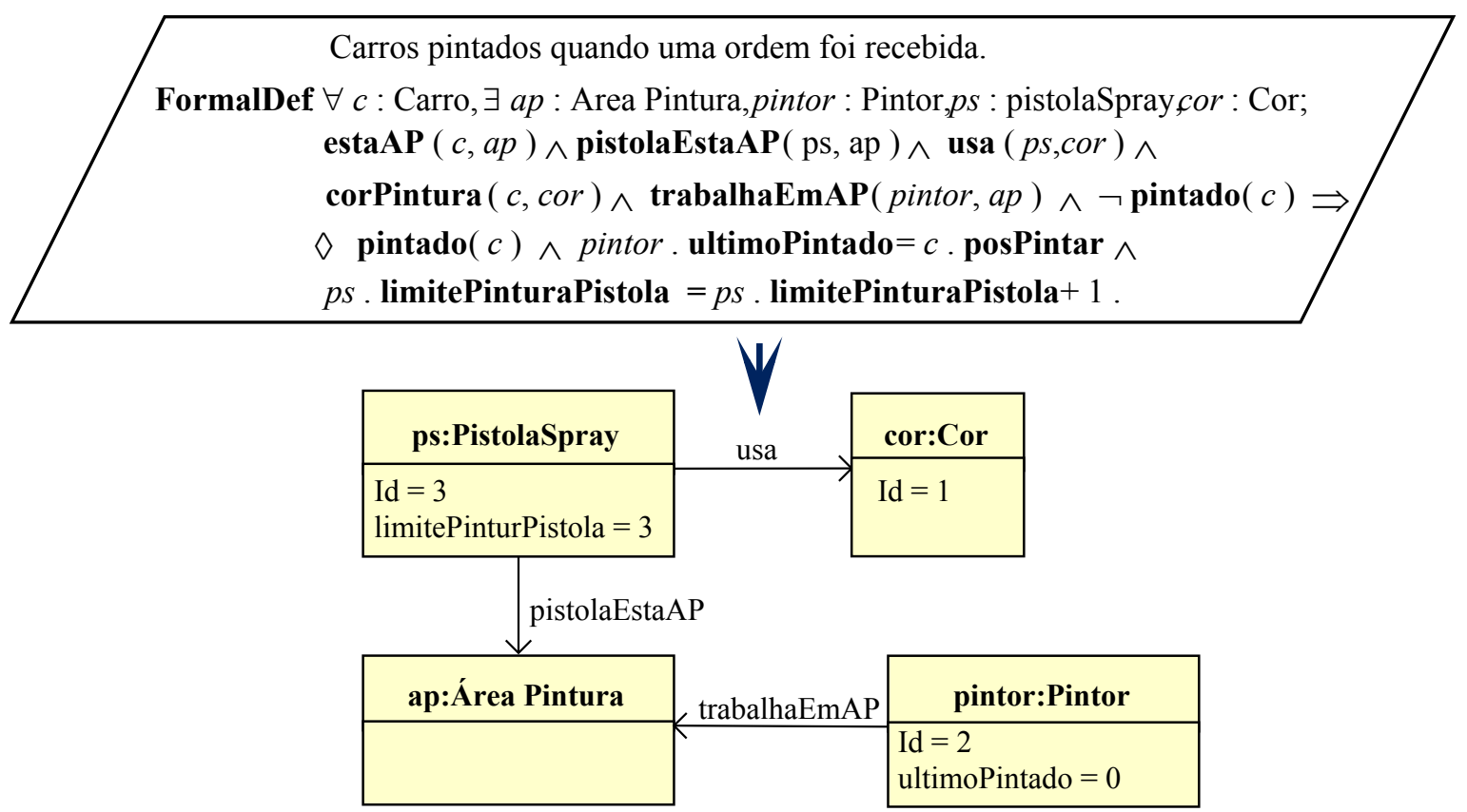

Figura 40 - Geração dos objetos do objetivo "Carros pintados na área de pintura quando a fábrica recebe uma solicitude".

Para este problema o resultado final é o diagrama de Classes representado na Figura 41 com todas os classes do sistema. 

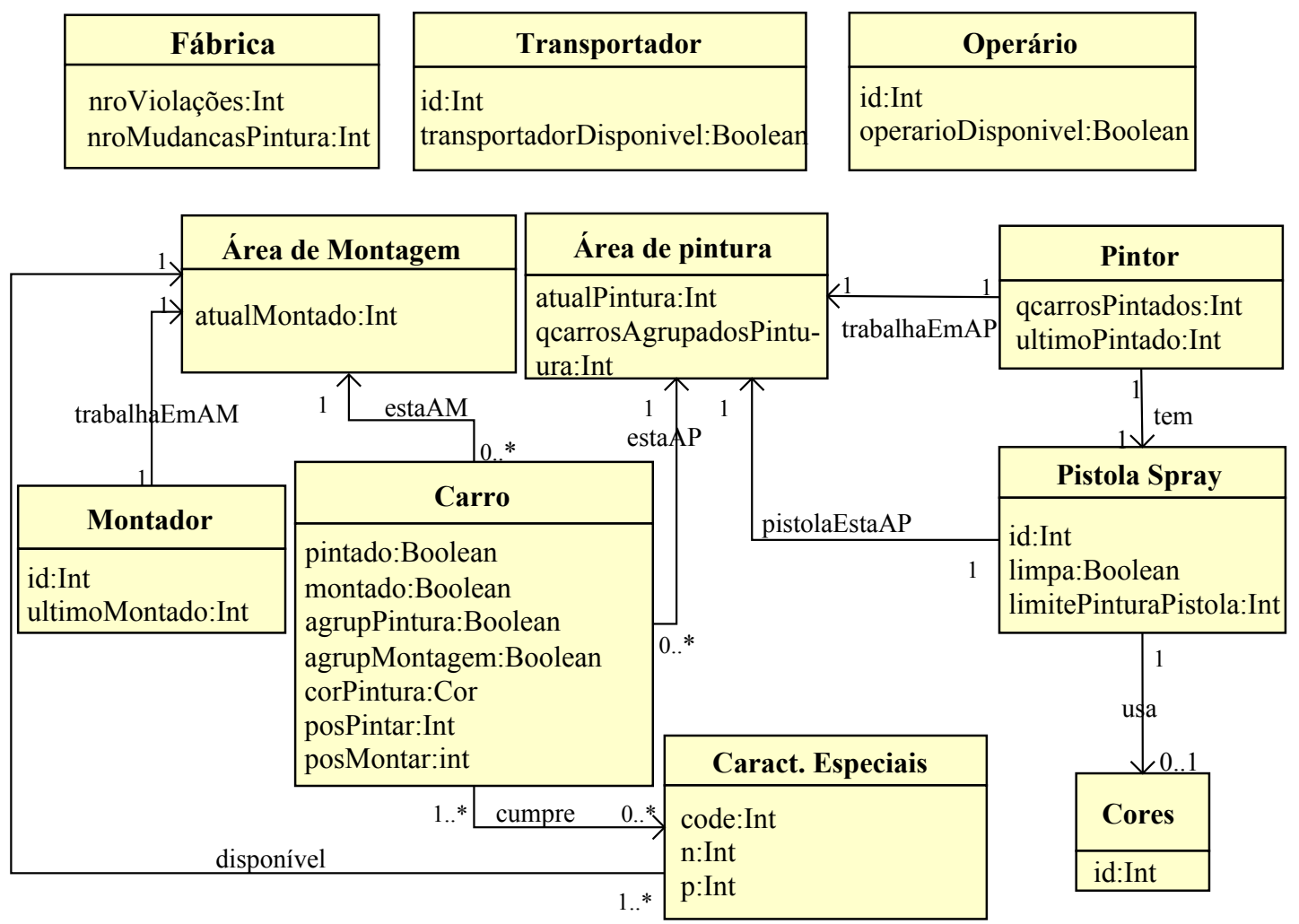

Figura 41 - Diagrama de Classe do domínio de manufatura ROADEF 2005 usando ReKPlan.

O resumo dos objetivos em KAOS para o problema Montagem Seqüencial de Carros com a sua formalização usando LTL pode ser consultado na Tabela 9.

Em termos de complexidade do problema, especial atenção merece a declaração em LTL das propriedades do domínio: número de violações dos razões $N / P$ de cada característica especial, na definição da sequiência de carros na linha de montagem (consultar Tabela 10).

A primeira das violações expressa que, se para toda característica especial, na área de montagem existe um carro que a cumpre, mas deseja-se montar um outro com a mesma característica, então o total de carros com essa característica não pode exceder a $N$ na seqüência.

Supondo que esse segundo carro a ser montado, não deve cumprir com essa característica especial e sim com alguma outra, de igual maneira o numero de carros montados não pode exceder aos $N$ carros especificados na restrição, fato que é expressado em na segunda das restrições da tabela.

Tanto a primeira como a segunda das restrições fazem com que o numero de violações da fábrica se incremente.

Por outro lado, se o novo carro não cumprira com essa restrição mas vai ser montados, então na área de montagem estará disponível uma nova característica especial a ser incorporada.

Por ultimo, o caso em que o novo carro cumprira com a mesma característica daquele que já está área de montagem, fará com que o numero de características especiais seja decrementado, 
Tabela 9 - Sentenças LTL associadas a cada objetivo do Diagrama de Objetivos do problema Montagem Seqüencial de Carros.

\begin{tabular}{|c|c|}
\hline Objetivo & Sentenças LTL \\
\hline $\begin{array}{l}\text { Carros pintados na área } \\
\text { de pintura quando a fábrica } \\
\text { recebe uma solicitude. }\end{array}$ & 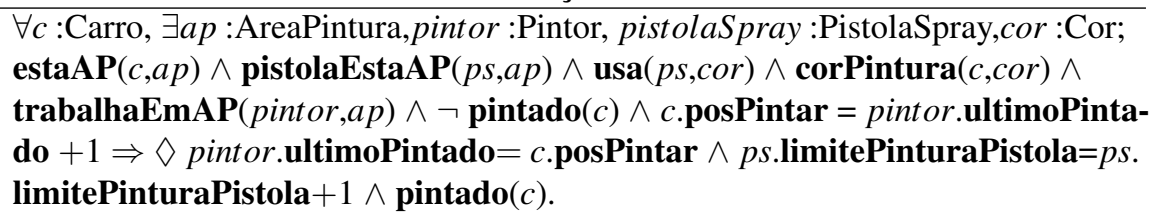 \\
\hline $\begin{array}{l}\text { Carros montados na área } \\
\text { de montagem uma vez } \\
\text { foram pintados. }\end{array}$ & $\begin{array}{l}\forall c: \text { Carro, } \exists m n t: \text { Montador, am :AreaMontagem; } \\
\operatorname{pintado}(c) \wedge \operatorname{estaAM}(c, a m) \wedge \operatorname{agrupadoMontagem}(c) \wedge \operatorname{trabalhaEmAM}(m n t \\
, a m \wedge \neg \operatorname{montado}(c) \wedge c \cdot \operatorname{posMontar}=m n t . \mathbf{u l t i m o M o n t a d o}+1 \Rightarrow \\
\diamond m n t \cdot \text { ultimoMontado }=c \cdot \operatorname{posMontar} \wedge \operatorname{montado}(c) .\end{array}$ \\
\hline $\begin{array}{l}\text { Carros agrupados para pin- } \\
\text { tura. }\end{array}$ & $\begin{array}{l}\forall \mathrm{c}: \text { Carro }, \exists \text { operario:Operario; } \\
\neg \operatorname{pintado}(c) \wedge \neg \operatorname{montado}(c) \wedge \text { operarioDisponivel }(\text { operario }) \wedge c \text {.posPin- } \\
\operatorname{tar}=0 \Rightarrow \diamond \text { agrupadoPintura }(c)\end{array}$ \\
\hline $\begin{array}{l}\text { Carros agrupados para mon- } \\
\text { tagem. }\end{array}$ & $\begin{array}{l}\forall c: \text { Carro, } \exists \text { operario:Operario; } \\
\operatorname{pintado}(c) \wedge \text { operarioDisponivel }(\text { operario }) \wedge \neg \operatorname{agrupadoMontagem}(c) \Rightarrow \\
\diamond \operatorname{agrupadoMontagem}(c) .\end{array}$ \\
\hline $\begin{array}{l}\text { Transportados para pintura } \\
\text { quando foram agrupados. }\end{array}$ & $\begin{array}{l}\forall c: \text { Carro, } \exists t r a: \text { Transportador, } \exists a p \text { :AreaPintura; } \\
\text { agrupadoPintura }(c) \wedge \text { transportadorDisponivel }(t r a) \wedge \neg \operatorname{pintado}(c) \wedge \neg \text { esta- } \\
\mathbf{A P}(c, a p) \wedge a p \text {.atualPintura }<p s . \text { limitePistola } \Rightarrow \diamond \operatorname{estaAP}(c, a p) \wedge a p \text {.atual- } \\
\text { Pintura }=a p \text {.atualPintura }+1 \wedge c \text {.posPintar }=a p \text {.atualPintura } .\end{array}$ \\
\hline $\begin{array}{l}\text { Transportados para mon- } \\
\text { tagem quando foram agru } \\
\text { pados. }\end{array}$ & $\begin{array}{l}\forall c: \text { Carro, } \exists \text { tra:Transportador, am }: \text { AreaMontagem; } \\
\neg \operatorname{montado}(c) \wedge \neg \operatorname{estaAM}(c, a m) \wedge \text { transportadorDisponivel }(t r a) \wedge \text { agrupa- } \\
\text { doMontagem }(c) \Rightarrow \diamond \operatorname{estaAM}(c, a m) \wedge \text { am.atualMontado }=a m . \text { atualMon- } \\
\text { tado }+1 \wedge c \cdot \operatorname{posMontar}=a m . \text { atualMontado } .\end{array}$ \\
\hline Pistola de Spray lavada. & $\begin{array}{l}\forall p s: \text { PistolaSpray, } \exists \text { pintor:Pintor; } \\
\neg \operatorname{limpa}(p s) \wedge \operatorname{tem}(\text { pintor }, p s) \wedge(\text { pintor }) . q \text { carrosPintados }>0 \Rightarrow \diamond \operatorname{limpa}(p s) \\
\wedge \text { pintor.qcarrosPintados }=0 .\end{array}$ \\
\hline $\begin{array}{l}\text { Pistola de Spray com pintu- } \\
\text { ra uma vez lavada. }\end{array}$ & $\begin{array}{l}\forall \text { c:Carro, ps:PistolaSpray, } \exists \text { pintor:Pintor; } \\
\operatorname{tem}(\text { pintor }, p s) \wedge \operatorname{limpa}(p s) \Rightarrow \diamond \neg \operatorname{limpa}(p s) .\end{array}$ \\
\hline
\end{tabular}

Tabela 10 - Sentenças LTL associadas à propriedade do domínio Cumprir N/P: $N$ carros em cada $P$ carros na seqüencia devem cumprir a característica especial.

\begin{tabular}{|c|c|}
\hline & Sentenças LTL da propriedade do domínio associada à Montagem \\
\hline 1 & $\begin{array}{l}\forall c e: \text { CarEsp, } \exists c, c_{1}: \text { Carro, am:AreaMontagem, } f: \text { Fabrica; cumpre }(c, c e) \wedge \operatorname{estaAM}(c, a m) \wedge \\
\text { cumpre }\left(c_{1}, c e\right) \wedge c_{1} . \text { posMontar }=c e . p \wedge \operatorname{estaAM}\left(c_{1}, a m\right) \\
\wedge \text { disponivel }(c e, a m) \wedge a e . q u a n t C a r E s p>c e . n \Rightarrow f . \text { nroViolações }=f \text {.nroViolações }+1 .\end{array}$ \\
\hline 2 & $\begin{array}{l}\forall c e: \text { CarEsp, } \exists c, c_{1}: \text { Carro, am:AreaMontagem, } f: \text { Fabrica; } \\
\text { cumpre }(c, c e) \wedge \text { estaAM }(c, a m) \wedge \neg \text { cumpre }\left(c_{1}, c e\right) \wedge c_{1} \cdot \text { posMontar }=c e . p \wedge \text { estaAM }\left(c_{1}, a m\right) \\
\wedge \text { disponivel }(c e, a m) \wedge \text { am.quantCarEsp }+1>c e . \mathbf{n} \Rightarrow f . \text { nroViolações }=f . \text { nroViolaçôes }+1 .\end{array}$ \\
\hline 3 & $\begin{array}{l}\forall c e: \text { CarEsp, } \exists c, c_{1}: \text { Carro, am:AreaMontagem, } f: \text { Fabrica; } \\
\text { cumpre }(c, c e) \wedge \operatorname{estaAM}(c, a m) \wedge \neg \text { cumpre }\left(c_{1}, c e\right) \wedge c_{1} \cdot \operatorname{posMontar}=c e . p \wedge \operatorname{estaAM}\left(c_{1}, a m\right) \\
\wedge \text { disponivel }(c e, a m) \Rightarrow a e . q u a n t C a r E s p=a e . q u a n t C a r E s p+1 .\end{array}$ \\
\hline 4 & 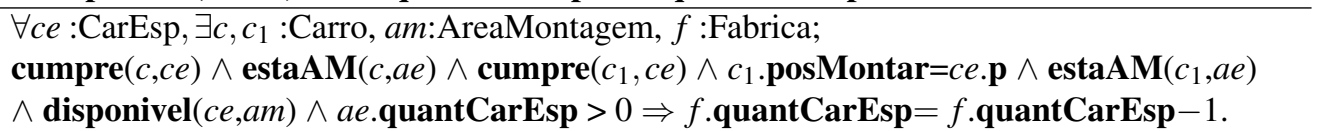 \\
\hline
\end{tabular}

sendo eliminada das pendências da solicitação.

Com base no raciocínio seguido para o problema do Mundo dos Blocos do capítulo anterior, a seguir mostra-se como a partir das expressões em LTL é possível inferir os predicados e os objetos em PDDL para esse problema. 
Os objetos envolvidos são: AreaMontagem, AreaPintura, PistolaSpray, Pintor, Montador, Transportador, Operario, Cor e CaractEsp, enquanto os predicados gerados podem ser consultados na Tabela 11.

Tabela 11 - Predicados PDDL gerados a partir das sentenças LTL para o domínio Montagem Seqüencial de Carros.

\begin{tabular}{|c|c|}
\hline KAOS (LTL) & Predicados PDDL \\
\hline \multicolumn{2}{|c|}{$\begin{array}{l}\text { trabalhaEmAE }(m n t, a m) \text {, com ens de } \\
\text { tipo Montador e am de tipo AreaMonta- (trabalhaEmAM ?mnt-Montador ?am-AreaMontagem) } \\
\text { gem. }\end{array}$} \\
\hline $\begin{array}{l}\text { trabalhaEmAP( } \text { pintor, ap), com pintor } \\
\text { de tipo Pintor e ap de tipo AreaPintura. }\end{array}$ & (trabalhaEmAP ?pintor-Pintor ?ap-AreaPintura) \\
\hline $\begin{array}{l}\text { usa }(p s, c o r), \text { com } p s \text { é de tipo Pistola- } \\
\text { Spray e cor de tipo Cor. }\end{array}$ & (usa ?ps -PistolaSpray ?cor-Cor) \\
\hline $\begin{array}{l}\text { usa }(p s, c o r), \text { com } p s \text { é de tipo Pistola- } \\
\text { Spray e cor de tipo Cor. }\end{array}$ & (usa ?ps -PistolaSpray ?cor-Cor) \\
\hline
\end{tabular}

operarioDisponivel $(o p)$, com $o p$ de (operarioDisponivel ?op-Operario)

tipo Operario.

transportadorDisponivel(trans), com

trans de tipo Transportador.

(transportadorDisponivel ?trans -Transportador)

pistolaEstaAP( $p s, a p)$, com $p s$ é de ti-

po PistolaSpray e ap de tipo AreaPin- （pistolaEstaAP ?ps-PistolaSpray ?ap -AreaPintura)

tura.

$\operatorname{estaAP}(c, a p)$, em que $c$ é de tipo Carro e ap de tipo AreaPintura.

(estaAP ?c-Carro ?ae-AreaPintura)

$\operatorname{estaAM}(c, a m)$, em que $c$ é de tipo $C a-$ rro e am de tipo AreaMontagem.

(estaAM ?c-Carro ?am-AreaMontagem)

limpa $(p s)$, com $p s$ é de tipo PistolaSpray.

(limpa ?ps -PistolaSpray)

pintado(carro) em que carro é de tipo Carro.

(pintado ?carro-Carro)

montado(c) em que carro é de tipo Carro.

(montado ?carro -Carro)

agrupadoPintura $(c)$ com carro é de tipo Carro.

(agrupadoPintura ?carro-Carro)

agrupadoMontagem $(c)$ em que $c a-$ rro é de tipo Carro.

(agrupadoMontagem ?carro-Carro)

cumpre( $c, \operatorname{car} E s p)$ em que $c$ é de tipo Carro, e carEsp de tipo CaractEsp.

(cumpre ?carro -Carro ?carEsp - CaractEsp) 


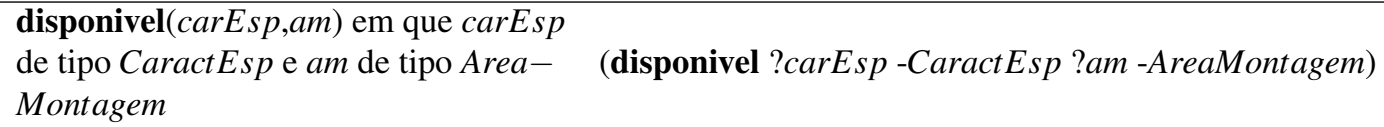

A lista de predicados PDDL é completada com predicados que são gerados a partir dos atributos booleanos associados às classes que descrevem os objetos declarados no Diagrama de Objetos, ou seja, para cada atributos booleano - os que podem ter associado como valor verdadeiro ou falso - são gerados predicados nas instruções PDDL. Por exemplo: para o atributo pintado da classe Carro terá o seguinte predicado no problema em PDDL: (pintado ?c -Carro) .

Já para o resto dos atributos não booleanos, são geradas funções PDDL que retornam o valor correspondente associado a esse atributo. Por exemplo, para o objeto Carro, existe um atributo que estabelece a ordem de entrada na área de pintura que é chamado de posPintar, em PDDL é gerada a seguinte função com o mesmo nome: (posPintar ? c).

As representações em PDDL do modelo do domínio para o problema de manufatura Montagem Seqüencial de Carros podem ser consultada no Apêndice 4.

\subsubsection{Modelagem do Problema de Planejamento}

Uma das principais características do processo de modelagem de um sistema de planejamento, além da modelagem do domínio, é a modelagem do problema de planejamento, que é composto por um estado inicial e um estado objetivo. $\mathrm{O}$ estado inicial é representado por um conjunto objetos que mudam seus atributos com a execução do plano até atingir o estado objetivo.

Os estados inicial e objetivos para um problema de planejamento sobre o domínio Montagem Seqüencial de Carros são representado na Figura 42 e Figura 43.

A representação desses objetos em ReKPlan é feita de forma direta desde que sejam representados como objetos associados aos objetivos durante o processo de modelagem dos objetivos comportamentais do sistema. As instruções em PDDL para esse problema pode ser consultada no Apêndice 5. 


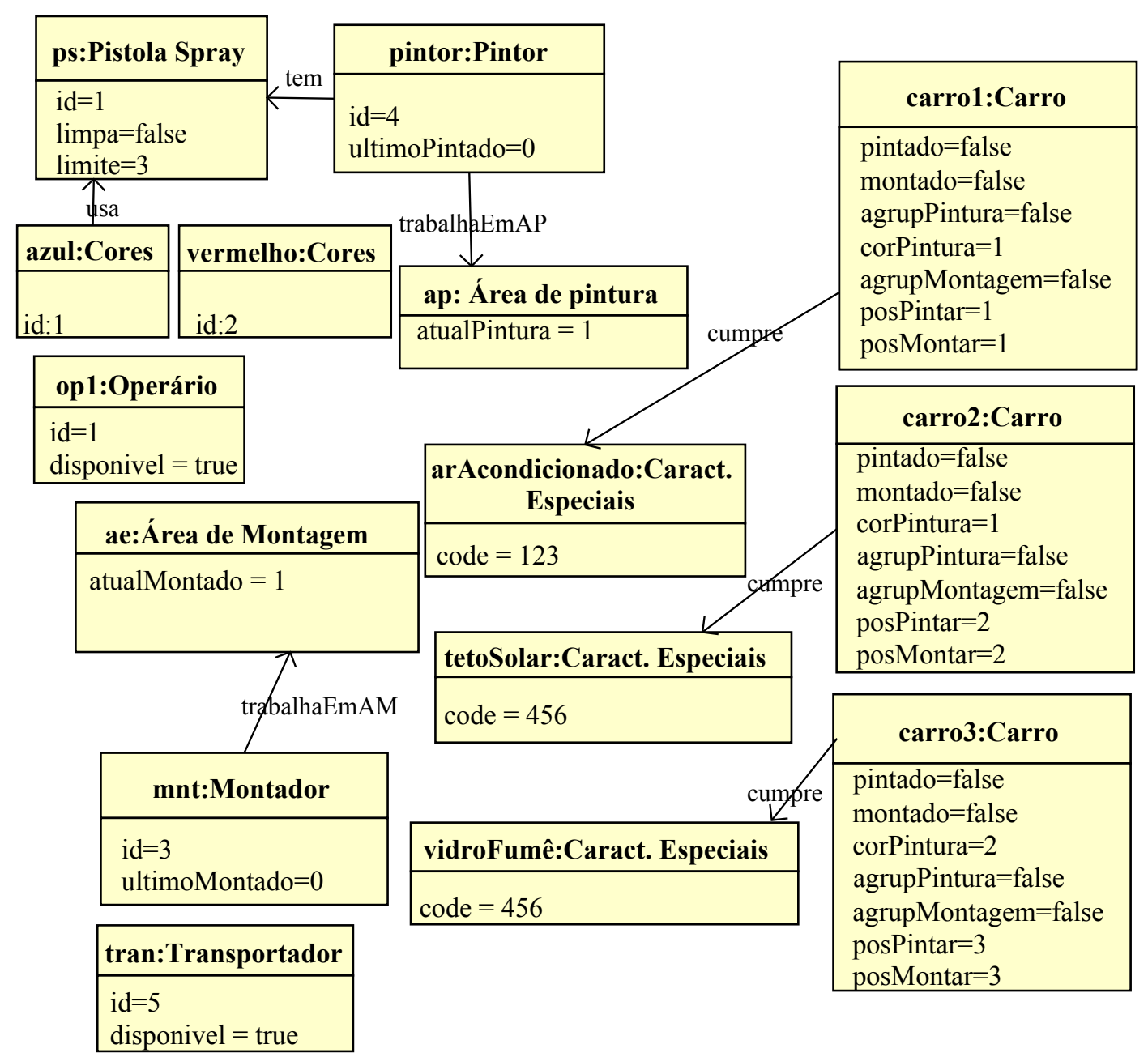

Figura 42 - Estado Inicial de um problema de planejamento no Montagem Seqüencial de Carros.

\begin{tabular}{|l|}
\hline \multicolumn{1}{|c|}{ carro1:Carro } \\
\hline pintado $=$ true \\
montado $=$ true \\
agrupPintura $=$ true \\
corPintura $=1$ \\
agrupMontagem $=$ true \\
posPintar $=1$ \\
posMontar $=1$ \\
\hline
\end{tabular}

\begin{tabular}{|l|}
\hline \multicolumn{1}{|c|}{ carro2:Carro } \\
\hline pintado=true \\
montado=true \\
agrupPintura $=$ true \\
corPintura $=1$ \\
agrupMontagem $=$ true \\
posPintar $=2$ \\
posMontar $=2$ \\
\hline
\end{tabular}

\begin{tabular}{|l|}
\hline \multicolumn{1}{|c|}{ carro3:Carro } \\
\hline pintado=true \\
montado=true \\
agrupPintura $=$ true \\
corPintura $=1$ \\
agrupMontagem $=$ true \\
posPintar $=3$ \\
posMontar $=3$ \\
\hline
\end{tabular}

Figura 43 - Estado Objetivo de um problema de planejamento no Montagem Seqüencial de Carros.

\subsubsection{Teste com planejador de um problema simples}

O problema foi testado usando o planejador Metric-FF proposto por (HOFFMANN, 2011) como parte da etapa Síntese do Plano Escalonador do processo de projeto seguido para problemas de planejamento resultando no seguinte plano: 


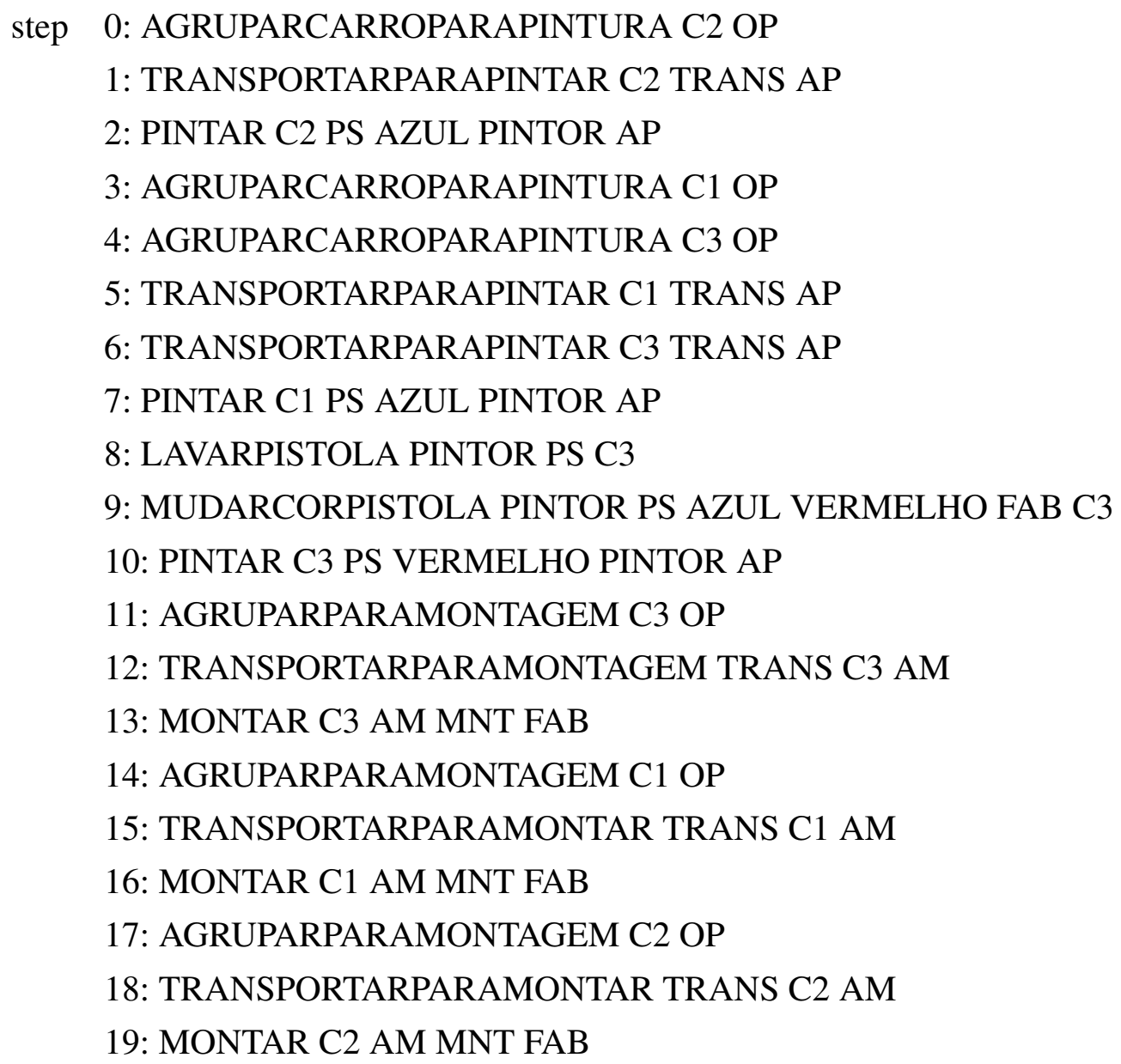

\subsubsection{Análise do Modelo do Domínio}

Para o estudo de caso de manufatura, a rede GHENeSys -resultante da tradução automáticapode ser consultada na Figura 44, estrutura base para a verificação de novos requisitos que possam ser inseridos. Antes dessa verificação, o framework proposto faz a análise das propriedades da rede para identificar possíveis estados o condições não deseixadas.

Entre outros, o resultado mais importante na hora de usar técnicas de análise do espaço de estados, é que a rede é livre de deadlock, ou seja, trata-se de uma rede de Petri viva em que garante-se que sempre exista alguma transição habilitada a ser disparada (ver Figura 45). 


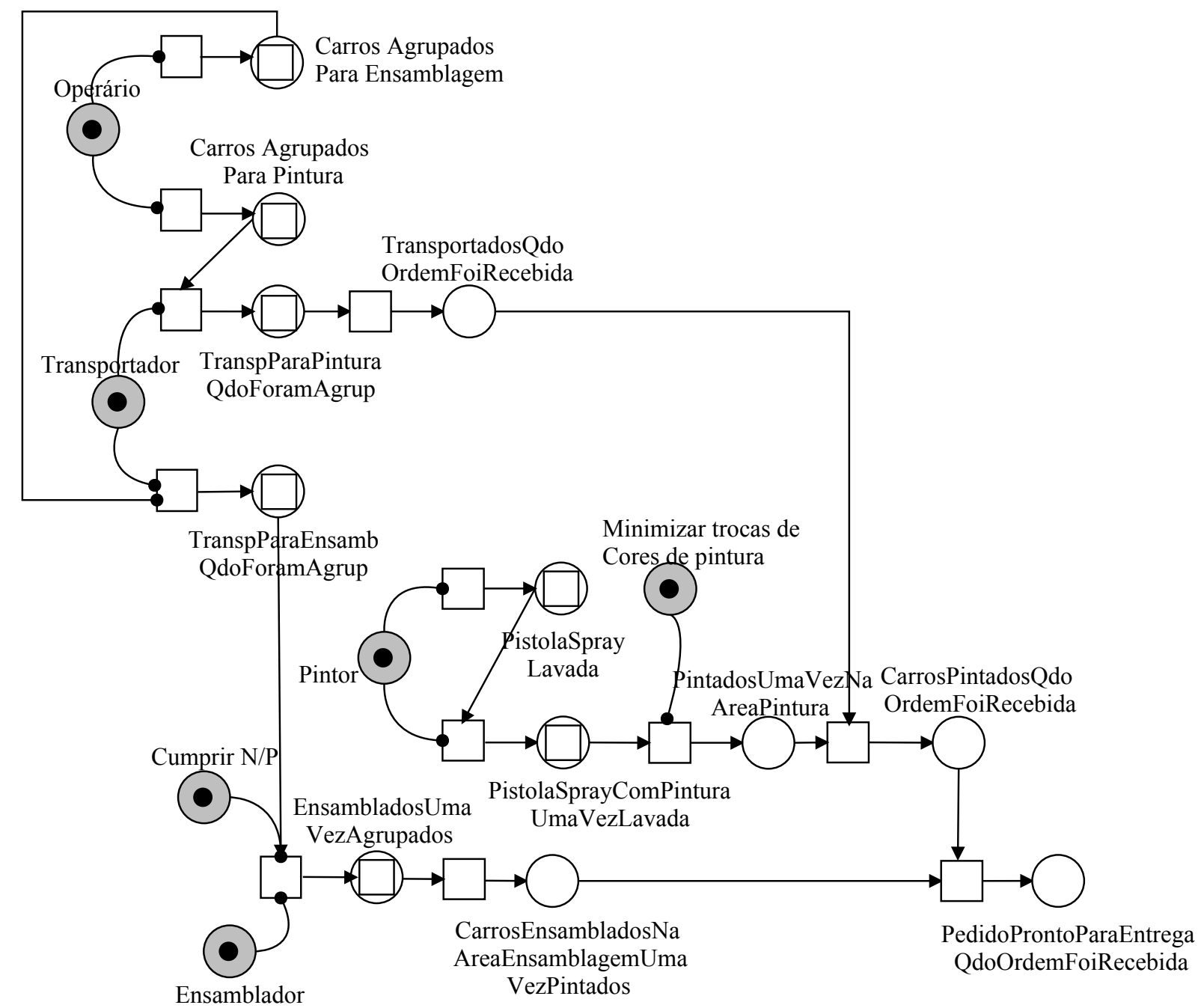

Figura 44 - Rede GHENeSys do problema de manufatura Montagem Seqüencial de Carros.

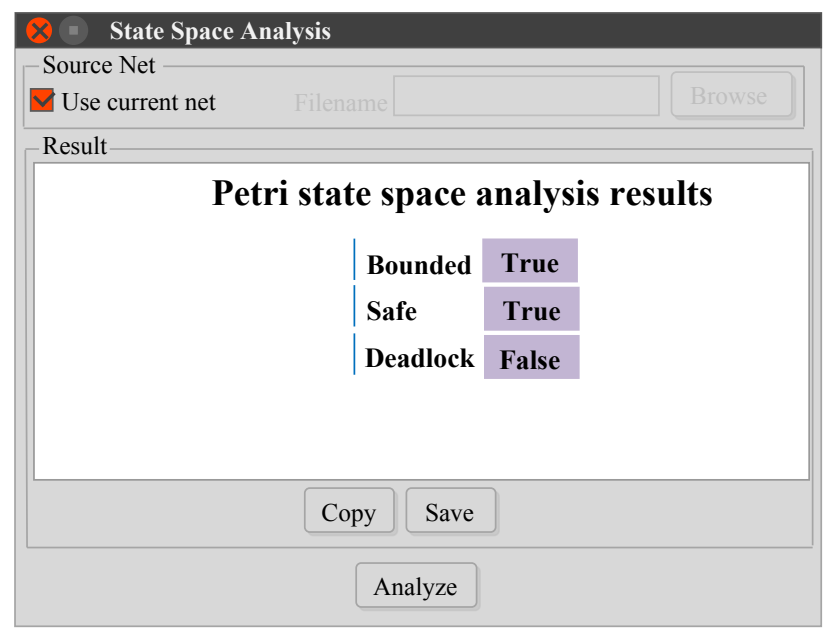

Figura 45 - Resultado de análise das propriedades da rede do domínio Montagem Seqüencial de Carros.

Já foi definido em capítulos anteriores os objetivos que expressam certo comportamentos em KAOS (objetos comportamentais), como sendo aquilos que capturam o conjunto maximal de 
comportamentos implícitos possíveis, e com operações e estados associados, expressados como uma sequência de transições em um sistema de transição - na presente proposta redes de Petri Lugar/Transição.

Para isso são usados macro-lugares, ajudando assim a preservar propriedades estruturais e de comportamento da rede global e modelar diversos níveis de abstração formando uma agregação de elementos reutilizáveis.

\subsubsection{Observações}

Com a modelagem e análise dos domínios Mundo dos Blocos e Montagem Seqüencial de Carros, foram detetadas algumas vantagens no ambiente proposto que argumentam a inserção de melhoras em trabalhos futuros. No domínio Mundos dos Blocos fica mais clara a intervenção dos agentes do domínio como responsáveis da realização das ações relacionadas com o atingimento dos objetivos. A resposta ao Quem? atinge o objetivo é introduzida como objecto em um predicado na sua correspondente instrução PDDL. Por exemplo, no predicado (asegurando ?b Bloco ?r-Robô ) a informação de quem asegura o bloco? pode ser relevante para os designers na hora de obter os planos. Caso não seja relevante, como a transferência em PDDL é feita de forma automática desde o diagrama Objetivo, poderia ser suprimida no diagrama de Objetivos para uma nova tradução a PDDL no novo ciclo do processo de projeto.

O processo de modelagem dos objetivos em KAOS fez com que definisse-se uma nova ação a ser executada pelo agente Pintor: Encher Pistola. Trata-se do caso em que deseja-se pintar $n$ carros de uma cor, mas a pistola de spray que é gerenciada pelo pintor só tem pintura para uma quantidade menor de carros.

A seguir é mostrado o plano resultante usando também o Metric-FF (HOFFMANN, 2011). O domínio testado é o mesmo representado no Apêndice 4, e o problema de entrada é caraterizado por contar com uma pistola de spray que só tem pintura para um carro e deseja-se pintar três carros da mesma cor (consultar Apêndice 6).

step 0: AGRUPARCARROPARAPINTURA C1 OP

1: AGRUPARCARROPARAPINTURA C2 OP

2: AGRUPARCARROPARAPINTURA C3 OP

3: ENCHERPISTOLA PINTOR PS AP

4: TRANSPORTARPARAPINTAR C1 TRANS AP

5: TRANSPORTARPARAPINTAR C2 TRANS AP

6: PINTAR C1 PS AZUL PINTOR AP

7: TRANSPORTARPARAPINTAR C3 TRANS AP

8: PINTAR C2 PS AZUL PINTOR AP

9: PINTAR C3 PS AZUL PINTOR AP 
O efeito uma vez executada a nova ação identificada, fara com que a pistola tenha pintura suficiente para pintar o resto dos carros que já foram agrupados na área de pintura.

Ao mesmo tempo, uma outra nova ação é relacionada como Encher pistola. Trata-se de AgruparCarroParaPintura, que uma vez executada antes de pintar, controla que a quantidade de pintura disponível seja suficiente para pintar os carros.

Por ultimo, em ambos estudos de casos foram usadas Propriedades do Domínio para declarar as regras ou restrições que limitam o atingimento de um objetivo. Embora não tenha incidência no resultado do problemas Mundo dos Blocos, foi declarada formando parte na documentação dos requisitos. Já no caso do problema de manufatura, as duas propriedades do domínio: Minimizar o numero de trocas das cores de pintura e Cumprir N/P são importantes na hora de definir em PDDL a função de otimização do problema de planejamento.

As necessidades geradas a partir dos estudos de caso para evolução do ReKPlan como ferramenta, serão apresentadas a seguir no próximo capítulo Conclusões e Trabalho Futuro. 


\section{5}

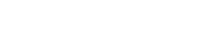

\section{CONCLUSÕES E TRABALHO FUTURO}

\subsection{Conclusões}

Neste trabalho, foi proposto um ambiente de design para a modelagem e análise dos requisitos durante as etapas inicias do ciclo de vida de projeto para problemas de planejamento que de fato engloba toda atividade básica na modelagem de conhecimento para este tipo de problema. Nesta proposta enquadrou-se um método formal bem atual e Orientado a Objetivos para modelar problemas na etapa de Engenharia de Requistos, e usou-se o formalismo das redes de Petri de Alto Nível para a análise deste modelo. Na verdade, a transferência para redes de Petri clássica permitiria por si só a inclusão da análise de propriedades como ausência de deadlocks, invariantes, etc. que ajudariam a verificar o modelo KAOS inicial. Porém, a proposta vai mais adiante propondo o uso de redes hierárquicas, contendo gates e elementos de transferência e representação de eventos observáveis e não controláveis: os pseudo-boxes.

\subsection{Considerações Finais}

Com os estudos de caso analisados, percebe-se como o uso de KAOS pode ser considerado um mecanismo promissor para a Engenharia de Requisitos em problemas de planejamentos. O próprio fato de tratar-se de uma metodologia do tipo GORE, avalia seu uso em comparação com o de outros mecanismos como a linguagem UML, ineficiente nas etapas inicias de um processo de projeto.

O KAOS como linguagem fornece ao designer de elementos com base formal em lógica LTL e representação gráfica para modelar os requisitos de um problema em termos de objetivos. Esses objetivos expressam as necessidades e viewpoints dos stakeholders em conflito ou não, porém eventualmente gerenciáveis.

Existe um mecanismo para obter o diagrama de Objetos que garante a completitude da 
vista estrutural do modelo de conhecimento, abarcando unicamente aqueles objetos necessários para o atingimento dos objetivos, sendo funcionais ou não-funcionais.

Esses objetos tem como ponto de partida uma representação formal, embora seja um quesito indispensável sua correta especificação sobre lógica temporal por parte dos engenheiros do conhecimento.

Outro aspecto importante da nova proposta é a possibilidade que oferece de inserir restrições temporais desde as primeiras etapas do processo, já não só como restrições das operações a serem realizadas, bem como na representação formal mesma do objetivo, por meio da quantificação dos operadores temporais "eventualmente" e "sempre". Essa possibilidade introduz a ideia de associar tempo às ações nas instruções PDDL correspondentes (Durative Actions).

A formalização temporal abre ainda uma possibilidade de introduzir obrigações de prova de propriedades lineares em mecanismos do tipo model-checking. Entretanto, neste trabalho preferiu-se concentrar os mecanismos de verificação em Redes de Petri e tratá-los junto com restrições de sincronismo, loops, etc. Mas esta é uma possibilidade de extensão do presente trabalho: incluir mecanismos de verificação direto em LTL.

Foi proposta uma disciplina de projeto para um novo sistema itSIMPLE onde as ações são expressas em termos de operações ligadas aos agentes, o que torna mais claro o que deve ser feito para o cumprimento dos objetivos. As operações não se circunscrevem a simples métodos declarados em uma classe, aliás, elas recebem objetos como entrada mudando seu conteúdo como saída ou gerando outros novos objetos.

Atualmente, as redes de Petri geradas a partir dos diagramas de Estados no itSIMPLE serão enriquecidas com o framework proposto sobre a base dos diagramas KAOS. O uso combinado de KAOS para a modelagem e as redes de Petri de Alto Nível para a análise deve ser feito separando o problema de planejamento com o domínio do ambiente - aspecto já intrínseco na metodologia KAOS - compreendendo de forma correta e coerente a dinâmica e estrutura do sistema todo.

\subsection{Contribuições}

A Engenharia do Conhecimento para sistemas inteligentes e planejamento combina métodos baseados em lógica com a manipulação de grande quantidade de dados. Assim, ambientes como o ReKPlan podem resultar de grande ajuda na modelagem do domínio de conhecimento para esses sistemas.

A presente proposta contribui ante a crescente perspectiva de usar o planejamento automático em problemas reais e complexos, como sendo uma solução flexíveis que incorpora métodos formais que descrevam conceitualmente os processos envolvidos. 
Definiu-se uma disciplina de projeto para a Engenharia de Requisitos, que aplicados em problemas de planejamento, incorpora o método KAOS como guia aos designers na elicitação e modelagem dos requisitos.

Foram desenvolvidos dois algoritmos de tradução: o primeiro que leva do Diagrama de Objetivos em KAOS para instruções PDDL considerando as restrições expressadas em forma de propriedades do domínio; um segundo algoritmo que leva o mesmo diagrama para GNML com as suas correspondentes estruturas topológicas de redes de Petri de Alto Nível GHENeSys. A tradução do modelo para PDDL, foi testada no planejador Metric-FF.

Foi proposta uma linguagem de transferência para o KAOS: o KML, que basicamente propõe uma estrutura XML para os elementos dos projetos exportados do ReKPlan.

O processo de mapeamento reflete como em todo caso, às ações dos planos resultantes são incorporados elementos KAOS, como por exemplo os agentes responsáveis da execução dessas ações.

O disciplina proposta é caraterizada por ser Model Driven Engineering: a partir de uma representação do domínio e problemas de planejamento expressado em KAOS, por um lado, é possível obter um modelo de redes de Petri; e por outro lado obter um modelo em PDDL do problema servindo como entrada aos planejadores incorporados no itSIMPLE.

Foram desenvolvidos dois estudos de caso: o primeiro, um problema simples que de forma didática com poucos elementos do domínio do conhecimento exemplifica as potencialidades da presente proposta; e o segundo: um problema de manufatura de complexidade intermediaria em que detetou-se algumas melhorias que deverão ser incorporadas em trabalhos futuros.

Entretanto, a contribuição mais importante deste trabalho é conceitual e está ligada ao processo ou disciplina de projeto proposta para ratificar a hipótese de que os problemas de planejamento e escalonamento ${ }^{1}$ devem passar por uma fase de Engenharia do Conhecimento, em primeiro lugar, e que esta Engenharia de Conhecimento tem como base a eliciação modelagem e análise de requisitos e do domínio de planejamento, dividido em problema de planejamento e domínio de trabalho (working domain).

Toda a abordagem é sistêmica, portanto o que queremos dizer com problema de planejamento na verdade é a definição genérica de um sistema capaz de realizar planos. Portanto não só estados definem este sistema mas também todas as ações que podem ser operacionalizadas por este sistema.

A escolha do KAOS privilegiou esta abordagem por um lado mas, por outro lado tornou menos visível a separação entre sistema de planejamento e domínio de trabalho (que pode ter

1 Embora todo o desenvolvimento feito neste trabalho repouse sobre os problemas de planejamento, desde o inicio, o objetivo é ter um processo de projeto único, que sirva também para escalonamento. Infelizmente, uma bolsa de doutorado direto antes concedida por cinco anos foi substancialmente reduzida para quatro e o tempo teve que ser dividido com atividades de sobrevivência. Mas manteve-se a preocupação de nunca inserir restrições que reduzissem o escopo do trabalho. 
também ações de sua própria iniciativa e controle que operam as restrições ao comportamento do sistema de planejamento).Entretanto, sendo a primeira vez que se usa uma abordagem goal oriented para este tipo de problema, não caberia propor mudanças ao método KAOS. Portanto outros aspectos mais pertinentes ao design de sistemas não puderam ser testados de fato.

Outro aspecto importante - também ligado ao design de sistemas - é a possibilidade de tratar os problemas de planejamento (escalonamento) usando a arquitetura de sistemas de sistemas. Nesse caso, vale notar que o próprio sistema proposto, o RekPlan é um destes sistemas completos que pode vir a integrar o itSIMPLE, ou outro ambiente do D-Lab, como pode funcionar stand-alone, como foi feito nos estudos de caso mostrados. Foi usado ainda em outros contextos, como no design de sistemas de manufatura (MARTINEZ; SILVA, 2015b)(SILVA; NOF, 2015); na modelagem de uma cadeia de suprimentos de produtos no domínio do agronegócio usando tecnologia RFID (CANDIDO; MARTINEZ; SILVA, 2015), e para o diagnóstico de falhas (MELANI et al., 2016). O mesmo se aplica à abordagem que é inerente ao ReKPlan.

\subsection{Trabalhos Futuros}

Nesta seção aborda-se as perspectivas futuras potencializando assim o trabalho apresentado.

Implementar os dois algoritmos de tradução propostos, em conjunto com o módulo de objetos que são gerados a partir das instruções em lógica LTL, que no momento é feito de forma manual.

A validação o ReKPlan no que se refere a problemas com restrições temporais, já seja o tempo como restrição que deve ser cumprida ou simplesmente como características que devem cumprir as ações envolvidas.

A nova linguagem de transferência proposta KML devera ser validada exportando os modelos de domínios para outras ferramentas como o ObjetivER (RESPECT, 2007).

Detectou-se que o processo de tradução das restrições dos problemas expressas em Propriedades do Domínio deve ser melhorado sobretudo, quando ações forem acrescentadas como predicados associadas a ações PDDL, contemplando assim o pós-design.

Embora a PDDL seja mundialmente aceita como a linguagem formal de especificação de problemas de planejamento, existem outros avanços como a proposta do RDDL (Relational Dynamic Influence Diagram Language), abordagem enquadra-se melhor na modelagem de problemas mais complexos. Seria portanto um desafio interessante usar a flexibilidade do RekPlan para criar um caminho que termine na RDDL. O mesmo se aplica de forma ainda mais simplificada se o problema é recuperar o trabalho já feito usando hierarquia e o HTN (Hierarchical Task Network) como linguagem de entrada para os planejadores, que então poderia se comparado com o uso das redes de Petri Hierárquicas. Mais informações sobre isso pode ser 
encontrada na tese de doutorado de Rosi Basbaum (BASBAUM, 2015) e em um trabalho recente enviado para o Engineering Appliations of Artificial Intelligence Journal. 



\section{REFERÊNCIAS}

ALRAJEH, D.; KRAMER, J.; LAMSWEERDE, A. V.; RUSSO, A.; UCHITEL, S. Generating Obstacle Conditions for Requirements Completeness. Proceedings of the 34th International Conference on Software Engineering, p. 705-715, 2012. Citado na página 47.

BAIER, C.; KATOEN, J.-P.; LARSEN, K. G. Principles of Model Checking. [S.1.]: MIT press, 2008. Citado 2 vezes nas páginas 45 e 50.

BARREIRO, J.; BOYCE, M.; DO, M.; FRANK, J.; IATAURO, M.; KICHKAYLO, T.; MORRIS, P.; ONG, J.; REMOLINA, E.; SMITH, T. EUROPA: A Platform for AI Planning, Scheduling, Constraint Programming, and Optimization. 4th International Competition on Knowledge Engineering for Planning and Scheduling (ICKEPS), 2012. Citado na página 38.

BART'K, R.; JASKA, M.; NOV'K, L.; ROVENSKY, V.; SKALICKY, T.; CULLY, M.; SHEAHAN, C.; THANH-TUNG, D. Workflow Optimization with FlowOpt: On Modelling, Optimizing, Visualizing, and Analysing Production Workflows. 2011 International Conference on Technologies and Applications of Artificial Intelligence, IEEE, p. 167-172, 2011. Citado na página 38.

BASBAUM, R. Modelagem Hierárquica e Análise de Requisitos de Problemas Reais em Planejamento Automático. Tese (Doutorado) - Escola Politecnica, Universidade de São Paulo, 2015. Citado 7 vezes nas páginas 16, 30, 73, 83, 84, 85 e 101.

BASBAUM, R.; MARTINEZ, J.; REINALDO, J. Using Hierarchical Models for Requirement Analysis of Real World Problems in Automated Planning. Proceedings in the 26th International Conference on Automated Planning and Scheduling, ICAPS, Londres, p. 101-108, 2016. Citado na página 83.

BASBAUM, R.; VAQUERO, T.; SILVA, J. R. Requirement analysis method for real world in automated planning systems. Proceedings of KEPS Workshop, ICAPS Conference, 2013. Citado na página 28.

BIDER, I.; JOHANNESSON, P.; NURCAN, S.; ETIEN, A.; KAABI, R.; ZOUKAR, I.; ROLLAND, C. A strategy driven business process modelling approach. Business Process Management Journal, Emerald Group Publishing Limited, v. 11, n. 6, p. 628-649, 2005. Citado na página 49.

BUEDE, D. M.; MILlER, W. D. The Engineering Design of Systems: Models and Methods. [S.1.]: Wiley, 2016. (Wiley Series in Systems Engineering and Management). ISBN 9781119028062. Citado 4 vezes nas páginas 15, 28, 29 e 40.

CAILLIAU, A.; LAMSWEERDE, A. V. Assessing requirements-related risks through probabilistic goals and obstacles. Requirements Engineering, Springer, v. 18, n. 2, p. 129-146, 2013. Citado 2 vezes nas páginas 45 e 71 .

CANDIDO, R.; MARTINEZ, J.; SILVA, J. R. Using RFID technology to enhance quality information to products in agribusiness supply chain. p. 1-5, 2015. Citado na página 100. 
CHUNG, L.; NIXON, B.; YU, E.; MYLOPOULOS, J. Non-functional Requirements in Software Engineering. [S.1.]: Springer Science \& Business Media, 2012. v. 5. Citado na página 49.

CIARDO., G.; KINDLER, E. Application and Theory of Petri Nets and Concurrency: 35th International Conference, PETRI NETS 2014, Tunis, Tunisia, June 23-27, 2014, Proceedings. [S.1.]: Springer Berlin Heidelberg, 2013. (Lecture Notes in Computer Science). ISBN 9783319077345. Citado na página 51.

CRETU, L.; DUMITRIU, F. Model-Driven Engineering of Information Systems: Principles, Techniques, and Practice. [S.1.]: CRC Press, 2014. Citado na página 32.

DARIMONT, R.; LAMSWEERDE, A. V. Formal Refinement Patterns for Goal-Driven Requirements Elaboration. ACM SIGSOFT Software Engineering Notes, ACM, v. 21, n. 6, p. 179-190, 1996. Citado na página 85.

DENARO, G.; PEZZE, M. Petri nets and software engineering. In: Lectures on Concurrency and Petri Nets. [S.1.]: Springer, 2004. p. 439-466. Citado na página 51.

DIAZ, M. Petri nets: Fundamental Models, Verification and Applications. [S.1.]: John Wiley \& Sons, 2013. Citado na página 51.

DROSTE, M.; SHORTT, R. M. From Petri Nets to Automata with Concurrency. Applied Categorical Structures, Springer, v. 10, n. 2, p. 173-191, 2002. Citado na página 51.

FOYO, P. M. del. Ghenesys: Uma Rede Estendida Orientada a Objetos para Projeto de Sistemas Discretos. Dissertação (Mestrado) - University of São Paulo, 2001. Citado na página 56.

FOYO, P. M. G. del. Verificação Formal de Sistemas Discretos Distribuídos. Tese (Doutorado) — Escola Politécnica, Universidade de São Paulo, 2009. Citado na página 30.

GENRICH, H.; LAUTENBACH, K. The analysis of distributed systems by means of predicate/transition-nets. In: Semantics of Concurrent Computation. [S.1.]: Springer, 1979. p. 123-146. Citado na página 55.

GHALLAB, M.; NAU, D.; TRAVERSO, P. Automated planning: theory \& practice. [S.1.]: Elsevier, 2004. Citado 4 vezes nas páginas 15, 30, 35 e 36.

GONZÁLEZ, A.; FERNÁNDEZ, J.; CASTILLO, L. JABBAH: A Java Application Framework for the Translation between Business Process Models and HTN. The 3rd International Competition on Knowledge Engineering for Planning and Scheduling (ICKEPS'09), 2009. Citado na página 38.

GRIGOREV, S.; KIRILENKO, I. GLR-based Abstract Parsing. Proceedings of the 9th Central \& Eastern European Software Engineering Conference, Russia, 2013. Citado na página 49.

HARPER, R. Programming in Standard ML-Draft: Version 1.2. [S.1.], 2011. Citado na página 55.

HASTIE, S.; WOJEWODA, S. Standish group 2015 chaos report with jennifer lynch. Retrieved, v. 1, n. 15, 2015. Citado na página 28. 
HICKMOTT, S.; RINTANEN, J.; THIEBAUX, S.; WHITE, L. Planning via Petri Net Unfolding. IJCAI, v. 7, p. 1904-1911, 2007. Citado na página 66.

HOFFMANN, J. The metric-ff planning system: Translating"ignoring delete lists"to numeric state variables. arXiv preprint arXiv:1106.5271, 2011. Citado 3 vezes nas páginas 80, 92 e 95.

HORKOFF, J.; YU, E. Comparison and evaluation of goal-oriented satisfaction analysis techniques. Requirements Engineering, Springer, v. 18, n. 3, p. 199-222, 2013. Citado na página 39.

IRWIN, G.; TURK, D. An ontological analysis of use case modeling grammar. Journal of the Association for Information Systems, v. 6, n. 1, p. 2, 2005. Citado na página 66.

JENSEN, K. Coloured petri nets and the invariant-method. Theoretical computer science, Elsevier, v. 14, n. 3, p. 317-336, 1981. Citado na página 55.

An introduction to the theoretical aspects of coloured Petri nets. Workshop/School/Symposium of the REX Project (Research and Education in Concurrent Systems), Springer, p. 230-272, 1993. Citado na página 55.

Coloured Petri Nets: Basic Concepts, Analysis Methods and Practical Use. [S.1.]: Springer Berlin Heidelberg, 2013. (Monographs in Theoretical Computer Science. An EATCS Series, v. 1). ISBN 9783662032411. Citado na página 54.

JENSEN, K.; KRISTENSEN, L. M.; WELLS, L. Coloured Petri Nets and CPN Tools for modelling and validation of concurrent systems. International journal on Software Tools for Technology Transfer, Springer, v. 9, n. 3-4, p. 213-254, 2007. Citado 3 vezes nas páginas 15, 55 e 56.

JENSEN, K.; ROZENBERG, G. High-level Petri Nets: Theory and Application. [S.1.]: Springer Science \& Business Media, 2012. Citado na página 51.

KENDAL, S. L.; CREEN, M. An Introduction to Knowledge Engineering. [S.1.]: Springer, 2007. Citado na página 30.

KRÖGER, F.; MERZ, S. Temporal Logic and State Systems. [S.1.]: Springer Berlin Heidelberg, 2008. ISBN 9783540674016. Citado na página 45.

LAMSWEERDE, A. V. Goal-oriented requirements engineering: From system objectives to uml models to precise software specifications. Proceedings of the 25th International Conference on Software Engineering, IEEE Computer Society, p. 744-745, 2003. Citado na página 39.

Elaborating security requirements by construction of intentional anti-models. Proceedings of the 26th International Conference on Software Engineering, IEEE Computer Society, p. 148-157, 2004. Citado 2 vezes nas páginas 71 e 85.

Requirements Engineering: From System Goals to Models to Software Specifications. [S.1.]: Wiley, 2009. ISBN 9780470012703. Citado 5 vezes nas páginas 15, 30, 40, 41 e 44 .

Risk-driven engineering of requirements for dependable systems. Engineering Dependable Software Systems, v. 34, n. 2, p. 207, 2013. Citado na página 45. 
LAPLANTE, P. A. Requirements Engineering for Software and Systems. [S.1.]: CRC Press, 2013. Citado 3 vezes nas páginas 15, 39 e 40.

LAPOUCHNIAN, A. Goal-oriented requirements engineering: An overview of the current research. University of Toronto, 2005. Citado na página 40.

LEITE, J. C. S. do P.; WERNECK, V.; OLIVEIRA, A. d. P. A.; CAPPELLI, C.; CERQUEIRA, A. L. A.; CUNHA, H. de S.; GONZALEZ-BAIXAULI, B. Understanding the strategic actor diagram: an exercise of meta modeling. In: WER. [S.1.: s.n.], 2007. p. 2-12. Citado na página 42.

MARTINEZ, J. Using GORE method for Requirement Engineering of Planning \& Scheduling. Proceedings in the 26th International Conference on Automated Planning and Scheduling, ICAPS. Londres, p. 137-140, 2016. Citado na página 50.

MARTINEZ, J.; SILVA, J. R. Combining KAOS and GHENeSys in the requirement and analysis of service manufacturing. IFAC Proceedings Volumes (IFAC-PapersOnline), v. 48, n. 3, p. 1634-1639, 2015. ISSN 14746670. Citado na página 71.

Using Oriented Requirements Analysis in the Design of Product-Service Artifacts. Simpósio Brasileiro de Automação Inteligente, Natal, 2015. Citado 2 vezes nas páginas 83 e 100 .

MCCLUSKEY, L.; PORTEOUS, J. M. Two Complementary Techniques in Knowledge Compilation for Planning. Proceedings in The 3rd International Workshop on Knowledge Compilation and Speedup Learning, 1993. Citado na página 37.

. Knowledge Engineering: Issues for the AI Planning Community. Proceedings of the AIPS-2002 Workshop on Knowledge Engineering Tools and Techniques for AI Planning, Toulouse. France, 2002. Citado na página 37.

MELANI, A.; MARTINEZ, J.; SOUZA, G. F. M.; SILVA, J. R. Fault diagnosis based on Petri Nets: the case study of a hydropower plant. Proceedings in 12th IFAC Workshop on Intelligent Manufacturing Systems. (IMS 2016), Austin, United States. December 5-7, 2016, 2016. Citado na página 100.

MIRALLES, J. A. S. P. GHENeSys, uma rede unificada e de alto nível. Tese (Doutorado) Universidade de São Paulo, 2012. Citado 7 vezes nas páginas 15, 23, 32, 49, 57, 64 e 68.

MIYAMOTO, T.; KUMAGAI, S. A survey of object-oriented Petri nets and analysis methods. IEICE transactions on fundamentals of electronics, communications and computer sciences, The Institute of Electronics, Information and Communication Engineers, v. 88, n. 11, p. 2964-2971, 2005. Citado na página 54.

MURATA, T. Petri nets: Properties, analysis and applications. Proceedings of the IEEE, IEEE, v. 77, n. 4, p. 541-580, 1989. Citado 2 vezes nas páginas 51 e 52.

MYERS, K. L.; WILKINS, D. E. The act formalism. Artificial Intelligence Center, 1997. Citado na página 37.

NAJM, E.; PRADAT-PEYRE, J.-F.; DONZEAU-GOUGE, V. V. Formal Techniques for Networked and Distributed Systems-FORTE 2006: 26th IFIP WG 6.1 International Conference, Paris, France, September 26-29, 2006, Proceedings. [S.1.]: Elsevier, 2006. v. 4229. Citado na página 68. 
NAU, D. S.; AU, T.-C.; ILGHAMI, O.; KUTER, U.; MURDOCK, J. W.; WU, D.; YAMAN, F. SHOP2: An HTN planning system. Journal of Artificial Intelligence Research (JAIR), v. 8249, p. 251-262, 2013. Citado na página 30.

NGUYEN, A. Challenge roadef 2005: Car sequencing problem. Online reference at http://challenge.roadef.org/2005/files/suite_industrielle_2005.pdf, last visited on August of 2016, v. 23, 2005. Citado 3 vezes nas páginas 65, 75 e 82.

NUSEIBEH, B.; EASTERBROOK, S. Requirements Engineering: A Roadmap. Proceedings of Conference on the Future of Software Engineering, ACM, p. 35-46, 2000. Citado na página 39.

OLIVEIRA, A.; LEITE, J. C.; CYSNEIROS, L. M.; SAMPAIO, J. C.; LAGES, E. M.; LUCENA, C. J. Integrating Scenarios, I*, and Aspect in the Context of Multi-Agent Systems. Proceedings of the $\mathbf{2 0 0 6}$ conference of the Center for Advanced Studies on Collaborative research, p. 16, 2006. Citado na página 43.

OMG. Unified Modelling Languages - 2.4.1. [S.1.], 2011. Disponível em: <http://www.omg. org/spec/UML/2.4.1/Infrastructure/PDF/>. Citado na página 38.

PETRI, C. A. Kommunikation mit Automaten. Tese (Doutorado) - Universität Hamburg, 1962. Citado na página 51.

PONSARDE, C.; DARIMONT, R.; MICHOT, A. Combining models, diagrams and tables for efficient requirements engineering: Lessons learned from the industry. In: INFORSID. [S.1.], 2015. Citado na página 44.

POTTS, C.; TAKAHASHI, K.; ANTÓN, A. I. Inquiry-based requirements analysis. IEEE software, IEEE Computer Society, v. 11, n. 2, p. 21, 1994. Citado na página 49.

REISIG, W. Petri Nets: An Introduction. [S.1.]: Springer Berlin Heidelberg, 2012. (Monographs in Theoretical Computer Science. An EATCS Series). ISBN 9783642699689. Citado na página 54.

RESPECT, I. A KAOS Tutorial. Objectiver, 2007. Disponível em: <http://www.objectiver.com/ fileadmin/download/documents/KaosTutorial.pdf>. Acesso em: 05/03/2016. Citado 2 vezes nas páginas 44 e 100.

RUSSELL, S.; NORVIG, P. Artificial Intelligence: A Modern Approach. 2010. (Prentice Hall Series in Artifi). ISBN 9780136042594. Disponível em: <https://books.google.com.br/books? id=8jZBksh-bUMC $>$. Citado na página 41 .

SALMON, A. O.; FOYO, P. M. del; SILVA, J. R. Scheduling Real-Time Systems with Periodic Tasks Using a Model-checking Approach. IEEE-INDIN, IEEE, 2014. Citado na página 59.

SETTE, F.; VAQUERO, T.; PARK, S. W.; SILVA, J. R. Are automated planners up to solve real problems? IFAC Proceedings Volumes, v. 41, n. 2, p. 15817-15824, 2008. Citado na página 27.

SIAU, K.; LEE, L. Are use case and class diagrams complementary in requirements analysis? an experimental study on use case and class diagrams in uml. Requirements Engineering, Springer, v. 9, n. 4, p. 229-237, 2004. Citado na página 66. 
SILVA, J. R.; MIYAGI, P. E. Pfs/mfg: A high level net for the modeling of discrete manufacturing systems. In: Balanced Automation Systems. [S.1.]: Springer, 1995. p. 349-362. Citado na página 56.

A Formal Approach to PFS/MFG: A Petri Net Representation of Discrete Manufacturing Systems, to appear in Studies in Informatic and Control. [S.1.]: IT Press, 1996. Citado na página 56.

SILVA, J. R.; NOF, S. Manufacturing service: From e-work and service-oriented approach towards a product-service architecture. INCOM Congress, 2015. Citado na página 100.

SILVA, M. Half a century after Carl Adam Petri's Ph. D. thesis: A perspective on the field. Annual reviews in control, Elsevier, v. 37, n. 2, p. 191-219, 2013. Citado 2 vezes nas páginas 51 e 68.

SIMPSON, R. M. Structural Domain Definition Using GIPO IV. Proceedings of the Second International Competition on Knowledge Engineering for Planning and Scheduling, 2007. Citado na página 37.

SIMPSON, R. M.; MCCLUSKEY, L.; ZHAO, W.; AYLETT, R.; DONIAT, C. GIPO: An Integrated Graphical Tool to Support Knowledge Engineering in AI planning. Proceedings in Sixth European Conference on Planning, p. 12-25, 2014. Citado na página 37.

SMITH, E. E.; KORSMEYER, D. J. Intelligent Systems Technologies for Ops. Proceedings in 12th International Conference on Space Operations, 2012. Citado na página 38.

STANDISH GROUP. Chaos manifesto. [S.1.], 2015. Citado 2 vezes nas páginas 15 e 28.

TATE, A.; DALTON, J. O-Plan: A Common Lisp planning web service. Proceedings of the International Lisp Conference 2003, p. 12-25, 2003. Citado na página 37.

VAQUERO, T. Post-Design Analysis for AI Planning Applications. Tese (Doutorado) - Ph. D. Dissertation, Polytechnic School of the University of Sao Paulo, Brazil, 2011. Citado 6 vezes nas páginas 15, 16, 41, 42, 66 e 67.

VAQUERO, T.; BASBAUM, R.; COSTA, G.; TONIDANDEL, F.; SILVA, J. R.; BECK, C. itsimple4. 0: Enhancing the modeling experience of planning problems. Proceedings of ICAPS 2012 System Demonstration, p. 11-14, 2012. Citado 4 vezes nas páginas 30, 66, 67 e 80.

VAQUERO, T.; ROMERO, V.; TONIDANDEL, F.; SILVA, J. R. itSIMPLE 2.0: An Integrated Tool for Designing Planning Domains. Proceedings in International Competition on Knowledge Engineering for Planning and Scheduling, ICAPS, 2007. Citado na página 37.

VAQUERO, T.; SILVA, J. R.; BECK, C. Post-design analysis for building and refining ai planning systems. Engineering Applications of Artificial Intelligence, v. 26, n. 8, p. 1967-1979, 2013. Citado 4 vezes nas páginas 27, 36, 37 e 41.

VAQUERO, T.; SILVA, J. R.; FERREIRA, M.; TONIDANDEL, F.; BECK, C. From Requirements and Analysis to PDDL in itSIMPLE3.0. Proceedings of the Third International Competition on Knowledge Engineering for Planning and Scheduling, ICAPS, p. 54-61, 2009. Citado 2 vezes nas páginas 38 e 65.

VAQUERO, T.; SILVA, J. R. S.; BECK, C. A brief review of tools and methods for knowledge engineering for planning \& scheduling. KEPS, p. 7, 2011. Citado na página 27. 
VAQUERO, T.; TONIDANDEL, F.; NUNES, L. de B.; SILVA, J. R. On the Use of UML.p for Modeling a Real Application as a Planning Problem. ICAPS, p. 434-437, 2006. Citado 2 vezes nas páginas 15 e 36 .

VODRÁZKA, J.; CHRPA, L. Visual Design of Planning Domains. Proceedings of ICAPS 2010 workshop on Scheduling and Knowledge Engineering for Planning and Scheduling (KEPS), p. 68-69, 2010. Citado na página 38.

WERNECK, V. M.; OLIVEIRA, A.; LEITE, J. C. Comparing GORE Frameworks: I-star and KAOS. WER, 2009. Citado 2 vezes nas páginas 39 e 49.

YU, E. Modelling Strategic Relationships for Process Reengineering. Tese (Doutorado) University of Toronto, 1996. UMI Order No. GAXNN-02887 (Canadian dissertation). Citado na página 42.

YU, E. Modelling strategic relationships for process re-engineering. Social Modeling for Requirements Engineering, MIT Press, v. 11, 2011. Citado 3 vezes nas páginas 15, 40 e 43. 

APPENDIX

A

\section{KML: EXTENSIBLE MARKUP LANGUAGE \\ FOR KAOS}

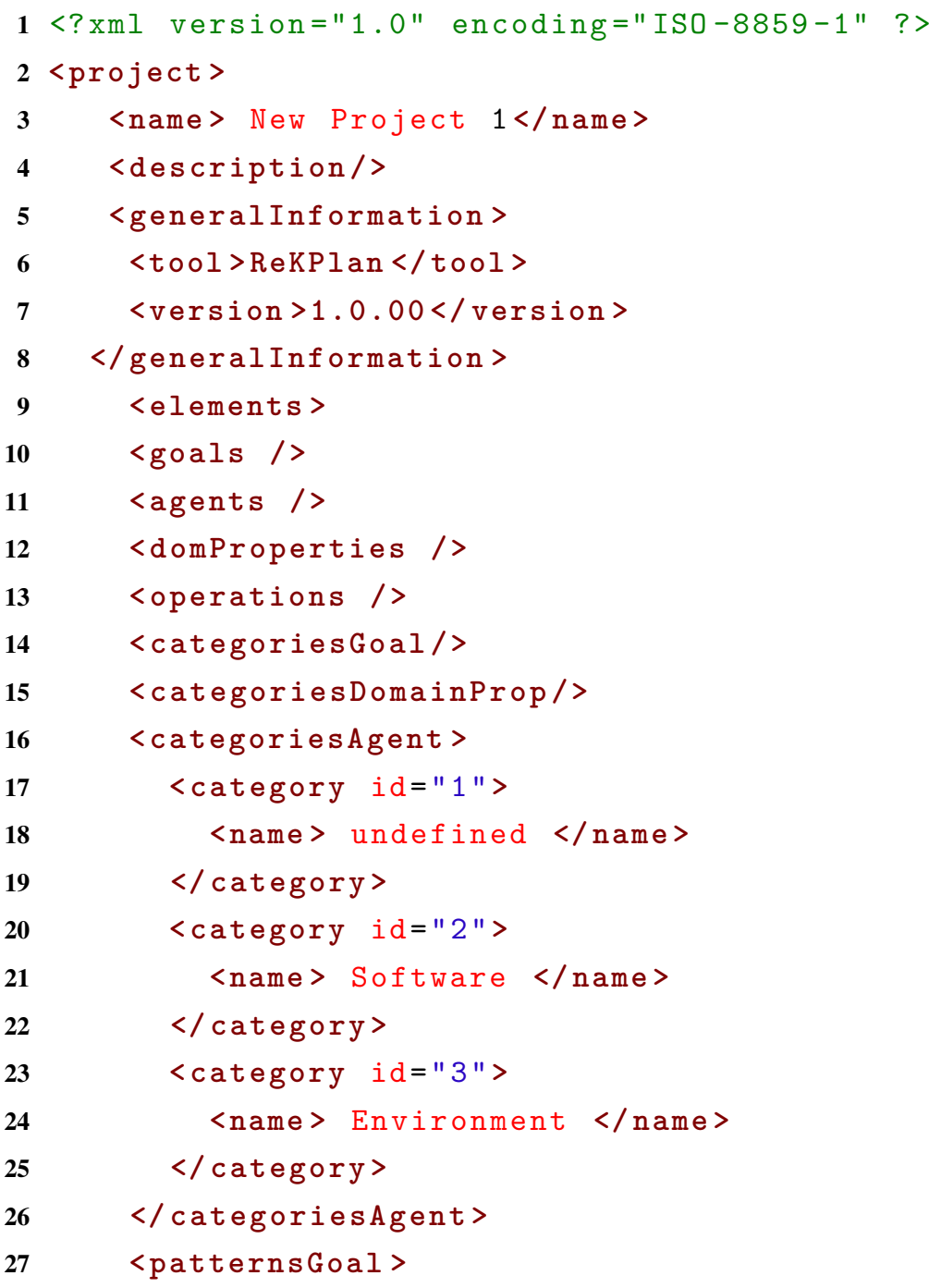




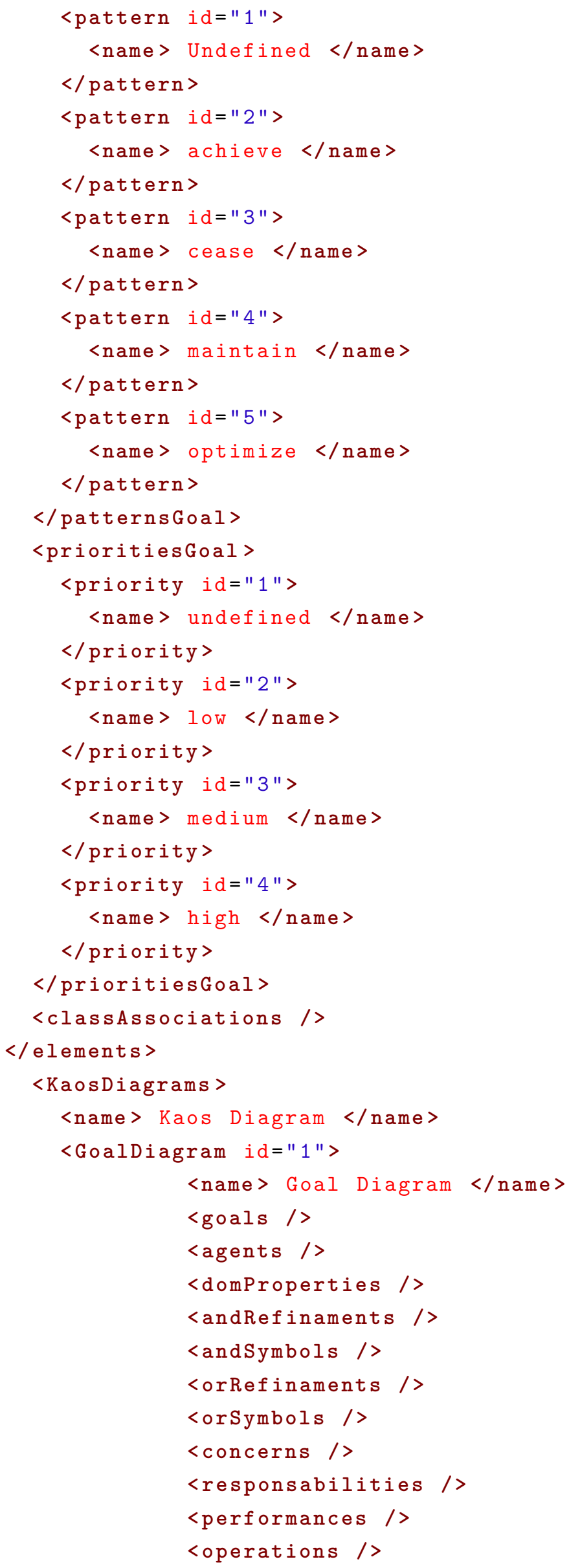


$75</$ GoalDiagram $>$

$76</$ KaosDiagrams >

$77\langle/$ project $>$ 

APPENDIX

B

\section{MODELOS DE DOMÍNIOS EM PDDL}

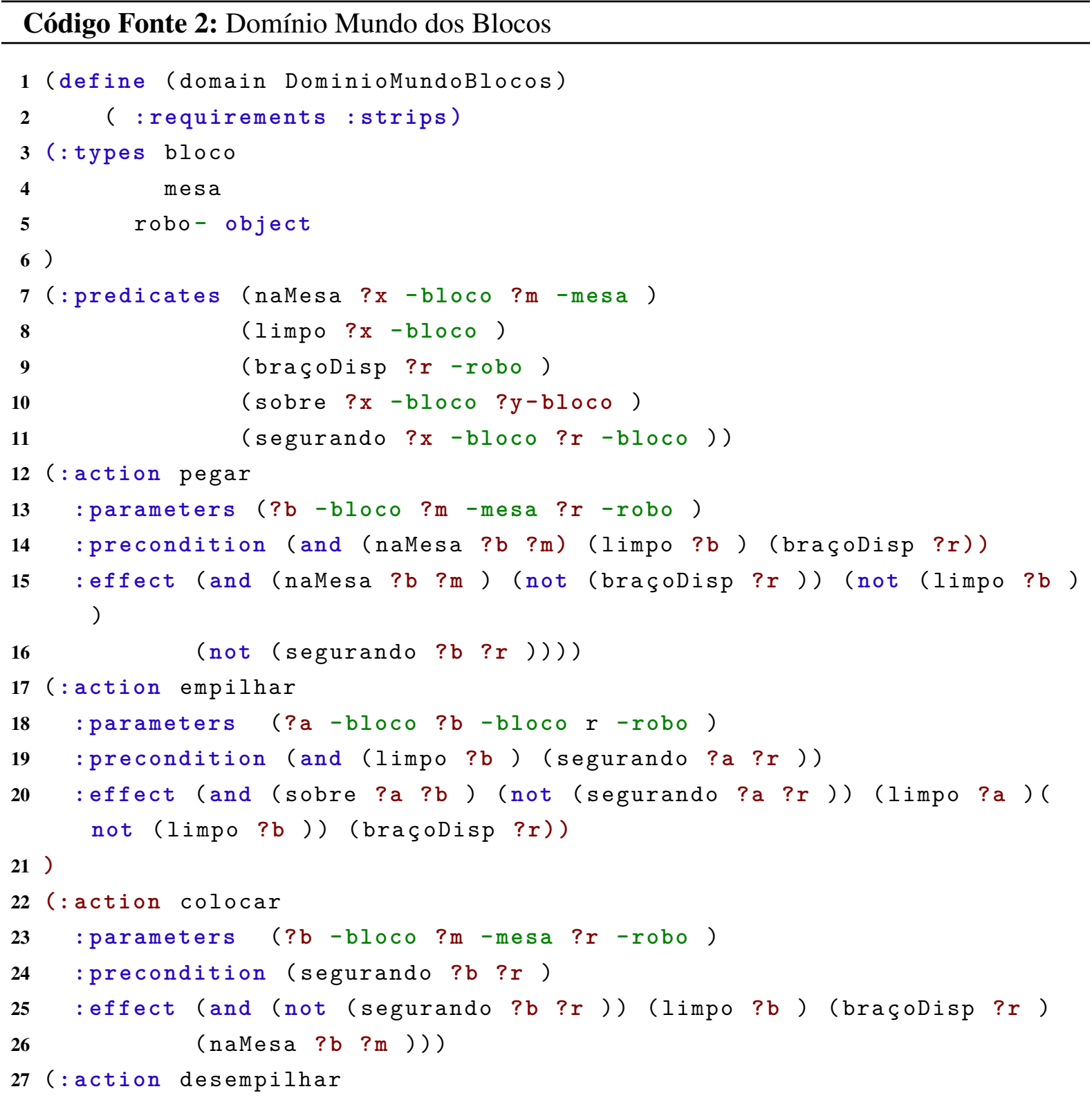




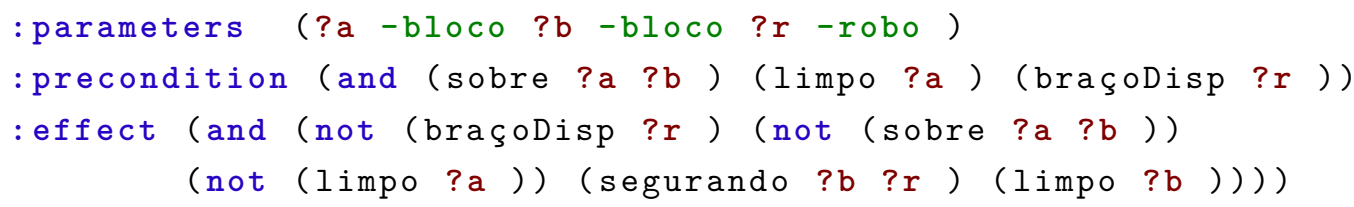

\section{Código Fonte 3: Problema Mundo dos Blocos}

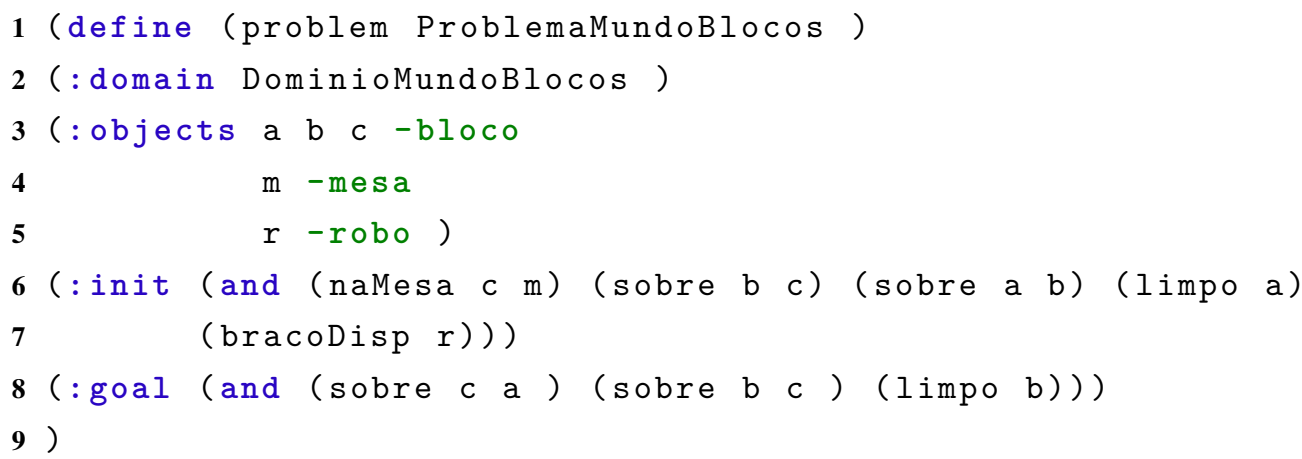

\section{Código Fonte 4: Domínio Montagem Seqüencial de Carros}

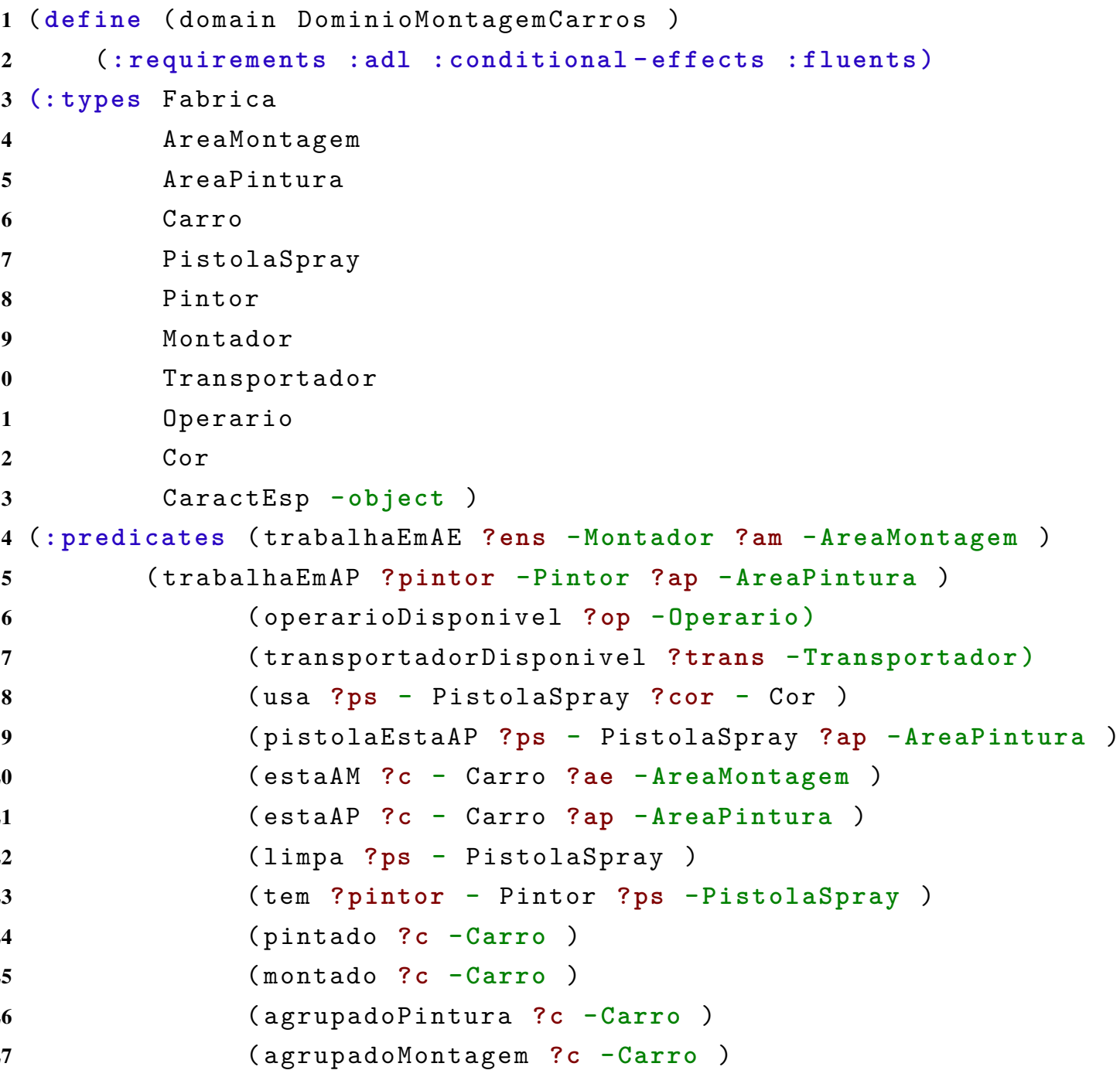


28

29

30

31 )

32

33

34

35

36

37

38

39

40

41

42

43

44

45

46

47

48

49 )

50

51

52

53

54

55

56

57

58

59

60

61

$62)$

64

65

66

67

68

69

70

71

72

73

74 (cumpre ?c - Carro ?caractEsp -CaractEsp )

(corpintura ?c - Carro ?cor - Cor )

(disponivel ?caractEsp -CaractEsp ?ae -AreaEnsamblagem )

(: functions (qcarrospintados )

(pospintar ?c-Carro ) ; Ordem na entrada na Area de Pintura

(atualPintura ?ap -AreaPintura ) ; Ultima posicao do carro que será pintado

(posmontar ?c -Carro)

(atualMontado ?am - AreaMontagem ) ; Ultima posicao

do carro que será montado,

(ultimoMontado ?mnt -Montador )

(ultimopintado ?pintor - Pintor )

(limitePinturaPistola)

( qcarrosAgrupadosPintura )

(quantCarEsp ?am -AreaMontagem ?caractEsp -CaractEsp)

(nroviolacoes ?fabrica -Fabrica )

(nroMudancaPintura ?fabrica -Fabrica )

(n ? carEsp - CaractEsp)

( p ? carEsp - CaractEsp)

( : action agruparCarroparaPintura

:parameters (?c -Carro ?operario -Operario)

: precondition

(and (not (pintado ?c) )

(not (montado ?c) )

$(=$ (pospintar ?c ) 0$)$

(operariodisponivel ?operario )

)

: effect

( and (agrupadopintura ?c )

(increase (qcarrosAgrupadosPintura ) 1)

)

( : action transportarParaPintar

:parameters (?c -Carro ?trans - Transportador

?ap - Areapintura )

(and (< (atualPintura ?ap ) (limitepinturaPistola )) (agrupadoPintura ?c )

(transportadorDisponivel ?trans )

(not (pintado ?c ))

(not (estaAP ?c ?ap))

)

: effect

(and (assign (pospintar ?c ) (atualpintura ?ap )) 


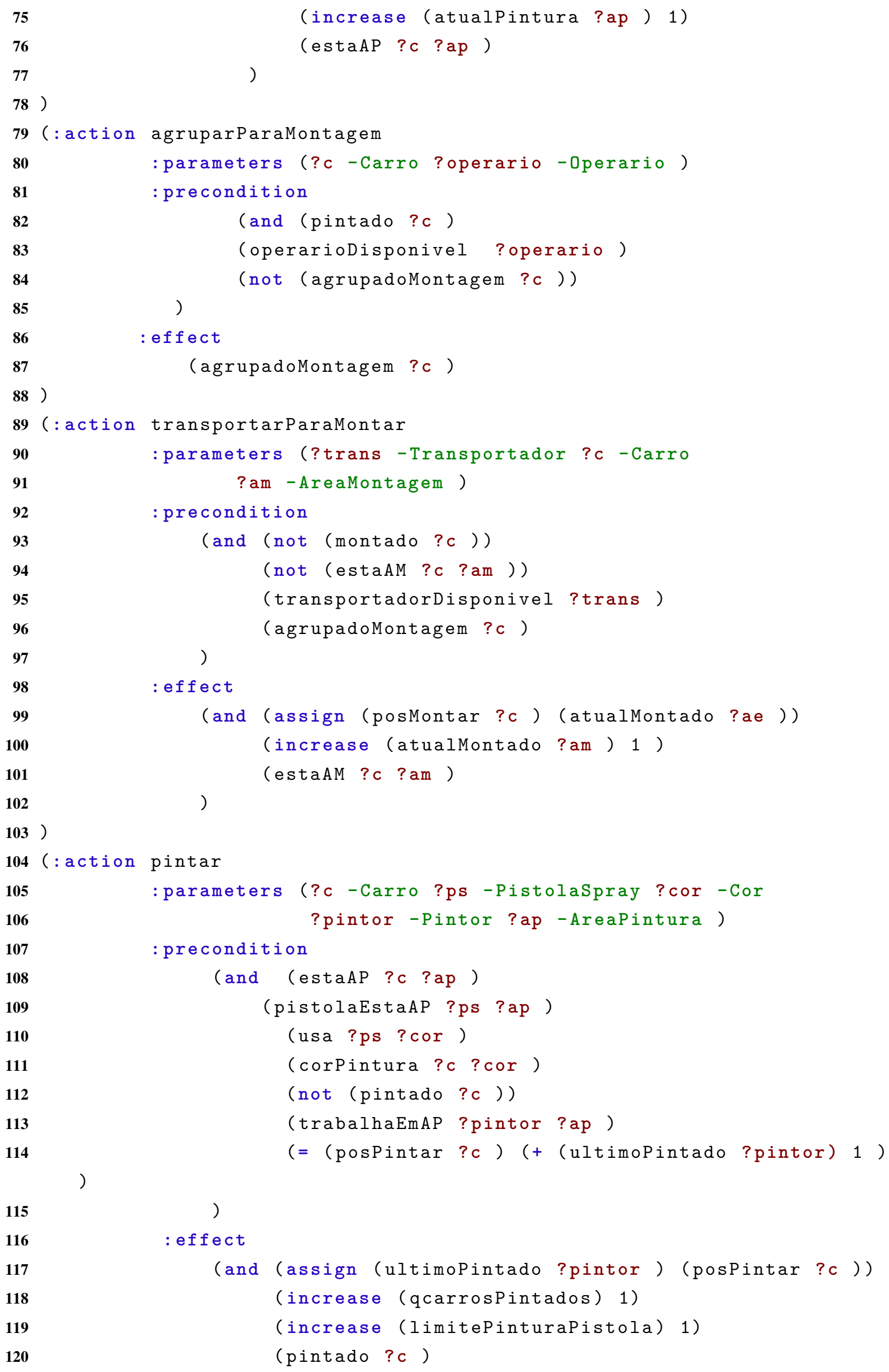




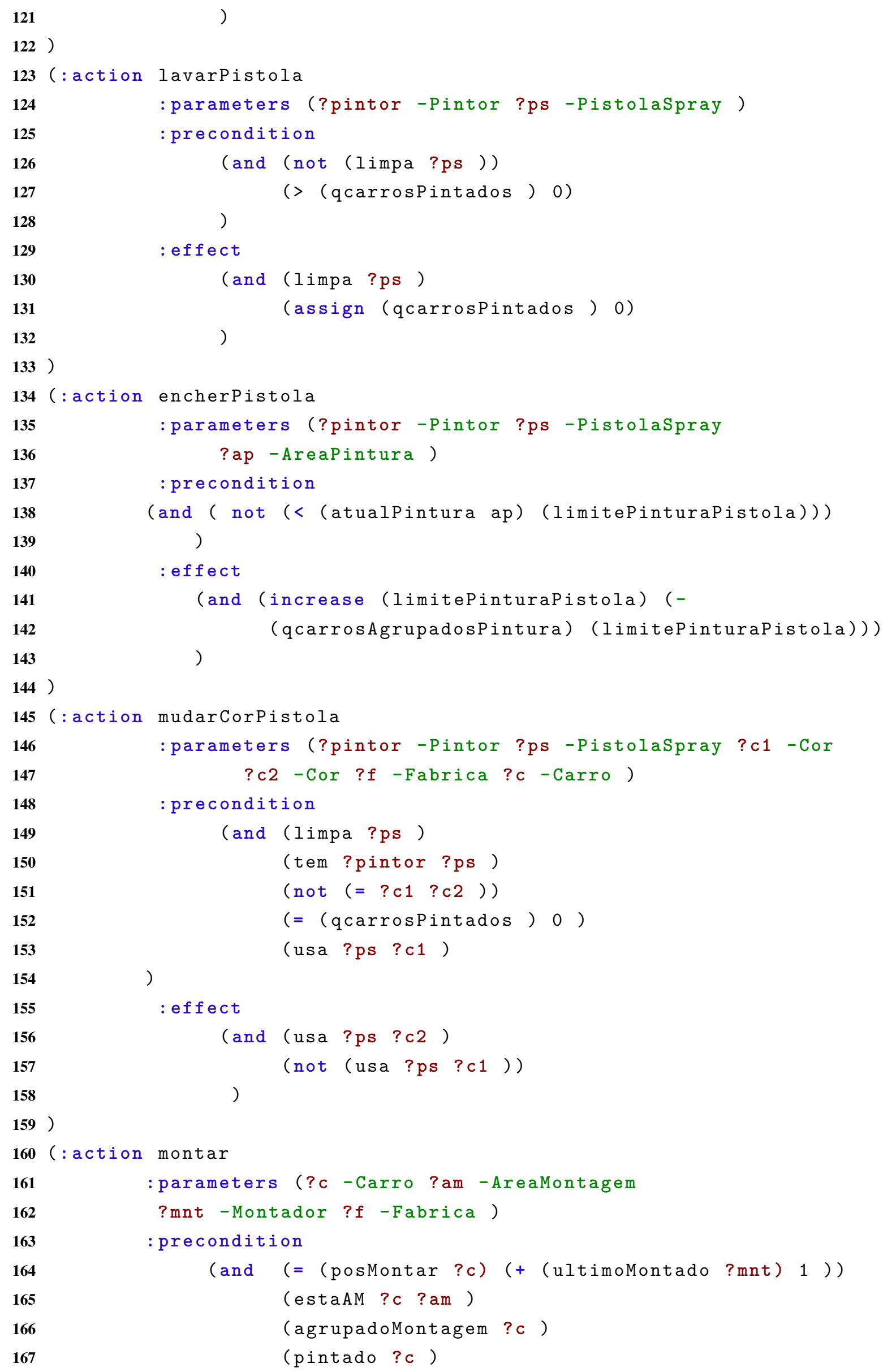




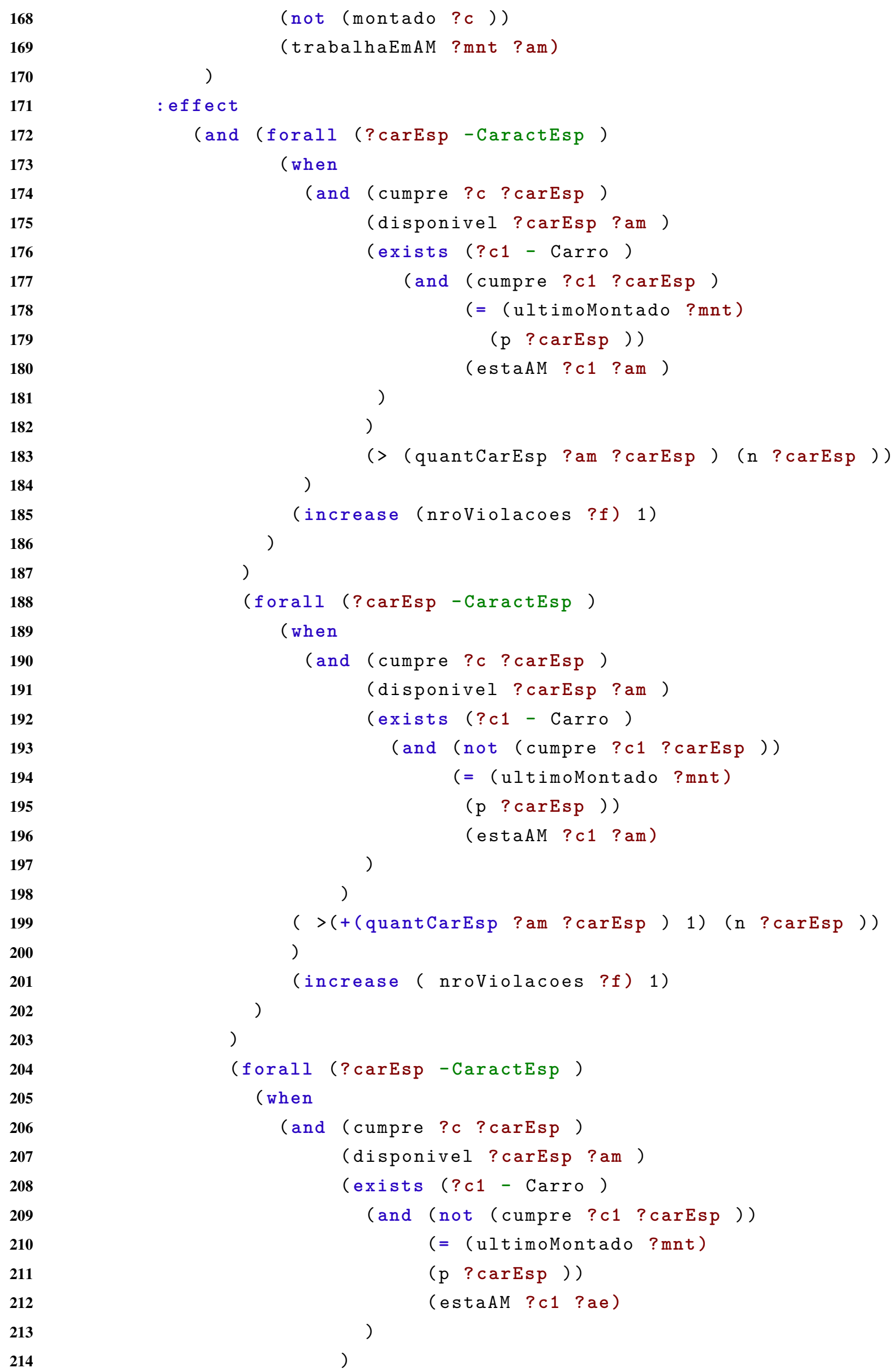




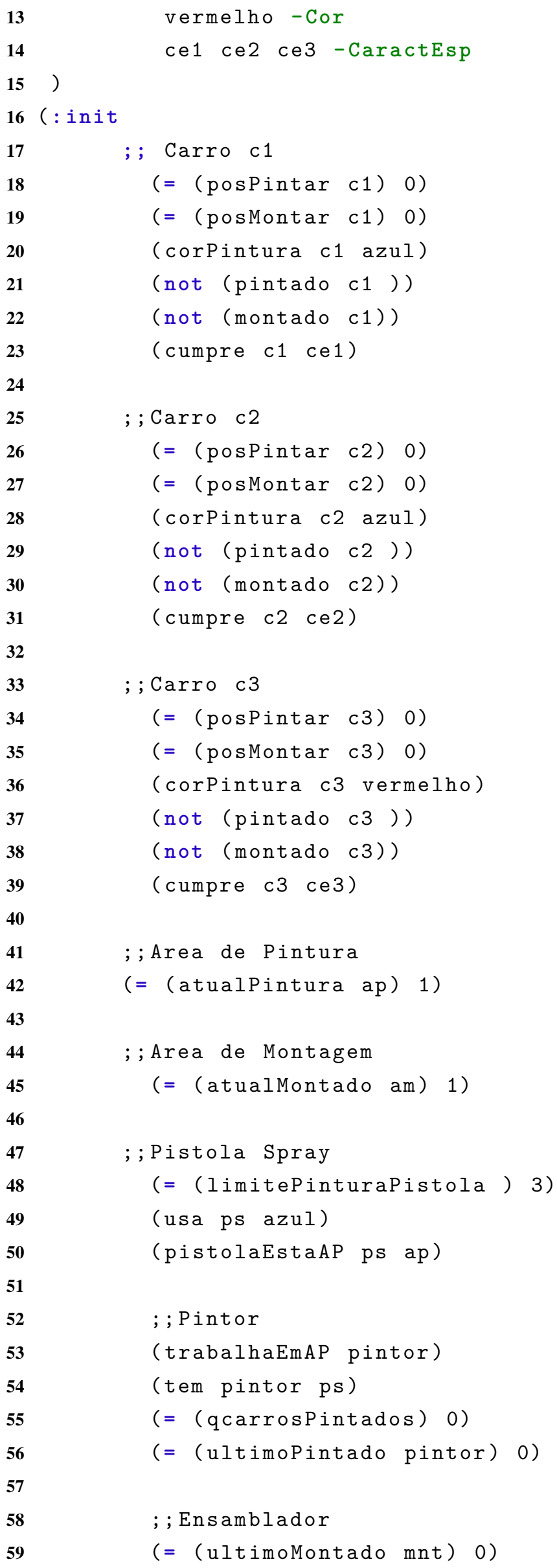




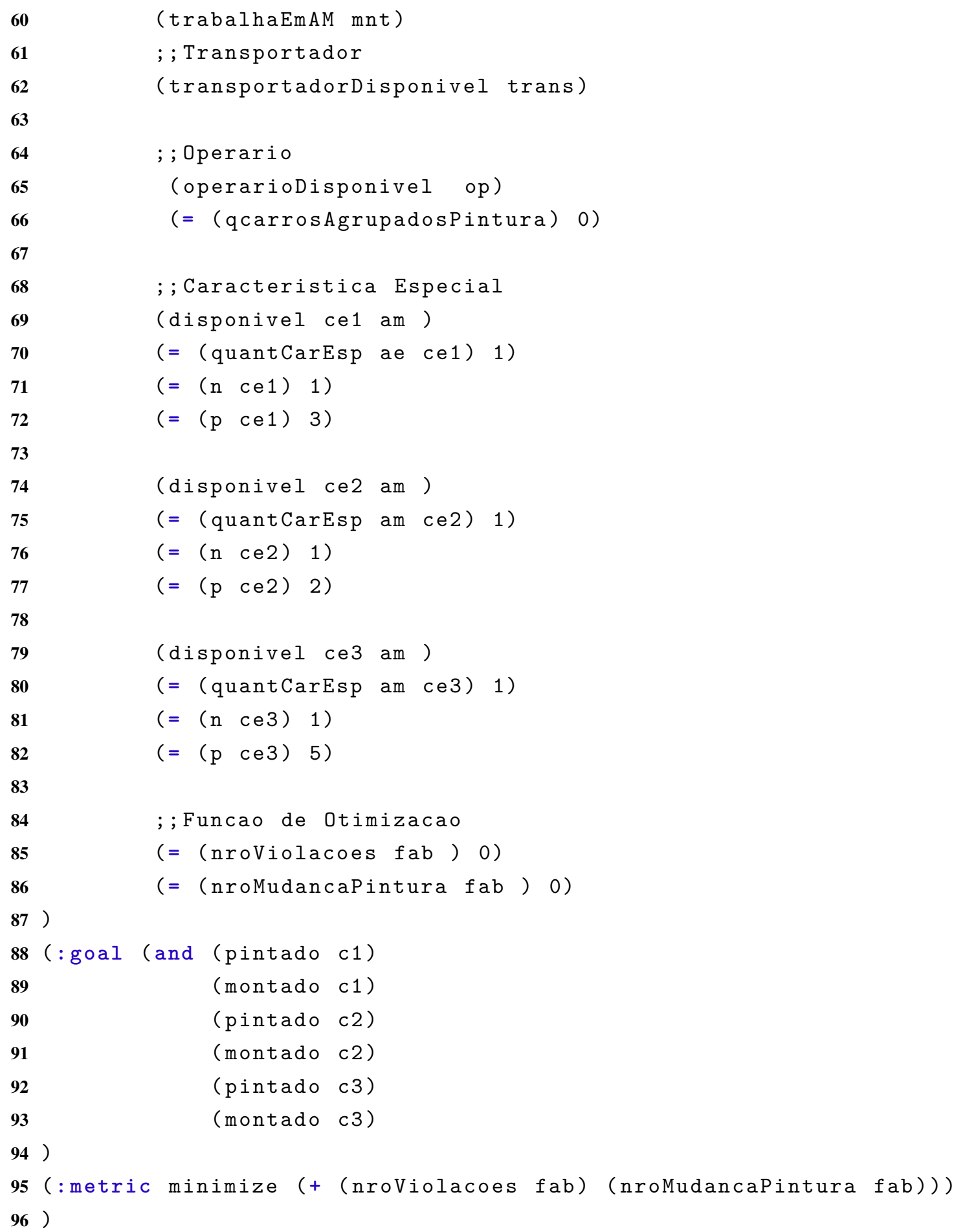

Código Fonte 6: Problema Montagem Seqüencial de Carros (3 carros azuis, pintura para 1)

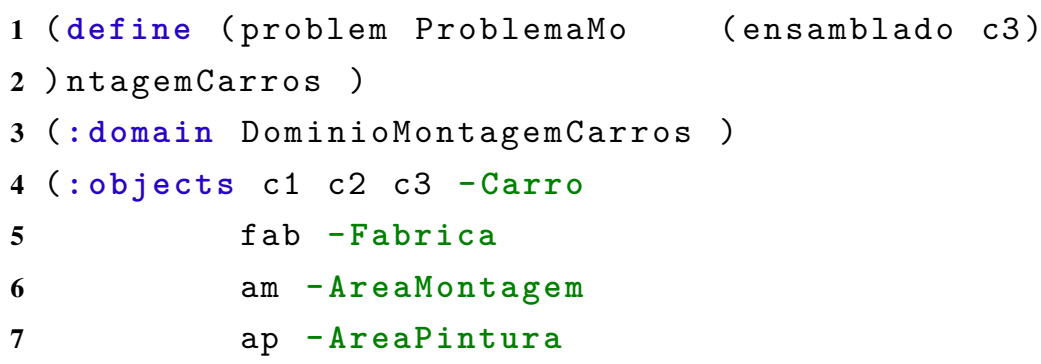




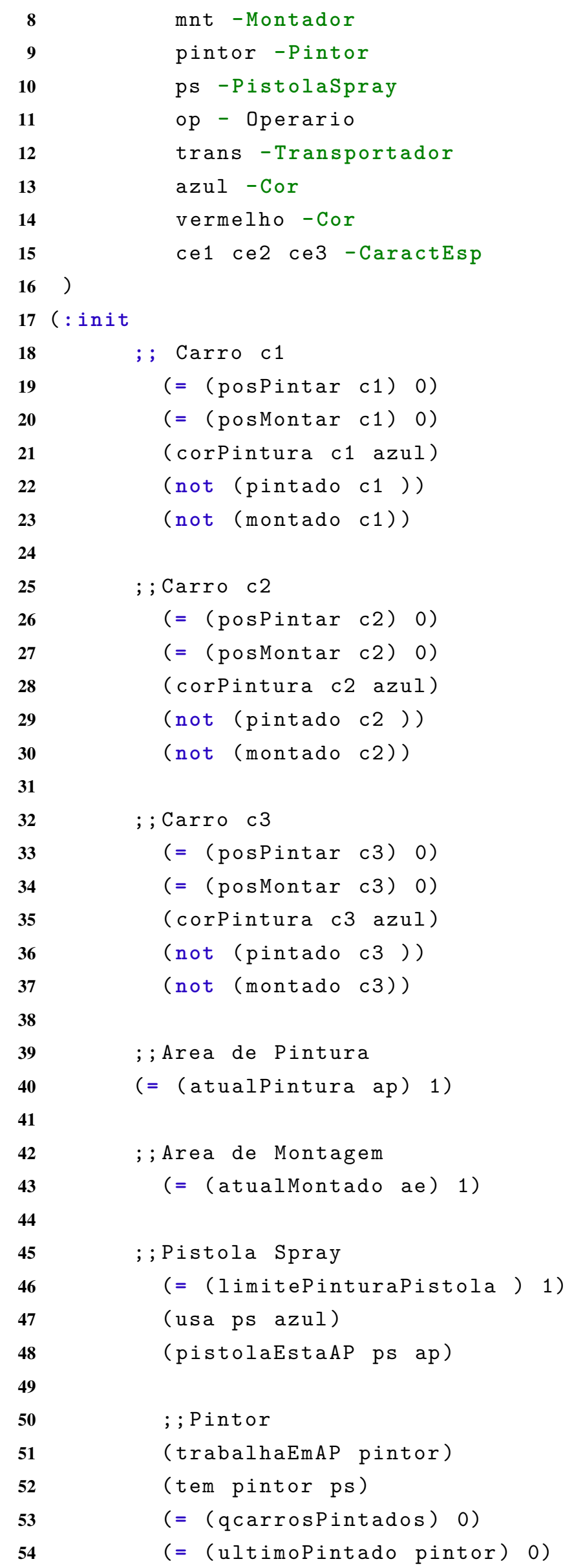




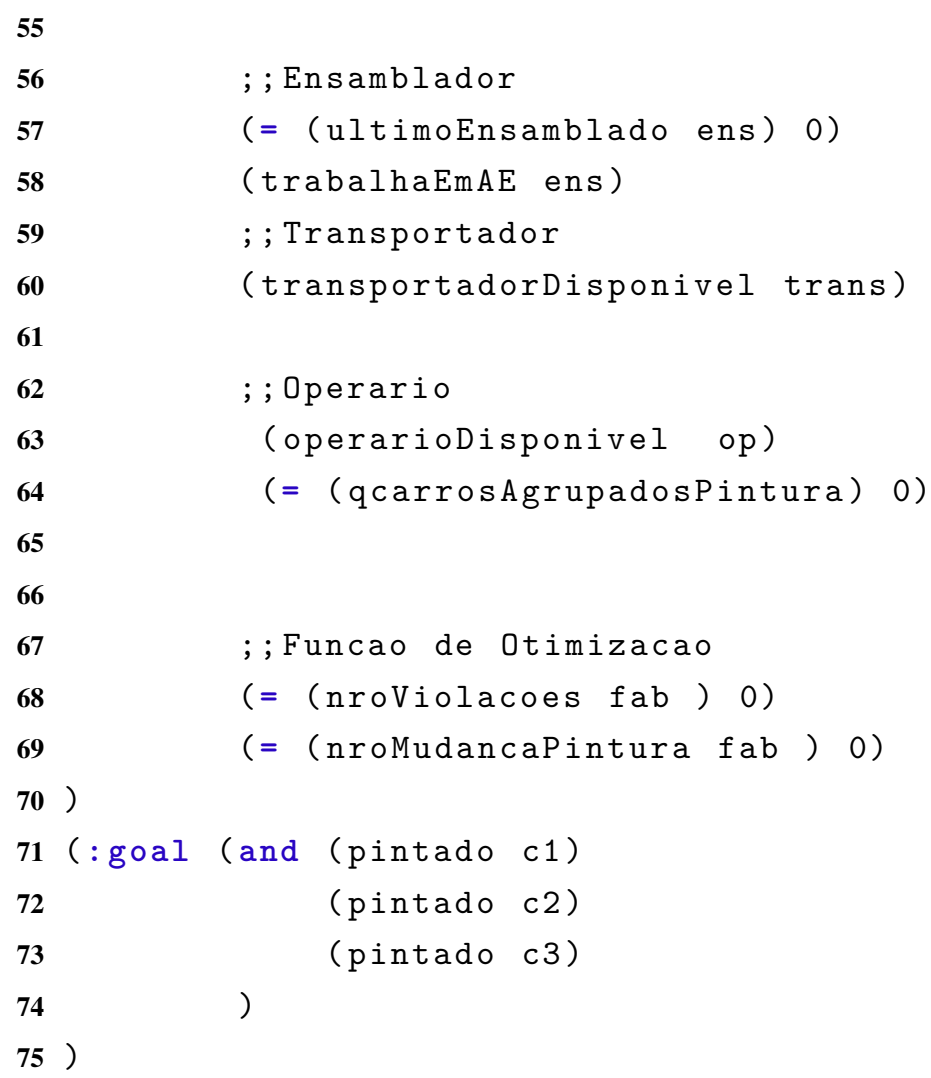



APPENDIX

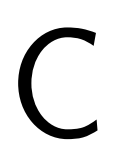

\section{GRAMÁTICA LTL PROPOSTA PARA O PROCESSAMENTO DE EXPRESSÕES LTL}

Código Fonte 7: Gramática LTL criada para reconhecer formulas LTL

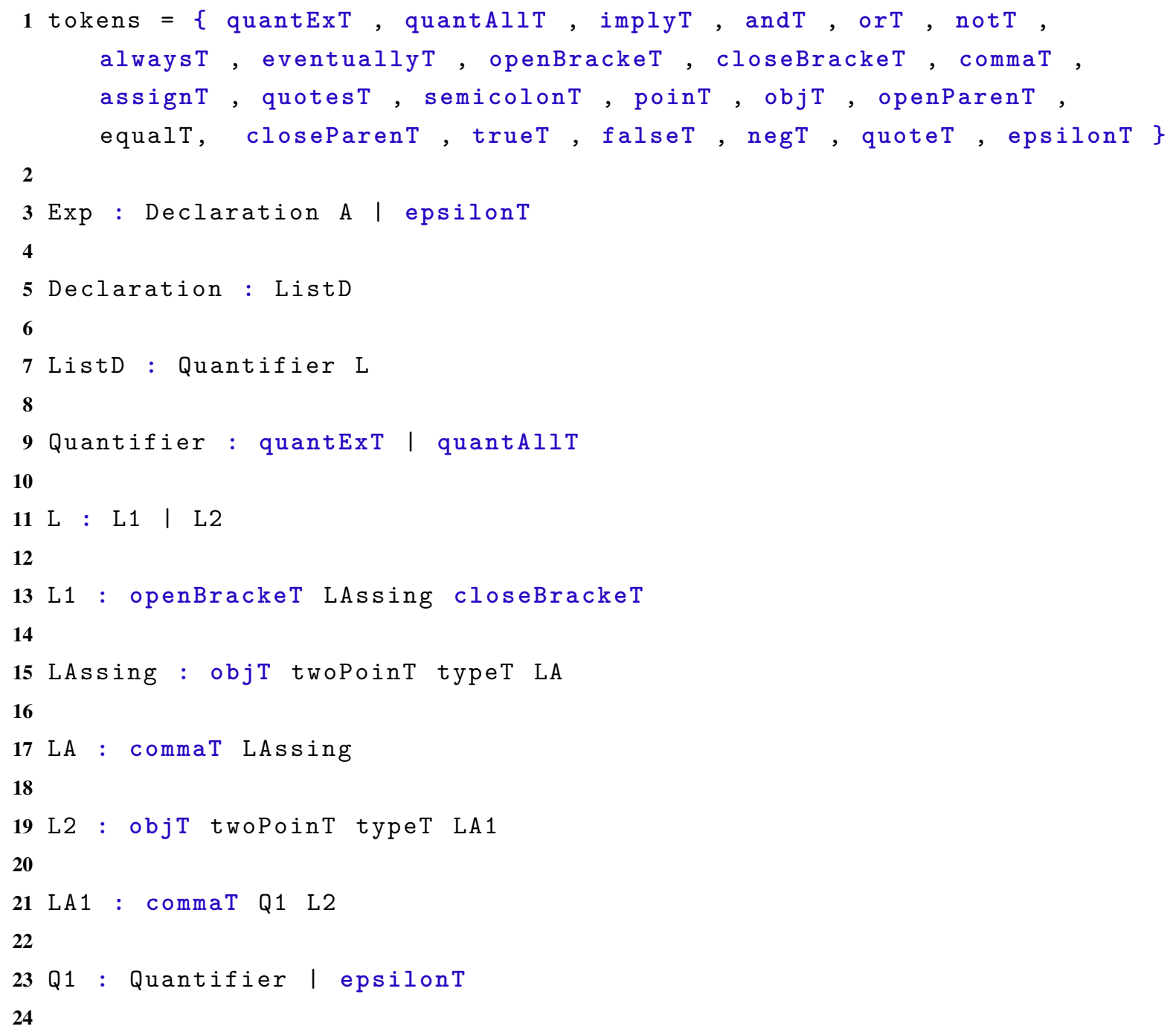




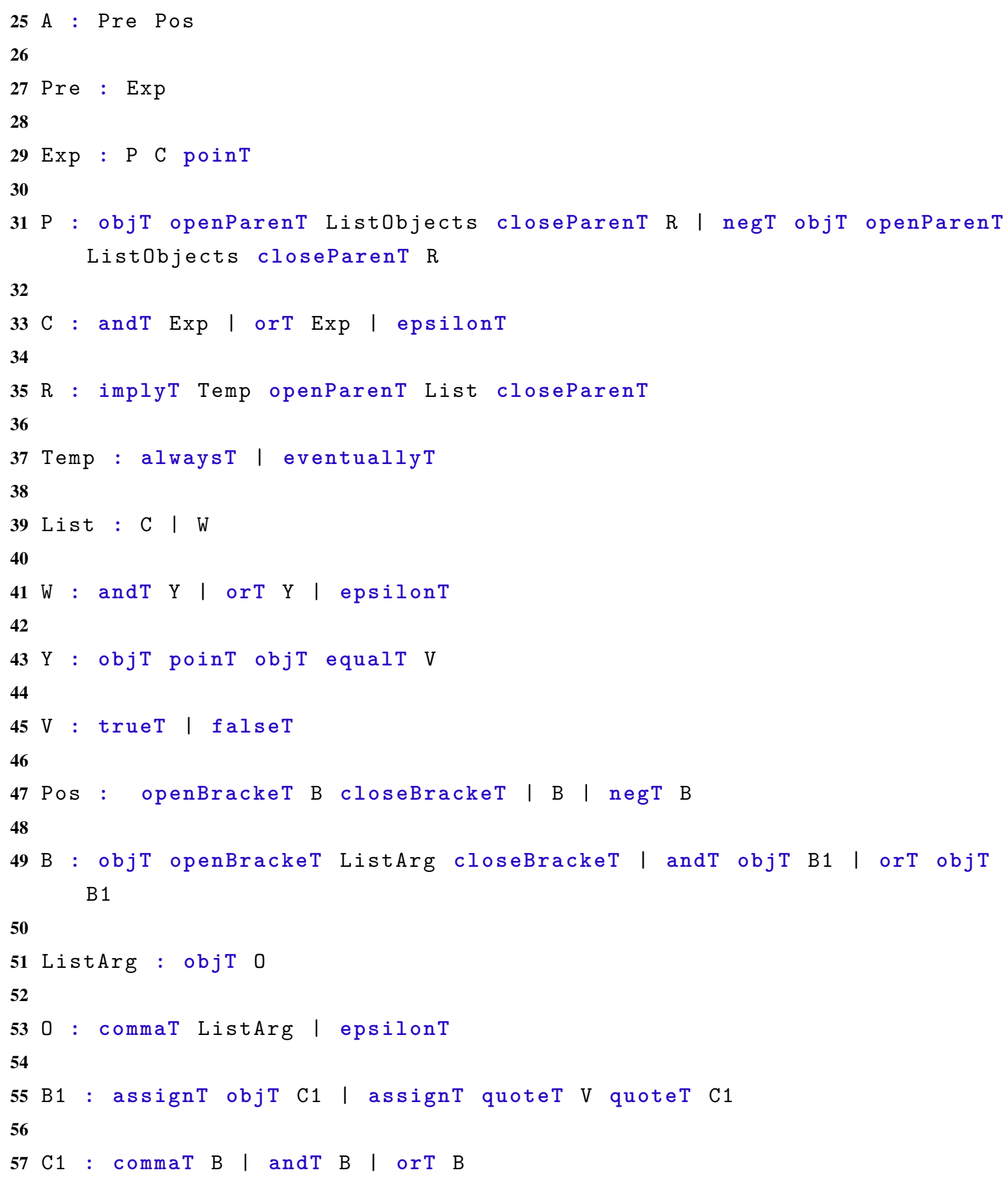

